\title{
Genome-Based Discovery of an Unprecedented Cyclization Mode in Fungal Sesterterpenoids Biosynthesis
}

\author{
Masahiro Okada, ${ }^{\dagger,}$ Y Ydai Matsuda, ${ }^{\dagger,}$ Takaki Mitsuhashi, ${ }^{\dagger}$ Shotaro Hoshino, ${ }^{\dagger}$ Takahiro Mori, ${ }^{\dagger}$ \\ Kazuya Nakagawa, ${ }^{\S}$ Zhiyang Quan, ${ }^{\dagger}$ Bin Qin, ${ }^{\dagger}$ Huiping Zhang, ${ }^{\ddagger}$ Fumiaki Hayashi, ${ }^{\ddagger}$ \\ Hiroshi Kawaide, ${ }^{\S}$ and Ikuro Abe ${ }^{\dagger, *}$ \\ ${ }^{\dagger}$ Graduate School of Pharmaceutical Sciences, The University of Tokyo, 7-3-1 Hongo, Bunkyo-ku, \\ Tokyo, 113-0033, Japan. \\ ${ }^{\S}$ Institute of Agriculture, Tokyo University of Agriculture and Technology, 3-5-8 Saiwai-cho, Fuchu, \\ Tokyo, 183-8509, Japan. \\ ${ }^{\ddagger}$ RIKEN Center for Life Science Technologies, 1-7-22 Suehiro-cho, Tsurumi-ku, Yokohama, \\ Kanagawa, 230-0045, Japan.
}

\section{Table of Contents}

Supplementary Material and Methods

S2-S3

Supplementary Tables S1-S11

S4-S12

Supplementary Figures S1- S38

S13-S41 


\section{Supplementary Materials and Methods}

\section{General}

Solvents and chemicals were purchased from Wako Chemicals Ltd. (Tokyo, Japan) or Kanto Chemical Co., Inc. (Tokyo, Japan), unless noted otherwise. Oligonucleotide primers were purchased from Eurofins Genetics (Tokyo, Japan). PCR was performed using a TaKaRa PCR Thermal Cycler Dice ${ }^{\circledR}$ Gradient (TaKaRa) with iProof DNA polymerase (Bio-Rad). Sequence analyses were performed by Eurofins Genetics (Tokyo, Japan). GC-MS analyses were performed with a GCMS-QP2010 Plus (Shimadzu) spectrometer, using a Restek $\mathrm{Rtx}^{\circledR}-5 \mathrm{MS}$ glass capillary column $(0.25 \mathrm{~mm}$ I.D. $\times 30 \mathrm{~m}, 0.25 \mu \mathrm{m}$ film thickness $)$. Silica gel column chromatography was performed using Silica Gel 60N. Preparative HPLC was performed on a Shimadzu Prominence system, using a TSK-gel ODS-80T $\mathrm{T}_{\mathrm{M}}$ column (7.8 i.d. x $300 \mathrm{~mm}$, Tosoh Co. Ltd.). NMR spectra were obtained at $500 \mathrm{MHz}\left({ }^{1} \mathrm{H}\right) / 125 \mathrm{MHz}\left({ }^{13} \mathrm{C}\right)$ with a JEOL ECX-500 or ECA-500 spectrometer or at 900 $\mathrm{MHz}\left({ }^{1} \mathrm{H}\right) / 225 \mathrm{MHz}\left({ }^{13} \mathrm{C}\right)$ with a Bruker Avance III HD $900 \mathrm{MHz}$ NMR spectrometer at RIKEN Yokohama, and chemical shifts were recorded with reference to solvent signals $\left({ }^{1} \mathrm{H}\right.$ NMR: $\mathrm{CDCl}_{3} 7.26 \mathrm{ppm}, \mathrm{C}_{6} \mathrm{D}_{6} 7.16$ ppm; ${ }^{13} \mathrm{C}$ NMR: $\mathrm{CDCl}_{3} 77.0$ ppm, $\mathrm{C}_{6} \mathrm{D}_{6} 128.0 \mathrm{ppm}$ ). EI-HR-MS analyses were performed with a JMS-SX102 mass spectrometer (JEOL). MALDI-HR-MS analyses were performed on an AXIMA $^{\circledR}-$ TOF $^{2}$ mass spectrometer (Shimadzu).

\section{Structural analysis of quiannulatene (1) by NMR}

The ${ }^{13} \mathrm{C}$ NMR spectrum of $\mathbf{1}$ (in $\mathrm{C}_{6} \mathrm{D}_{6}$ ) revealed 25 signals, consisting of three singlet and three doublet methyls, eight methylenes, six aliphatic methines, and two $s p^{2}(\mathrm{C}-16$ and $\mathrm{C}-17)$ and three $s p^{3}$ quaternary carbons. Thus, the results indicated that 1 possesses a pentacyclic chemical structure. Interpretation of the ${ }^{1} \mathrm{H}-{ }^{1} \mathrm{H}$ COSY spectrum revealed the spin systems of $\mathrm{H}-2 / \mathrm{H}-3, \mathrm{H}-4 / \mathrm{H}-5 / \mathrm{H}-20 / \mathrm{H}-21 / \mathrm{H}-22, \mathrm{H}-6 / \mathrm{H}-7$, H-9/H-10/H-11/H-12/H-23 and H-13/H-14 (Figure 3A). Additionally, HMBC correlations from the methyl signals were observed, as follows: $\mathrm{H}_{3}-19\left(\delta\right.$ 0.99) to $\mathrm{C}-1, \mathrm{C}-2, \mathrm{C}-5$, and $\mathrm{C}-18 ; \mathrm{H}_{3}-24(\delta 0.96)$ to $\mathrm{C}-8, \mathrm{C}-14$, $\mathrm{C}-15$, and $\mathrm{C}-16$; and $\mathrm{H}_{3}-25$ ( $\delta$ 1.46) to $\mathrm{C}-15, \mathrm{C}-16$, and $\mathrm{C}-17$. These cross peaks confirmed the connections of C-1 to C-2, C-5, C-18, and C-19, C-15 to C-8, C-14, C-16, and C-24, and C-16 to C-17 and C-25 (Figure 3A). Furthermore, the HMBC correlations of H-3 ( $\delta 1.52)$ to C-20, H-7 ( $\delta 2.86)$ to C-8 and C-15, and H-18 $(\delta 2.29)$ to $\mathrm{C}-16$ and $\mathrm{C}-17$ established the connections of $\mathrm{C}-3$ to $\mathrm{C}-4, \mathrm{C}-7$ to $\mathrm{C}-8$, and $\mathrm{C}-17$ to $\mathrm{C}-18$, respectively (Figure 3A). Subsequently, the HMBC correlations of H-5 ( $\delta 1.72)$ to C-7 and H-18 $(\delta 2.29)$ to C-7 revealed the connection of C-5 to C-6 and C-7 to C-18. Finally, the HMBC correlations of H-7 ( $\delta$ 2.86) to C-12, H-9 ( $\delta$ 1.91) to $\mathrm{C}-7$, and $\mathrm{H}-12(\delta 1.56)$ to $\mathrm{C}-13$ confirmed the connections of $\mathrm{C}-7$ to $\mathrm{C}-8, \mathrm{C}-8$ to $\mathrm{C}-12$, and $\mathrm{C}-12$ to $\mathrm{C}-13$, thus establishing the planar structure of 1 consisting of a 5-6-5-5-5 membered pentacyclic ring system (Figure 3A). 


\section{Interpretation of the ${ }^{13} \mathrm{C}$ NMR spectra of the isotopically labeled compounds}

Labeling experiment with $\left[2-{ }^{13} \mathbf{C},{ }^{2} \mathrm{H}_{3}\right]$-sodium acetate. Compound $\mathbf{1}$ labeled with $\left[2-{ }^{13} \mathrm{C},{ }^{2} \mathrm{H}_{3}\right]$-sodium acetate was subjected to proton and deuterium simultaneously decoupled ${ }^{13} \mathrm{C} N M R$, to clearly detect the isotope shifts (Table S7 and Figure S37). The shifts in the signals are generally attributed to the presence of deuterium atom(s) attached either directly to the carbon $\left({ }^{1} \Delta_{\delta}\right)$ or to the adjacent carbon $\left({ }^{2} \Delta_{\delta}\right.$, which is smaller than the ${ }^{1} \Delta_{\delta}$ value), and the isotope shifts exhibit additivity, from which the number of deuterium atoms present in the neighborhood can be deduced. The isotope shifts were observed at all of the ${ }^{13} \mathrm{C}$-labeled positions except for C-17 (C-2, -4, -5, -7, -8, -10, -12, -14, -19, -21, -22, -23, -24, and -25). These $\Delta_{\delta}$ values indicated that the isotope shifts, except for those of $\mathrm{C}-8$ and $\mathrm{C}-12$, are all derived from the deuterium(s) attached to the carbons themselves. In contrast, the $\Delta_{\delta}$ values for C-8 and C-12 revealed that the deuterium atoms originally bound to these carbons were respectively transferred to their next carbons, suggesting the occurrence of 1,2-hydride shifts from C-12 to C-11 and from C-8 to C-12.

Labeling experiment with $\left[1-{ }^{13} \mathbf{C},{ }^{2} \mathbf{H}_{3}\right]$-sodium acetate. In the ${ }^{13} \mathrm{C}$ NMR spectrum of quiannulatene (1) labeled with $\left[1-{ }^{13} \mathrm{C},{ }^{2} \mathrm{H}_{3}\right]$-sodium acetate, eight signals derived from $\mathrm{C}-1,-3,-6,-11,-13,-15,-16$, and -20 are accompanied by one or three upfield-shifted signals (Table S6 and Figure S36). The observed $\Delta_{\delta}$ values indicated that the isotope shifts, except for that at $\mathrm{C}-13$, are all caused by the deuterium(s) attached to the next carbon, and the relatively small isotope shift at $\mathrm{C}-13$ would be attributed to the presence of a deuterium at C-11, which appears to be the consequence of the 1,2-hydride shift from H-12 to H-11. The fact that no isotope shift was observed on the signal for C-9 supports the hypothesis that the deuterium originally attached to $\mathrm{C}-8$ is transferred to $\mathrm{C}-12$ by the 1,2-hydride shift. 
Table S1. Primers used in this study

\begin{tabular}{l|l}
\hline Primer & Sequence (5' to 3') \\
\hline EcoRl-EvQS-F & TACTAGGAATTCATGGCGTCCGAGGTCATAG \\
Kpnl-EvQS-R & CCCGCGGTACCCTAAACCCAAAGCCTCCTAAG \\
Kpnl-Qnn-P450-F & ATCAGGTACCATGGATGCATTCAAGGGAGCCATG \\
Kpnl-Qnn-P450-R & GTCTCGGTACCTTACTGCTGCTCCCAGCTTC \\
Spel-pAdeA-F & GAGGAACTAGTTCATGGTGTTTTGATCATTTTAA \\
Spel-pAdeA-R & GACCATACTAGTTTCCGTTCCTTTGCTTTCTGC \\
BamHI-EvQS-F & CGGGATCCATGGCGTCCGAGGTCATAGT \\
Xbal-EvQS-N381-R & GCTCTAGAATTTACCTTGCTCTCAATAATAGAT \\
Sacl-EvVS-C356-F & CGAGCTCAGGAAACCACAGGCTCT \\
Xbal-EvVS-R & GCTCTAGACACCTTCAAGCGGTGAAT \\
pCold-F & AGTAGCGGACTGGTGCCACGCGGTAGTG \\
pCold-R & ACCGCTACTGTGATGATGATGATGATGCACTTTGT
\end{tabular}

Table S2. Plasmids constructed in this study and PCR conditions

\begin{tabular}{|c|c|c|c|c|c|}
\hline Plasmid & vector & Insert & Primer 1 & Primer 2 & PCR Template \\
\hline pTAex3-EvQS & pTAex3 digested with EcoRI and Kpnl & $E v Q S$ & EcoRI-EvQS-F & Kpnl-EvQS-F & gDNA \\
\hline pTAex3-Qnn-P450 & pTAex3 digested with Kpnl & Qnn-P450 & Kpnl-Qnn-P450-F & Kpnl-Qnn-P450-R & gDNA \\
\hline pAdeA-Qnn-P450 & pAdeA digested with Spel & PamyB-Qnn-P450-TamyB & Spel-pAdeA-F & Spel-pAdeA-R & pTAex3-Qnn-P450 \\
\hline pCold-TF-[356-705]EvVS & pCold-TF digested with $\mathrm{Sacl}$ and $\mathrm{Xbal}$ & [356-705]EvVS & Sacl-EvVS-C356-F & Xbal-EvVS-R & cDNA \\
\hline pColdX-[1-381]EvQS & pColdX digested with BamHI and Xbal & [1-381]EvQS & BamHI-EvQS-F & Xbal-EvQS-N381-R & cDNA \\
\hline
\end{tabular}




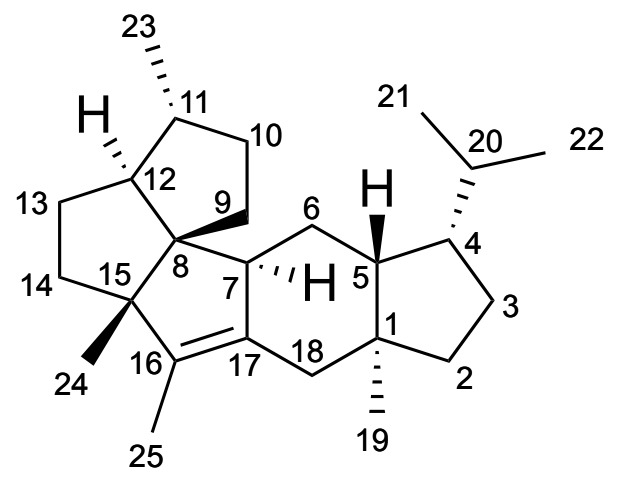

Table S3. NMR data for quiannulatene (1)

\begin{tabular}{|c|c|c|c|c|c|c|}
\hline position & $\delta_{c}(p p m)$ & $\delta_{H}(p p m)$ & Multiplicity $(\mathrm{J}$ in $\mathrm{Hz}$ ) & COSY correlation & HMBC correlation & NOESY correlation \\
\hline 1 & 43.0, C & - & - & - & - & - \\
\hline \multirow{2}{*}{2} & \multirow{2}{*}{$42.4, \mathrm{CH}_{2}$} & $1.55(\mathrm{a})$ & $\mathrm{m}$ & $\mathrm{H}-2 \mathrm{~b}, \mathrm{H}-3 \mathrm{~b}$ & C-5, C-19 & $\mathrm{H}-2 \mathrm{~b}, \mathrm{H}-19$ \\
\hline & & $1.12(b)$ & $\mathrm{dt}(12.0,8.0)$ & $\mathrm{H}-2 \mathrm{a}, \mathrm{H}-3 \mathrm{a}, \mathrm{H}-3 \mathrm{~b}$ & $C-1, C-3, C-18, C-19$ & $\mathrm{H}-2 \mathrm{a}, \mathrm{H}-3 \mathrm{a}, \mathrm{H}-18 \mathrm{a}$ \\
\hline \multirow{2}{*}{3} & \multirow{2}{*}{$29.19, \mathrm{CH}_{2}$} & $1.74(\mathrm{a})$ & $\mathrm{m}$ & $\mathrm{H}-2 \mathrm{~b}, \mathrm{H}-3 \mathrm{~b}, \mathrm{H}-4$ & C-5, C-19 & $\mathrm{H}-2 \mathrm{~b}, \mathrm{H}-3 \mathrm{~b}, \mathrm{H}-22$ \\
\hline & & $1.52(b)$ & $\mathrm{m}$ & $\mathrm{H}-2 \mathrm{a}, \mathrm{H}-2 \mathrm{~b}, \mathrm{H}-3 \mathrm{a}, \mathrm{H}-4$ & C-2, C-20 & $\mathrm{H}-3 \mathrm{a}, \mathrm{H}-19$ \\
\hline 4 & $45.2, \mathrm{CH}$ & 1.59 & $\mathrm{~m}$ & $\mathrm{H}-3 \mathrm{a}, \mathrm{H}-3 \mathrm{~b}, \mathrm{H}-5, \mathrm{H}-20$ & C-20, C-21 & $\mathrm{H}-20, \mathrm{H}-21, \mathrm{H}-22$ \\
\hline 5 & $45.8, \mathrm{CH}$ & 1.72 & $\mathrm{~m}$ & $\mathrm{H}-4$ & C- $6, C-19$ & - \\
\hline \multirow{2}{*}{6} & \multirow{2}{*}{$27.2, \mathrm{CH}_{2}$} & $1.75(\mathrm{a})$ & $\mathrm{m}$ & $\mathrm{H}-7$ & C-5, C-7 & $\mathrm{H}-7, \mathrm{H}-19, \mathrm{H}-20, \mathrm{H}-21$ \\
\hline & & $1.68(b)$ & $\mathrm{m}$ & $\mathrm{H}-7$ & $C-5$ & $\mathrm{H}-9 \mathrm{a}, \mathrm{H}-21$ \\
\hline 7 & $52.4, \mathrm{CH}$ & 2.86 & brt (9.0) & $\mathrm{H}-6 \mathrm{a}, \mathrm{H}-6 \mathrm{~b}, \mathrm{H}-25$ & C-6, C-8, C-12, C-15, C-16, C-17 & $\mathrm{H}-6 \mathrm{a}, \mathrm{H}-12, \mathrm{H}-19$ \\
\hline 8 & $63.3, \mathrm{C}$ & - & - & - & - & - \\
\hline \multirow{2}{*}{9} & \multirow{2}{*}{$29.21, \mathrm{CH}_{2}$} & $1.91(\mathrm{a})$ & ddd $(13.0,6.0,3.0)$ & $\mathrm{H}-9 \mathrm{~b}, \mathrm{H}-10 \mathrm{~b}$ & C-7, C-8, C-11, C-12 & $\mathrm{H}-6 \mathrm{~b}, \mathrm{H}-9 \mathrm{~b}, \mathrm{H}-10 \mathrm{a}, \mathrm{H}-10 \mathrm{~b}, \mathrm{H}-24$ \\
\hline & & 1.35 (b) & $\mathrm{m}$ & $\mathrm{H}-9 \mathrm{a}, \mathrm{H}-10 \mathrm{a}, \mathrm{H}-10 \mathrm{~b}$ & C-7, C-11 & $\mathrm{H}-9 \mathrm{a}, \mathrm{H}-10 \mathrm{a}, \mathrm{H}-10 \mathrm{~b}$ \\
\hline \multirow{2}{*}{10} & \multirow{2}{*}{$35.8, \mathrm{CH}_{2}$} & $1.73(\mathrm{a})$ & $\mathrm{m}$ & $\mathrm{H}-9 \mathrm{~b}, \mathrm{H}-10 \mathrm{~b}$ & $\mathrm{C}-8$ & $\mathrm{H}-9 \mathrm{a}, \mathrm{H}-9 \mathrm{~b}, \mathrm{H}-10 \mathrm{~b}$ \\
\hline & & $1.22(b)$ & $\mathrm{m}$ & $\mathrm{H}-9 \mathrm{a}, \mathrm{H}-9 \mathrm{~b}, \mathrm{H}-10 \mathrm{a}, \mathrm{H}-11$ & $C-9, C-11, C-23$ & $\mathrm{H}-9 \mathrm{a}, \mathrm{H}-9 \mathrm{~b}, \mathrm{H}-10 \mathrm{a}, \mathrm{H}-11, \mathrm{H}-23$ \\
\hline 11 & $43.3, \mathrm{CH}$ & 1.36 & $\mathrm{~m}$ & $\mathrm{H}-10 \mathrm{~b}, \mathrm{H}-12, \mathrm{H}-23$ & - & $\mathrm{H}-10 \mathrm{~b}, \mathrm{H}-23$ \\
\hline 12 & $65.6, \mathrm{CH}$ & 1.56 & $\mathrm{~m}$ & $\mathrm{H}-11$ & C-7, C-8, C-10, C-13, C-15, C-23 & $\mathrm{H}-7, \mathrm{H}-23$ \\
\hline \multirow{2}{*}{13} & \multirow{2}{*}{$29.5, \mathrm{CH}_{2}$} & $1.51(\mathrm{a})$ & $\mathrm{m}$ & $H-13 b, H-14 a, H-14 b$ & C-11, C-12, C-14 & $H-13 b$ \\
\hline & & $1.23(b)$ & $\mathrm{m}$ & $\mathrm{H}-13 \mathrm{a}, \mathrm{H}-14 \mathrm{~b}$ & $C-14, C-15$ & $\mathrm{H}-13 \mathrm{a}$ \\
\hline \multirow{2}{*}{14} & \multirow{2}{*}{$34.8, \mathrm{CH}_{2}$} & $1.67(a)$ & $\mathrm{m}$ & $\mathrm{H}-13 \mathrm{a}, \mathrm{H}-14 \mathrm{~b}$ & C-12, C-16 & $\mathrm{H}-14 \mathrm{~b}, \mathrm{H}-24, \mathrm{H}-25$ \\
\hline & & 1.34 (b) & $\mathrm{m}$ & $\mathrm{H}-13 \mathrm{a}, \mathrm{H}-13 \mathrm{~b}, \mathrm{H}-14 \mathrm{a}$ & $C-13, C-15, C-16, C-24$ & $\mathrm{H}-14 \mathrm{a}$ \\
\hline 15 & $60.2, \mathrm{C}$ & - & - & - & - & - \\
\hline 16 & 135.2, C & - & - & - & - & - \\
\hline 17 & 135.6, C & - & - & - & - & - \\
\hline \multirow{2}{*}{18} & \multirow{2}{*}{$40.5, \mathrm{CH}_{2}$} & $2.29(a)$ & $d(15.0)$ & $\mathrm{H}-18 \mathrm{~b}$ & C-1, C-2, C-7, C-16, C-17, C-19 & $\mathrm{H}-2 \mathrm{~b}, \mathrm{H}-18 \mathrm{~b}, \mathrm{H}-25$ \\
\hline & & 2.04 (b) & dquin $(15.0,1.5)$ & $\mathrm{H}-18 \mathrm{a} \mathrm{H}-25$ & $C-1, C-5, C-16, C-17, C-19$ & $\mathrm{H}-18 \mathrm{a}, \mathrm{H}-19$ \\
\hline 19 & 23.3, $\mathrm{CH}_{3}$ & 0.99 & s & - & $C-1, C-2, C-5, C-18$ & $\mathrm{H}-2 \mathrm{a}, \mathrm{H}-3 \mathrm{~b}, \mathrm{H}-6 \mathrm{a}, \mathrm{H}-7, \mathrm{H}-18 \mathrm{~b}, \mathrm{H}-20, \mathrm{H}-22$ \\
\hline 20 & $30.4, \mathrm{CH}$ & 1.54 & $\mathrm{~m}$ & $\mathrm{H}-4, \mathrm{H}-21, \mathrm{H}-22$ & - & $\mathrm{H}-4, \mathrm{H}-6 \mathrm{a}, \mathrm{H}-19, \mathrm{H}-21, \mathrm{H}-22$ \\
\hline 21 & $24.3, \mathrm{CH}_{3}$ & 0.94 & $d(6.0)$ & $\mathrm{H}-20$ & $C-4, C-20, C-22$ & $\mathrm{H}-4, \mathrm{H}-6 \mathrm{a}, \mathrm{H}-6 \mathrm{~b}, \mathrm{H}-20, \mathrm{H}-22$ \\
\hline 22 & $21.16, \mathrm{CH}_{3}$ & 0.86 & $d(6.5)$ & $\mathrm{H}-20$ & C-4, C-20, C-21 & $\mathrm{H}-3 \mathrm{a}, \mathrm{H}-4, \mathrm{H}-19, \mathrm{H}-20, \mathrm{H}-21$ \\
\hline 23 & $20.1, \mathrm{CH}_{3}$ & 1.05 & $d(6.5)$ & $\mathrm{H}-11$ & C-10, C-11, C-12 & $\mathrm{H}-10 \mathrm{~b}, \mathrm{H}-11, \mathrm{H}-12$ \\
\hline 24 & $21.24, \mathrm{CH}_{3}$ & 0.96 & s & - & $C-8, C-14, C-15, C-16$ & $\mathrm{H}-9 \mathrm{a}, \mathrm{H}-14 \mathrm{a}, \mathrm{H}-25$ \\
\hline 25 & $9.4, \mathrm{CH}_{3}$ & 1.46 & $t(1.5)$ & $\mathrm{H}-7, \mathrm{H}-18 \mathrm{~b}$ & $C-15, C-16, C-17$ & $\mathrm{H}-14 \mathrm{a}, \mathrm{H}-18 \mathrm{a}, \mathrm{H}-24$ \\
\hline
\end{tabular}

${ }^{1} \mathrm{H}$ NMR: $900 \mathrm{MHz},{ }^{13} \mathrm{C}$ NMR: $225 \mathrm{MHz}$ (in $\mathrm{C}_{6} \mathrm{D}_{6}$ ) 


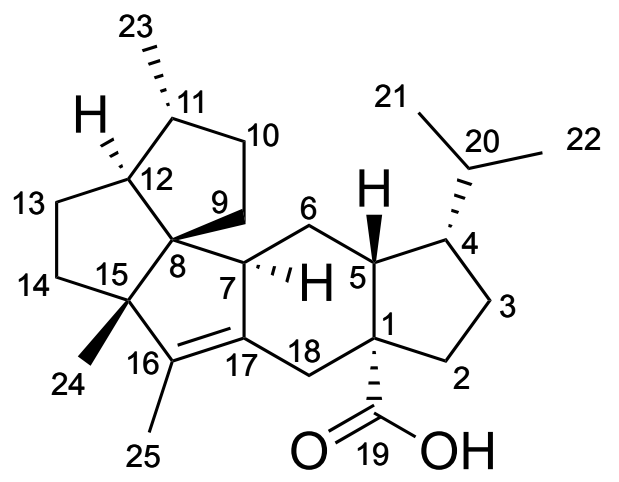

Table S4. NMR data for quiannulatic acid (2)

\begin{tabular}{|c|c|c|c|c|c|c|}
\hline position & $\delta_{c}(p p m)$ & $\delta_{H}(p p m)$ & Multiplicity $(\mathrm{J}$ in $\mathrm{Hz}$ ) & COSY correlation & HMBC correlation & NOESY correlation \\
\hline 1 & $54.7, \mathrm{C}$ & - & - & - & - & - \\
\hline \multirow{2}{*}{2} & \multirow{2}{*}{$39.1, \mathrm{CH}_{2}$} & $2.12(a)$ & $\mathrm{dd}(12.0,6.5)$ & $\mathrm{H}-2 \mathrm{~b}, \mathrm{H}-3 \mathrm{~b}$ & $C-4, C-5, C-19$ & $\mathrm{H}-2 \mathrm{~b}, \mathrm{H}-3 \mathrm{~b}$ \\
\hline & & 1.37 (b) & $\mathrm{m}$ & $\mathrm{H}-2 \mathrm{a}, \mathrm{H}-3 \mathrm{a}, \mathrm{H}-3 \mathrm{~b}$ & C-1, C-18, C-19 & $\mathrm{H}-2 \mathrm{a}, \mathrm{H}-18 \mathrm{~b}$ \\
\hline \multirow{2}{*}{3} & \multirow{2}{*}{ 31.2, $\mathrm{CH}_{2}$} & $1.87(\mathrm{a})$ & $\mathrm{m}$ & $\mathrm{H}-2 \mathrm{~b}, \mathrm{H}-3 \mathrm{~b}, \mathrm{H}-4$ & C-1, C-5 & $\mathrm{H}-3 \mathrm{~b}, \mathrm{H}-4, \mathrm{H}-22$ \\
\hline & & $1.55(b)$ & $\mathrm{m}$ & $\mathrm{H}-2 \mathrm{~b}, \mathrm{H}-3 \mathrm{a}, \mathrm{H}-4$ & C-2, C-4, C-20 & $\mathrm{H}-2 \mathrm{a}, \mathrm{H}-3 \mathrm{a}, \mathrm{H}-20, \mathrm{H}-22$ \\
\hline 4 & $45.8, \mathrm{CH}$ & 1.69 & $\mathrm{~m}$ & $\mathrm{H}-3 \mathrm{~b}, \mathrm{H}-5, \mathrm{H}-20$ & $C-1, C-5, C-20, C-21$ & $\mathrm{H}-3 \mathrm{a}, \mathrm{H}-5, \mathrm{H}-21, \mathrm{H}-22$ \\
\hline 5 & $46.1, \mathrm{CH}$ & 1.91 & $\mathrm{~m}$ & $\mathrm{H}-4, \mathrm{H}-6 \mathrm{a}, \mathrm{H}-6 \mathrm{~b}$ & C-1, C-4, C-6, C-19 & $\mathrm{H}-4, \mathrm{H}-6 \mathrm{~b}, \mathrm{H}-18 \mathrm{~b}, \mathrm{H}-21$ \\
\hline \multirow{2}{*}{6} & \multirow{2}{*}{ 28.3, $\mathrm{CH}_{2}$} & $2.10(a)$ & $\mathrm{m}$ & $\mathrm{H}-5, \mathrm{H}-6 \mathrm{~b}, \mathrm{H}-7$ & C-7, C-17 & $\mathrm{H}-6 \mathrm{~b}, \mathrm{H}-7, \mathrm{H}-20, \mathrm{H}-21$ \\
\hline & & $1.49(b)$ & $\mathrm{dt}(11.5,9.0)$ & $\mathrm{H}-5, \mathrm{H}-6 \mathrm{a}, \mathrm{H}-7$ & C-1, C-5, C-7, C-8 & $\mathrm{H}-5, \mathrm{H}-6 \mathrm{a}, \mathrm{H}-9 \mathrm{a}, \mathrm{H}-21$ \\
\hline 7 & $53.2, \mathrm{CH}$ & 2.45 & $\mathrm{t}(9.0)$ & $\mathrm{H}-6 \mathrm{a}, \mathrm{H}-6 \mathrm{~b}$ & C-6, C-8, C-12, C-15, C-16, C-17 & $\mathrm{H}-6 \mathrm{a}, \mathrm{H}-12$ \\
\hline 8 & $62.7, \mathrm{C}$ & - & - & - & - & - \\
\hline \multirow{2}{*}{9} & \multirow{2}{*}{$29.2, \mathrm{CH}_{2}$} & $1.75(\mathrm{a})$ & ddd $(13.0,5.5,2.0)$ & $\mathrm{H}-9 \mathrm{~b}, \mathrm{H}-10 \mathrm{~b}$ & C-7, C-11, C-12 & $\mathrm{H}-6 \mathrm{~b}, \mathrm{H}-9 \mathrm{~b}, \mathrm{H}-24$ \\
\hline & & 1.32 (b) & $\mathrm{m}$ & $\mathrm{H}-9 \mathrm{a}$ & - & $\mathrm{H}-9 \mathrm{a}$ \\
\hline \multirow{2}{*}{10} & \multirow{2}{*}{$35.8, \mathrm{CH}_{2}$} & $1.69(\mathrm{a})$ & $\mathrm{m}$ & $\mathrm{H}-10 \mathrm{~b}, \mathrm{H}-11$ & - & $\mathrm{H}-10 \mathrm{~b}, \mathrm{H}-11$ \\
\hline & & $1.14(b)$ & $\mathrm{m}$ & $\mathrm{H}-9 \mathrm{a}, \mathrm{H}-10 \mathrm{a}$ & - & $\mathrm{H}-10 \mathrm{a}, \mathrm{H}-23$ \\
\hline 11 & $43.1, \mathrm{CH}$ & 1.34 & $\mathrm{~m}$ & $\mathrm{H}-10 \mathrm{a}, \mathrm{H}-23$ & - & $\mathrm{H}-10 \mathrm{a}$ \\
\hline 12 & $65.2, \mathrm{CH}$ & 1.36 & $\mathrm{~m}$ & - & C-7, C-11, C-13, C-14, C-23 & $\mathrm{H}-7, \mathrm{H}-23$ \\
\hline \multirow{2}{*}{13} & \multirow{2}{*}{ 29.3, $\mathrm{CH}_{2}$} & $1.31(a)$ & $\mathrm{m}$ & $\mathrm{H}-13 \mathrm{~b}, \mathrm{H}-14 \mathrm{a}$ & - & $H-13 b$ \\
\hline & & $1.14(b)$ & $\mathrm{m}$ & $\mathrm{H}-13 \mathrm{a}$ & C-15 & $\mathrm{H}-13 \mathrm{a}$ \\
\hline \multirow{2}{*}{14} & \multirow{2}{*}{$34.8, \mathrm{CH}_{2}$} & $1.61(a)$ & $\mathrm{m}$ & $\mathrm{H}-13 \mathrm{a}, \mathrm{H}-14 \mathrm{~b}$ & $C-8, C-12, C-15, C-16$ & $\mathrm{H}-14 \mathrm{~b}, \mathrm{H}-24, \mathrm{H}-25$ \\
\hline & & $1.30(b)$ & $\mathrm{m}$ & $\mathrm{H}-14 \mathrm{a}$ & C-16 & $\mathrm{H}-14 \mathrm{a}$ \\
\hline 15 & $60.6, \mathrm{C}$ & - & - & - & - & - \\
\hline 16 & $135.7, \mathrm{C}$ & - & - & - & - & - \\
\hline 17 & $134.0, \mathrm{C}$ & - & - & - & - & - \\
\hline \multirow{2}{*}{18} & \multirow{2}{*}{$36.8, \mathrm{CH}_{2}$} & $2.93(a)$ & $d(16.0)$ & $\mathrm{H}-18 \mathrm{~b}$ & $C-1, C-5, C-16, C-17, C-19$ & $H-18 b$ \\
\hline & & $2.22(b)$ & $d(16.0)$ & $\mathrm{H}-18 \mathrm{a}$ & C-1, C-2, C-7, C-16, C-17, C-19 & $\mathrm{H}-2 \mathrm{~b}, \mathrm{H}-5, \mathrm{H}-18 \mathrm{a}, \mathrm{H}-25$ \\
\hline 19 & $184.0, \mathrm{C}$ & - & - & - & - & - \\
\hline 20 & $29.0, \mathrm{CH}$ & 1.97 & $\mathrm{~m}$ & $\mathrm{H}-4, \mathrm{H}-21, \mathrm{H}-22$ & - & $\mathrm{H}-3 \mathrm{~b}, \mathrm{H}-6 \mathrm{a}, \mathrm{H}-21, \mathrm{H}-22$ \\
\hline 21 & $24.2, \mathrm{CH}_{3}$ & 0.94 & $d(6.5)$ & $\mathrm{H}-20$ & $C-4, C-20, C-22$ & $\mathrm{H}-4, \mathrm{H}-5, \mathrm{H}-6 \mathrm{a}, \mathrm{H}-6 \mathrm{~b}, \mathrm{H}-20, \mathrm{H}-22$ \\
\hline 22 & $21.6, \mathrm{CH}_{3}$ & 0.84 & $d(7.0)$ & $\mathrm{H}-20$ & $C-4, C-20, C-21$ & $\mathrm{H}-3 \mathrm{a}, \mathrm{H}-3 \mathrm{~b}, \mathrm{H}-4, \mathrm{H}-20, \mathrm{H}-21$ \\
\hline 23 & $20.0, \mathrm{CH}_{3}$ & 0.97 & $d(6.5)$ & $\mathrm{H}-11$ & C-10, C-11, C-12 & $\mathrm{H}-10 \mathrm{~b}, \mathrm{H}-12$ \\
\hline 24 & 21.6, $\mathrm{CH}_{3}$ & 0.93 & s & - & $C-8, C-14, C-15, C-16$ & $\mathrm{H}-9 \mathrm{a}, \mathrm{H}-14 \mathrm{a}, \mathrm{H}-25$ \\
\hline 25 & $9.5, \mathrm{CH}_{3}$ & 1.44 & $\mathrm{~s}$ & - & $C-15, C-16, C-17$ & $\mathrm{H}-14 \mathrm{a}, \mathrm{H}-18 \mathrm{~b}, \mathrm{H}-24$ \\
\hline
\end{tabular}

${ }^{1} \mathrm{H}$ NMR: $900 \mathrm{MHz},{ }^{13} \mathrm{C}$ NMR: $225 \mathrm{MHz}$ (in $\mathrm{CDCl}_{3}$ ) 


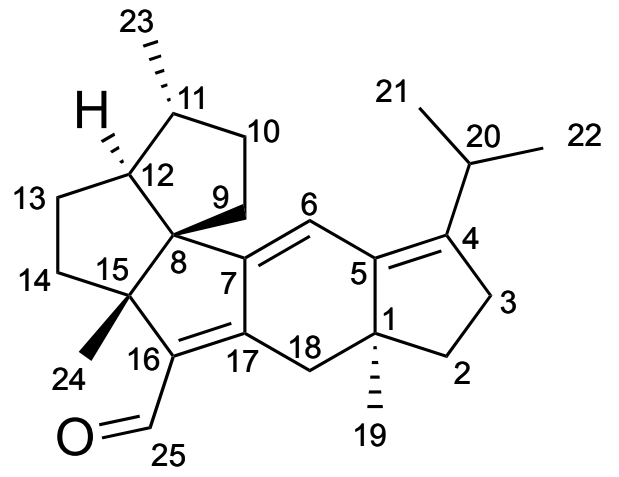

Table S5. NMR data for compound $\mathbf{3}$

\begin{tabular}{|c|c|c|c|}
\hline position & $\delta_{c}(p p m)$ & $\delta_{\mathrm{H}}(\mathrm{ppm})$ & Multiplicity $(\mathrm{J}$ in $\mathrm{Hz})$ \\
\hline 1 & $45.4, C$ & & - \\
\hline \multirow{2}{*}{2} & \multirow{2}{*}{$37.9, \mathrm{CH}_{2}$} & 1.62 & $\mathrm{~m}$ \\
\hline & & 1.34 & $\mathrm{~m}$ \\
\hline \multirow{2}{*}{3} & \multirow{2}{*}{$29.4, \mathrm{CH}_{2}$} & 2.3 & $\mathrm{~m}$ \\
\hline & & 2.26 & $\mathrm{~m}$ \\
\hline 4 & 143.0, C & - & - \\
\hline 5 & $138.0, \mathrm{C}$ & - & - \\
\hline 6 & $116.8, \mathrm{CH}$ & 6.45 & $\mathrm{~s}$ \\
\hline 7 & $156.4, \mathrm{C}$ & - & - \\
\hline 8 & $64.7, \mathrm{C}$ & - & - \\
\hline \multirow{2}{*}{9} & \multirow{2}{*}{$32.5, \mathrm{CH}_{2}$} & 1.77 & $\mathrm{~m}$ \\
\hline & & 1.76 & $\mathrm{~m}$ \\
\hline \multirow{2}{*}{10} & \multirow{2}{*}{ 37.2, $\mathrm{CH}_{2}$} & 1.74 & $\mathrm{~m}$ \\
\hline & & 1.35 & $\mathrm{~m}$ \\
\hline 11 & $40.8, \mathrm{CH}$ & 1.3 & $\mathrm{~m}$ \\
\hline 12 & $65.9, \mathrm{CH}$ & 1.62 & $\mathrm{~m}$ \\
\hline \multirow{2}{*}{13} & \multirow{2}{*}{ 27.6, $\mathrm{CH}_{2}$} & 1.43 & $\mathrm{~m}$ \\
\hline & & 1.32 & $\mathrm{~m}$ \\
\hline \multirow{2}{*}{14} & \multirow{2}{*}{ 34.2, $\mathrm{CH}_{2}$} & 2.56 & $\mathrm{~m}$ \\
\hline & & 1.43 & $\mathrm{~m}$ \\
\hline 15 & $59.3, \mathrm{C}$ & - & - \\
\hline 16 & $143.2, \mathrm{C}$ & - & - \\
\hline 17 & $155.4, \mathrm{C}$ & - & - \\
\hline \multirow{2}{*}{18} & \multirow{2}{*}{ 36.7, $\mathrm{CH}_{2}$} & 2.81 & $d(16.5)$ \\
\hline & & 1.94 & $d(16.5)$ \\
\hline 19 & 23.3, $\mathrm{CH}_{3}$ & 0.86 & $\mathrm{~s}$ \\
\hline 20 & $27.0, \mathrm{CH}$ & 2.79 & $\mathrm{~m}$ \\
\hline 21 & $21.5, \mathrm{CH}_{3}$ & 0.99 & $\mathrm{~d}(7.0)$ \\
\hline 22 & 20.7, $\mathrm{CH}_{3}$ & 0.89 & $\mathrm{~d}(7.0)$ \\
\hline 23 & $19.0, \mathrm{CH}_{3}$ & 0.86 & $\mathrm{~d}(7.0)$ \\
\hline 24 & $21.4, \mathrm{CH}_{3}$ & 1.36 & $\mathrm{~s}$ \\
\hline 25 & $186.8, \mathrm{CH}$ & 10.03 & s \\
\hline
\end{tabular}

${ }^{1} \mathrm{H}$ NMR: $900 \mathrm{MHz},{ }^{13} \mathrm{C}$ NMR: $225 \mathrm{MHz}$ (in $\mathrm{C}_{6} \mathrm{D}_{6}$ ) 
Table S6. NMR data for labeled quiannulatene (1), obtained from the $\left[1-{ }^{13} \mathrm{C},{ }^{2} \mathrm{H}_{3}\right]$-sodium acetate-feeding experiment, at $125 \mathrm{MHz}$ in $\mathrm{C}_{6} \mathrm{D}_{6}$. The isotope shift value shown in parentheses indicates the $\gamma$-deuterium isotope shift.

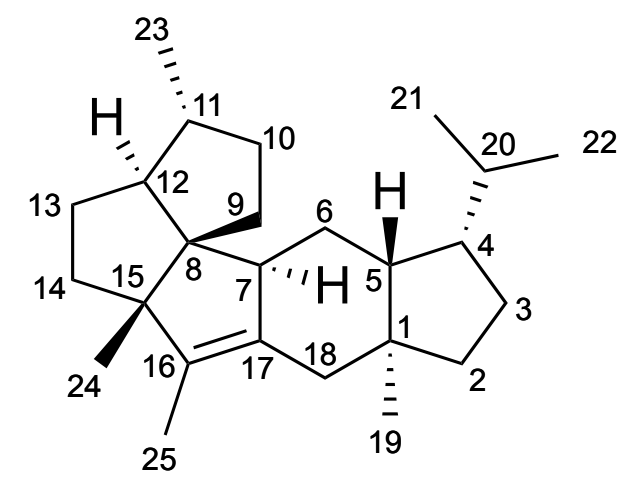

\begin{tabular}{ccccccc}
\hline \multirow{2}{*}{ position } & \multicolumn{3}{c}{${ }^{13} \mathrm{C}$} & & \multicolumn{3}{c}{$\beta$-deuterium isotope shift $\left({ }^{2} \Delta_{\delta}, \mathrm{ppm}\right)$} \\
\cline { 2 - 3 } \cline { 5 - 6 } 1 & $\delta(\mathrm{ppm})$ & enrichment & & $d_{1}$ & $d_{2}$ & $d_{3}$ \\
\hline 2 & 42.0 & $\bullet$ & -0.08 & -0.13 & -0.22 \\
3 & 29.2 & & - & - & - \\
4 & 45.2 & & -0.20 & - & - \\
5 & 45.8 & & - & - & - \\
6 & 27.2 & $\bullet$ & - & - & - \\
7 & 52.4 & & -0.10 & - & - \\
8 & 63.3 & & - & - & - \\
9 & 29.2 & $\bullet$ & - & - & - \\
10 & 35.8 & & - & - & - \\
11 & 43.3 & $\bullet$ & -0.08 & -0.16 & -0.23 \\
12 & 65.6 & & - & - & - \\
13 & 29.5 & $\bullet$ & $-0.05)$ & - & - \\
14 & 34.8 & & - & - & - \\
15 & 60.2 & $\bullet$ & -0.07 & -0.14 & -0.20 \\
16 & 135.2 & $\bullet$ & -0.05 & -0.07 & -0.17 \\
17 & 135.6 & & - & - & - \\
18 & 40.5 & $\bullet$ & - & - & - \\
19 & 23.3 & & - & - & - \\
20 & 30.4 & $\bullet$ & -0.08 & -0.16 & -0.25 \\
21 & 24.3 & & - & - & - \\
22 & 21.17 & & - & - & - \\
23 & 20.1 & & - & - & - \\
24 & 21.25 & & - & - & - \\
25 & 9.4 & & - & - & - \\
\hline & & & & - & \\
\hline
\end{tabular}


Table S7. NMR data for labeled quiannulatene (1), obtained from the $\left[2-{ }^{13} \mathrm{C},{ }^{2} \mathrm{H}_{3}\right]$-sodium acetate-feeding experiment, at $225 \mathrm{MHz}$ in $\mathrm{C}_{6} \mathrm{D}_{6}$. The isotope shift values shown in parentheses indicate the $\beta$-deuterium isotope shift.

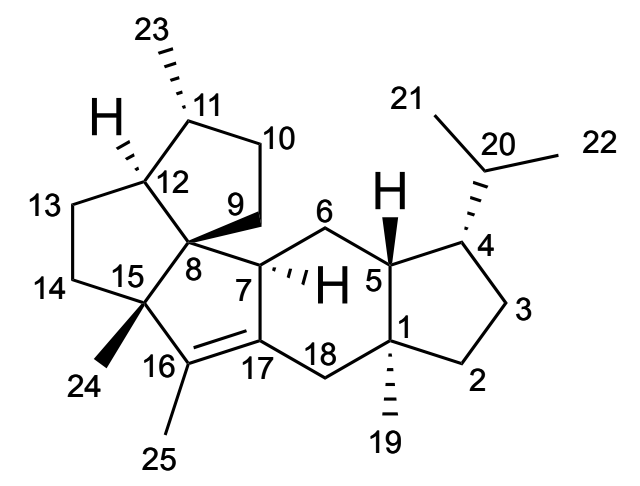

\begin{tabular}{|c|c|c|c|c|c|}
\hline \multirow[b]{2}{*}{ position } & \multicolumn{2}{|c|}{${ }^{13} \mathrm{C}$} & \multicolumn{3}{|c|}{ a-deuterium isotope shift $\left({ }^{(} \Delta_{\delta}, \mathrm{ppm}\right)$} \\
\hline & $\delta(\mathrm{ppm})$ & enrichment & $d_{1}$ & $d_{2}$ & $d_{3}$ \\
\hline 1 & 43.0 & & 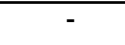 & - & - \\
\hline \multirow[t]{2}{*}{2} & 42.4 & - & -0.38 & -0.82 & - \\
\hline & & & -0.43 & & \\
\hline 3 & 29.2 & & - & - & - \\
\hline 4 & 45.2 & - & -0.55 & - & - \\
\hline 5 & 45.8 & - & -0.51 & - & - \\
\hline 6 & 27.2 & & - & - & - \\
\hline 7 & 52.4 & - & -0.50 & - & - \\
\hline 8 & 63.3 & - & $(-0.09)$ & - & - \\
\hline 9 & 29.2 & & - & - & - \\
\hline \multirow[t]{2}{*}{10} & 35.8 & - & -0.37 & -0.78 & - \\
\hline & & & -0.42 & & \\
\hline 11 & 43.3 & & - & - & - \\
\hline 12 & 65.6 & - & $(-0.11)$ & - & - \\
\hline 13 & 29.5 & & - & - & - \\
\hline \multirow[t]{2}{*}{14} & 34.8 & - & -0.35 & -0.74 & - \\
\hline & & & -0.39 & & \\
\hline 15 & 60.2 & & - & - & - \\
\hline 16 & 135.2 & & - & - & - \\
\hline 17 & 135.6 & • & - & - & - \\
\hline 18 & 40.6 & & - & - & - \\
\hline 19 & 23.3 & $\bullet$ & -0.31 & -0.61 & -0.91 \\
\hline 20 & 30.4 & & - & - & - \\
\hline 21 & 24.3 & • & -0.31 & -0.62 & - \\
\hline 22 & 21.17 & $\bullet$ & -0.31 & -0.61 & -0.92 \\
\hline 23 & 20.1 & • & -0.31 & -0.61 & -0.92 \\
\hline 24 & 21.25 & • & -0.30 & -0.60 & -0.90 \\
\hline 25 & 9.4 & • & -0.26 & -0.53 & -0.80 \\
\hline
\end{tabular}


Table S8. Key thermodynamic parameters (a.u.) of the optimized conformer 3a-3d at the B3LYP/6-31G(d) level with the PCM model in ethanol.

\begin{tabular}{lllll} 
Conformers & $E$ & $E^{\prime}=E+Z P E$ & $H$ & $G$ \\
\hline 3a & -1047.804728 & -1047.829808 & -1047.803784 & -1047.883118 \\
3b & -1047.80263 & -1047.827491 & -1047.801686 & -1047.880147 \\
3c & -1047.800448 & -1047.825428 & -1047.799504 & -1047.878355 \\
3d & -1047.799759 & -1047.824704 & -1047.798815 & -1047.877389 \\
\hline$E, E^{\prime}, H$, G: total energy, total energy with zero point energy (ZPE), enthalpy
\end{tabular}
and Gibbs free energy.

Table S9. Conformational analysis of $\mathbf{3}$.

\begin{tabular}{lllllll} 
Conformers & $\Delta E^{a}$ & $P_{E} \%^{b}$ & $\Delta E^{\prime c}$ & $P_{E^{\circ}} \%^{d}$ & $\Delta G^{o}$ & $P_{G} \%^{d}$ \\
\hline 3a & 0 & 89 & 0 & 91 & 0 & 95.1 \\
3b & 5.5 & 9.6 & 6.1 & 7.7 & 7.8 & 4.1 \\
3c & 11.2 & 1 & 11.5 & 0.9 & 12.5 & 0.6 \\
3d & 13 & 0.5 & 13.4 & 0.4 & 15 & 0.2 \\
\hline
\end{tabular}

${ }^{a}$ Relative energy, ${ }^{c}$ relative energy with ZPE, and ${ }^{e}$ relative Gibbs free energy in $\mathrm{kJ} / \mathrm{mol}$.

${ }_{b, d, f}$ Conformational distribution of each conformer based on the Boltzmann distribution $(T=298 \mathrm{~K})$ using the respective parameters. 
Table S10. Excited states of 3a responsible for ECD calculation.

\begin{tabular}{l|lllll} 
Excited State & Energy $(\mathrm{eV})$ & Wavelength $(\mathrm{nm})$ & $\begin{array}{l}\text { Oscillattor } \\
\text { strength }\end{array}$ & $\mathrm{R}$ (velocity) & $\begin{array}{l}\text { Major contribution } \\
(>10 \%)\end{array}$ \\
\hline 1 & 2.9961 & 413.82 & 0.5819 & -85.7285 & $96->97(96 \%)$ \\
\hline 2 & 3.3682 & 368.1 & 0.0228 & 81.2677 & $95->97(93 \%)$ \\
\hline 3 & 4.3377 & 285.83 & 0.2267 & 11.9424 & $94->97(88 \%)$ \\
\hline 5 & 4.832 & 256.59 & 0.0375 & -8.6759 & $\begin{array}{l}93->97(40 \%), \\
96->98(29 \%), \\
96->99(22 \%)\end{array}$ \\
\hline 6 & 4.8617 & 255.02 & 0.009 & -7.2776 & $\begin{array}{l}93->97(47 \%), \\
96->99(31 \%), \\
96->98(13 \%)\end{array}$ \\
\hline 7 & 4.9476 & 250.6 & 0.0007 & 1.8466 & $92->97(82 \%)$ \\
\hline 8 & 5.0726 & 244.42 & 0.1994 & -33.6991 & $\begin{array}{l}96->98(40 \%), \\
96->99(40 \%)\end{array}$ \\
\hline 9 & 5.183 & 239.21 & 0.0095 & 6.79 & $\begin{array}{l}91->97(60 \%), \\
90->97(19 \%)\end{array}$ \\
\hline 10 & 5.1953 & 238.65 & 0.02 & 3.8497 & $96->101(91 \%)$ \\
\hline 11 & 5.2571 & 235.84 & 0.0031 & -0.1282 & $96->100(84 \%)$ \\
\hline 12 & 5.3083 & 233.57 & 0.0101 & 0.4517 & $\begin{array}{l}96->102(71 \%), \\
90->97(10 \%)\end{array}$ \\
\hline & 5.3228 & 232.93 & 0.014 & $\begin{array}{l}88->97(44 \%), \\
91->97(22 \%), \\
96->102(15 \%)\end{array}$ \\
\hline
\end{tabular}


Table S11. Excited states of $\mathbf{3 b}$ responsible for ECD calculation.

\begin{tabular}{|c|c|c|c|c|c|}
\hline Excited State & Energy $(e V)$ & Wavelength (nm) & $\begin{array}{l}\text { Oscillattor } \\
\text { strength }\end{array}$ & $\mathrm{R}$ (velocity) & $\begin{array}{l}\text { Major contribution } \\
(>10 \%)\end{array}$ \\
\hline 1 & 3.0071 & 412.3 & 0.5853 & -100.3425 & $96->97(96 \%)$ \\
\hline 2 & 3.369 & 368.01 & 0.0245 & 84.5086 & $95->97(93 \%)$ \\
\hline 3 & 4.3374 & 285.85 & 0.2247 & 13.4732 & 94->97 (88\%) \\
\hline 4 & 4.8096 & 257.78 & 0.0269 & -6.2271 & $\begin{array}{l}93->97(79 \%), \\
96->98(10 \%)\end{array}$ \\
\hline 5 & 4.858 & 255.22 & 0.0165 & -13.5032 & $\begin{array}{l}96->99(53 \%), \\
96->98(29 \%), \\
93->97(12 \%)\end{array}$ \\
\hline 6 & 5.0408 & 245.96 & 0.0761 & 61.6368 & $\begin{array}{l}91->97(30 \%), \\
96->98(19 \%), \\
96->99(18 \%), \\
92->97(17 \%)\end{array}$ \\
\hline 7 & 5.0775 & 244.18 & 0.1252 & -75.6189 & $\begin{array}{l}96->98(25 \%), \\
96->99(20 \%), \\
92->97(18 \%), \\
91->97(18 \%)\end{array}$ \\
\hline 8 & 5.1902 & 238.88 & 0.008 & 5.5942 & $\begin{array}{l}90->97(55 \%), \\
91->97(20 \%), \\
88->97(11 \%)\end{array}$ \\
\hline 9 & 5.2052 & 238.19 & 0.0287 & -0.0059 & $\begin{array}{l}96->101(70 \%), \\
96->100(21 \%)\end{array}$ \\
\hline 10 & 5.2711 & 235.21 & 0.0009 & 1.0277 & $\begin{array}{l}96->100(70 \%), \\
96->101(22 \%)\end{array}$ \\
\hline 11 & 5.3068 & 233.63 & 0.0057 & -3.3017 & $\begin{array}{l}92->97(52 \%), \\
90->97(21 \%), \\
91->97(16 \%)\end{array}$ \\
\hline 12 & 5.3588 & 231.37 & 0.0093 & -1.1342 & 96->102 (92\%) \\
\hline
\end{tabular}



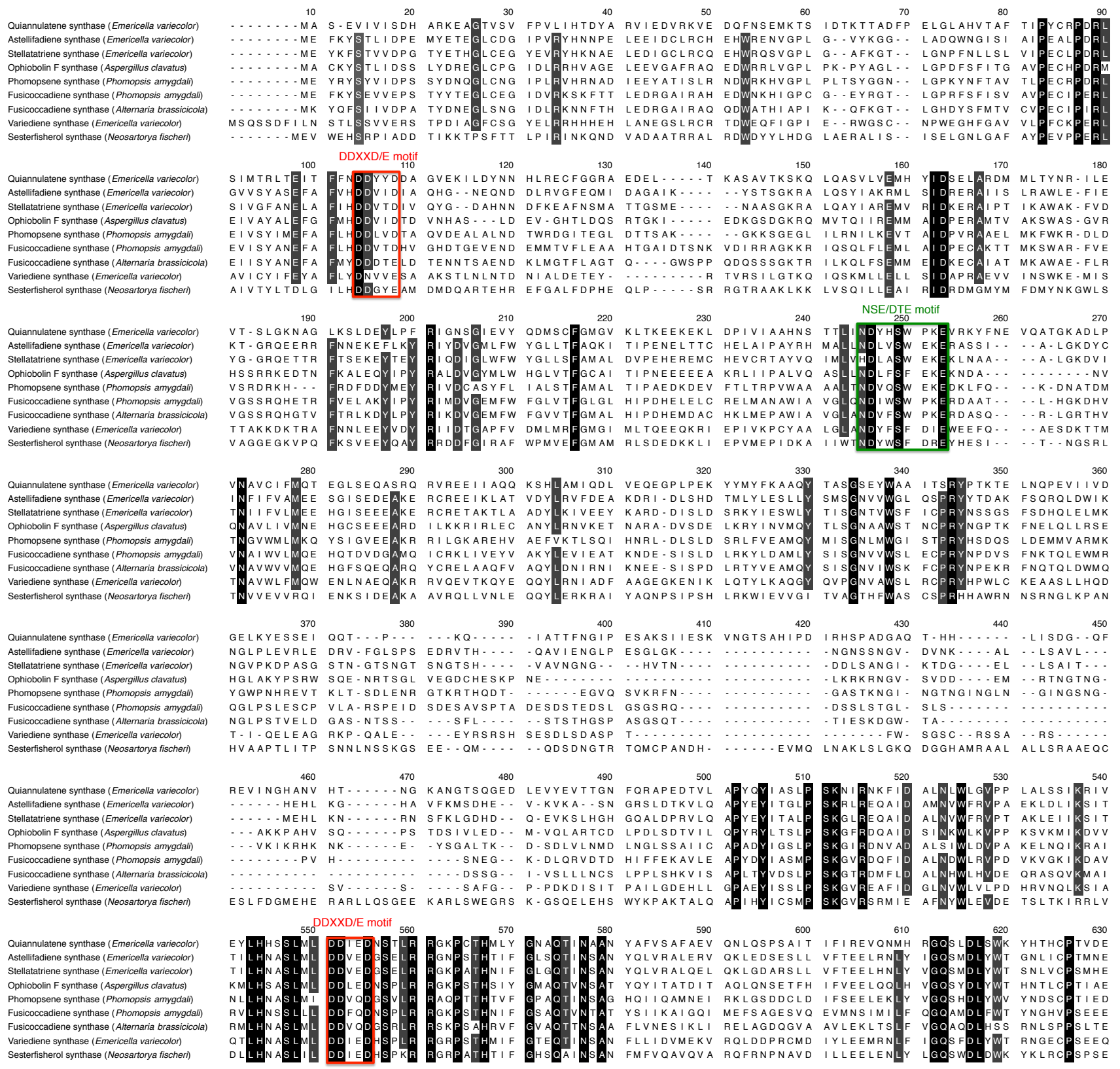

$590 \quad 600060$
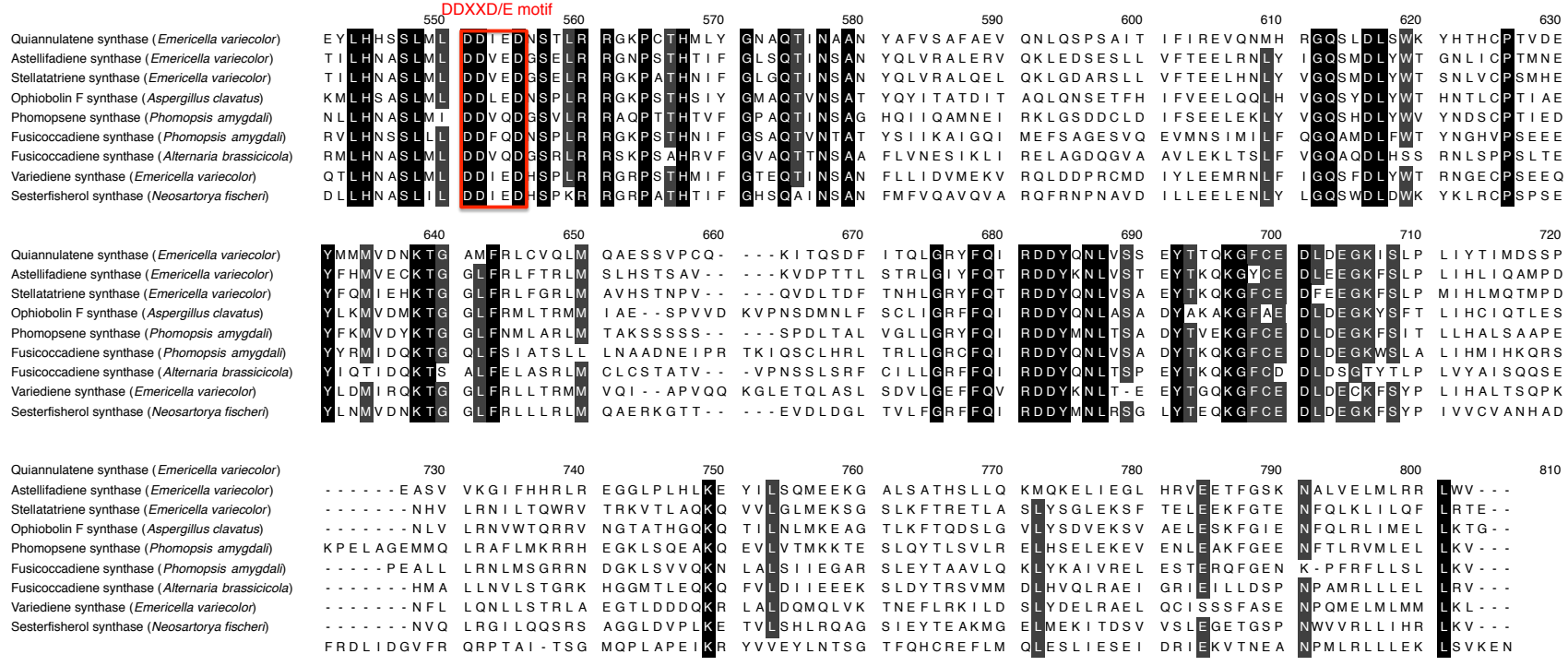

Figure S1. Sequence alignment of EvQS (quiannulatene synthase) and homologous bifunctional terpene synthases. The red boxes and green box indicate the conserved DDXXD/E motifs and NSE/DTE motif, respectively. 


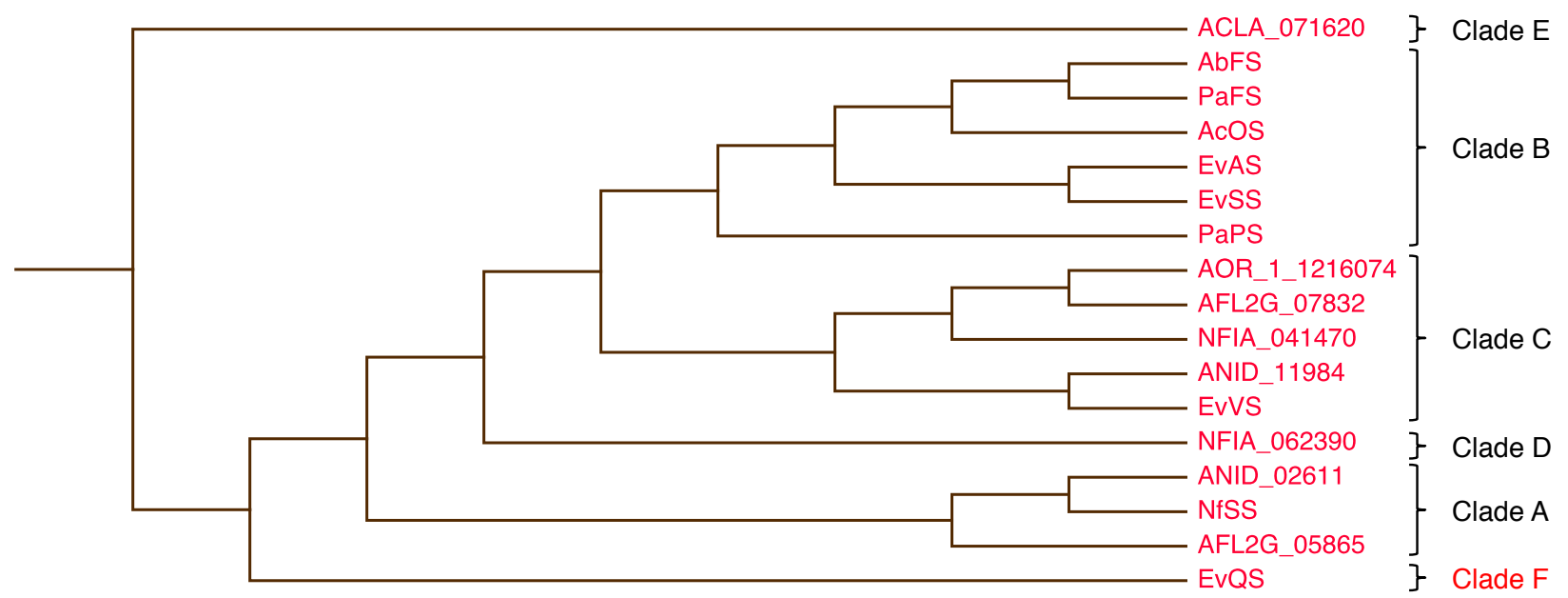

Figure S2. Phylogenetic analysis of terpene cyclase (TC) domains of fungal bifunctional terpene synthases. 
(A)

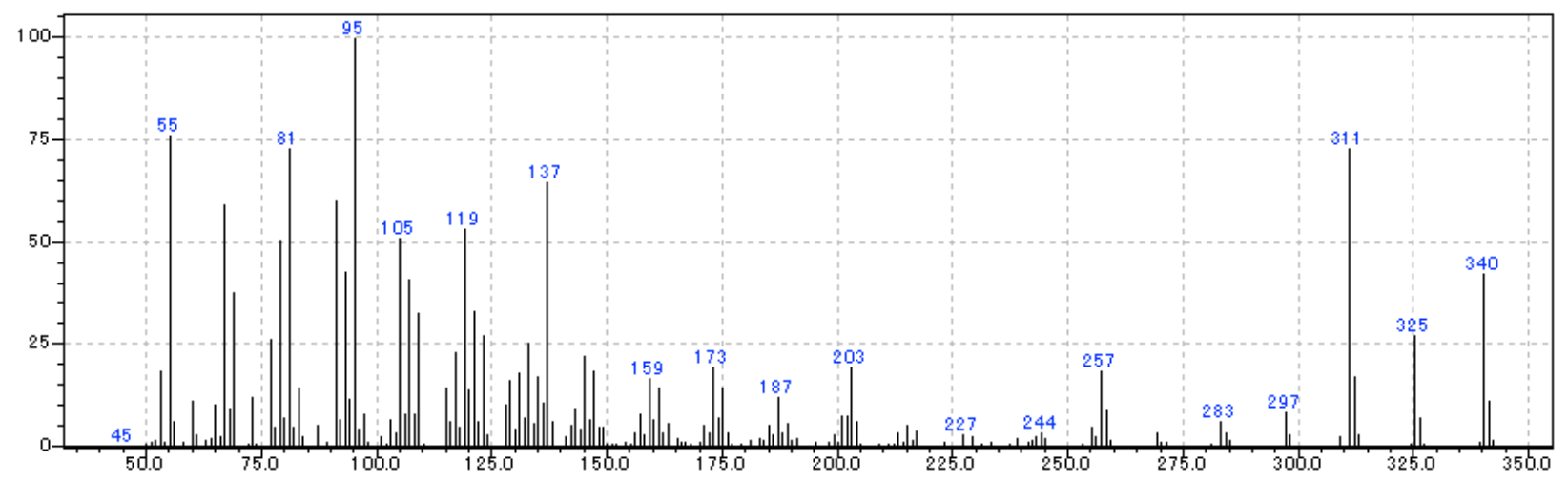

(B)

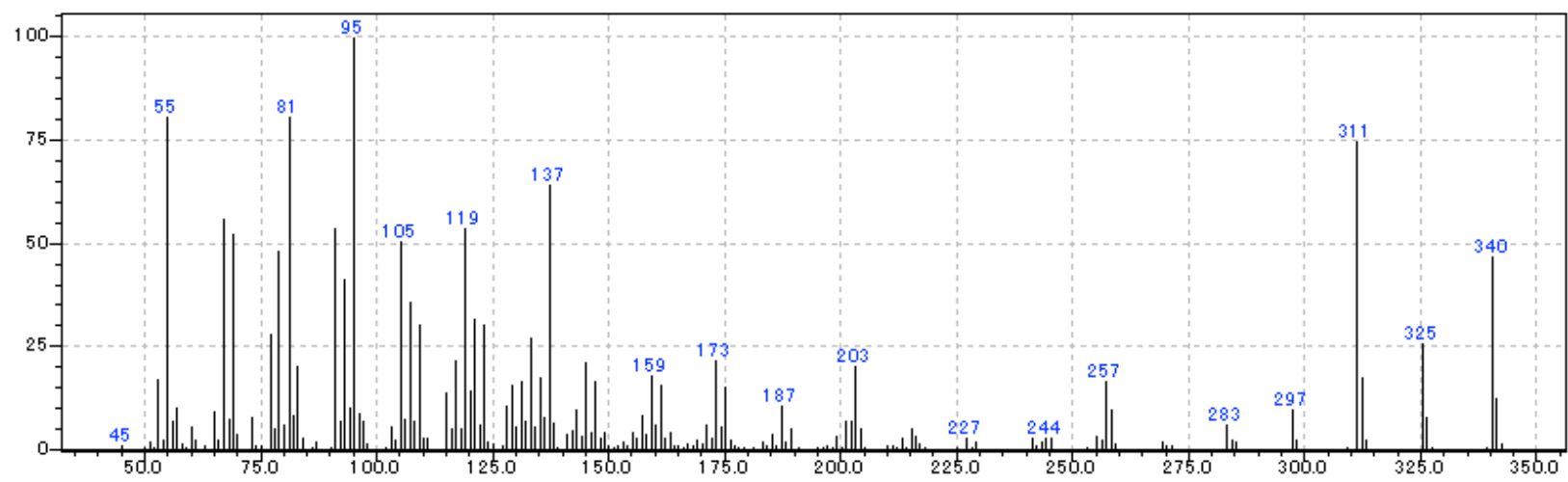

(C)

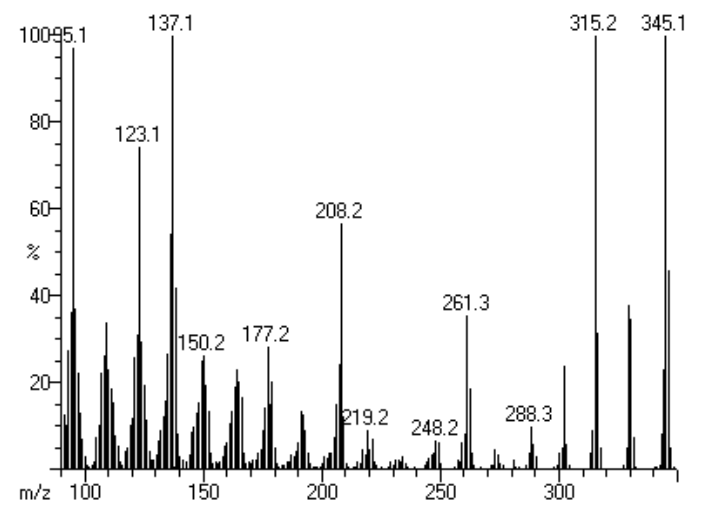

(to be continued to the next page) 
(D)

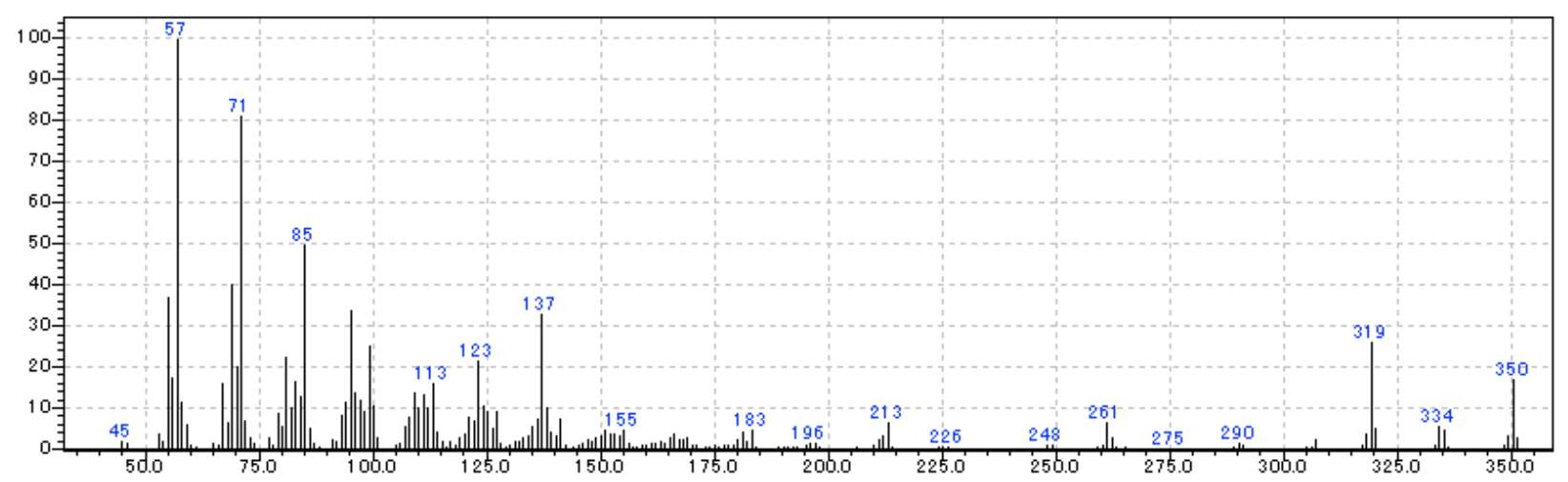

$(\mathrm{E})$

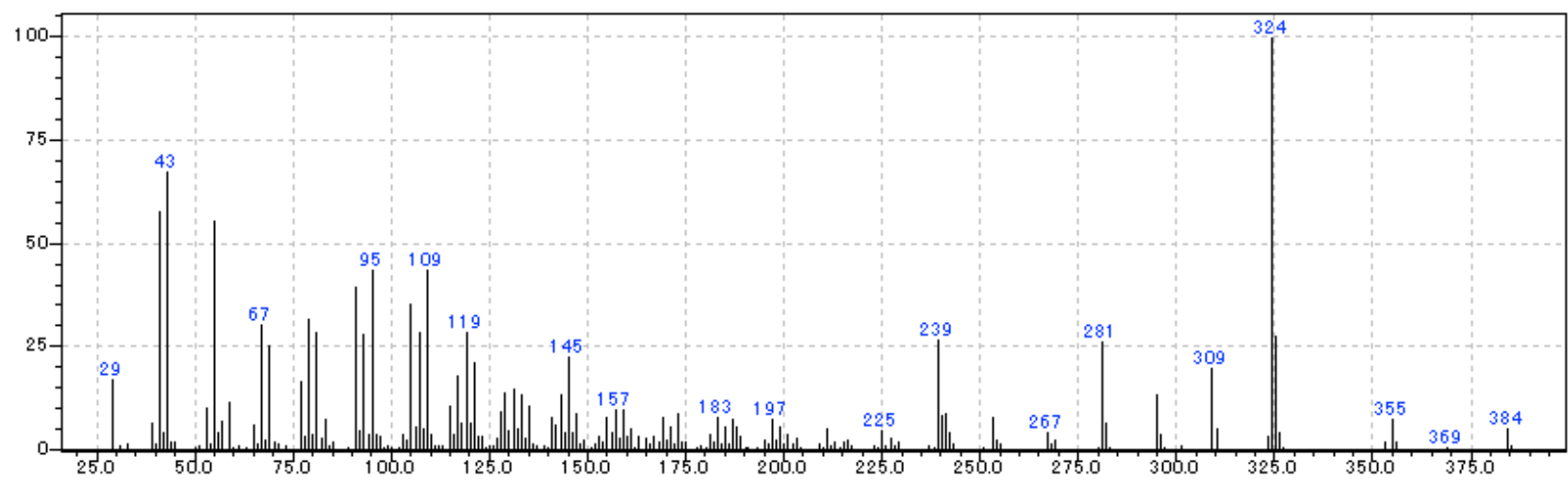

Figure S3. MS spectrum of (A) unlabeled quiannulatene (1), (B) 1 obtained from the enzymatic reaction performed in ${ }^{2} \mathrm{H}_{2} \mathrm{O}$, (C) $\left[14,16,17,18,25-{ }^{13} \mathrm{C}_{5}\right] \mathbf{1}$, (D) $\left[10,11,12,13,14,16,17,18,13,25-{ }^{13} \mathrm{C}_{10}\right] \mathbf{1}$, and (E) methyl quiannulatate (4). 

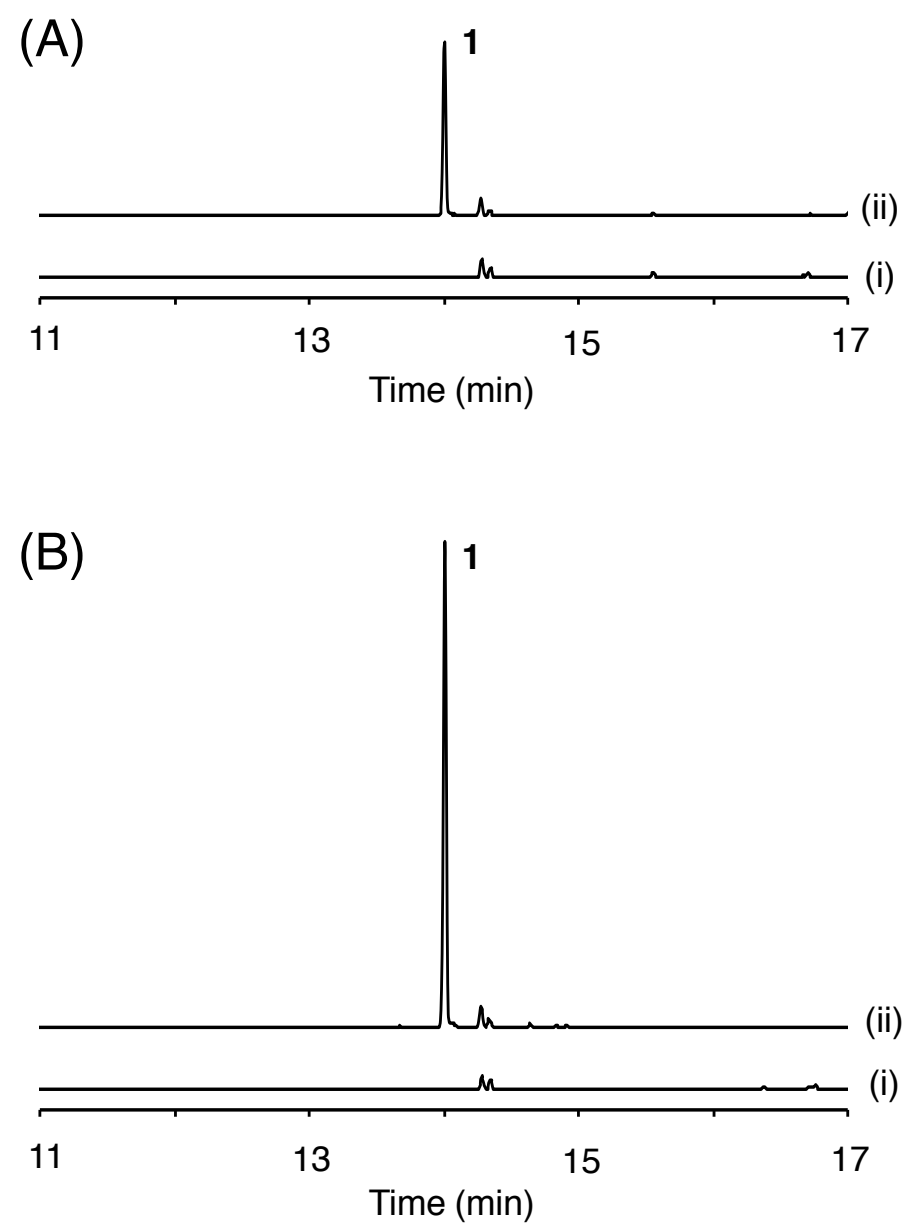

Figure S4. GC-MS profiles of the products of in vitro enzymatic reactions of [1-381]EvQS. (A) The standard reaction: (i) with the boiled enzyme, (ii) the complete reaction. (B) The reaction using $\mathrm{D}_{2} \mathrm{O}$ : (i) with the boiled enzyme, (ii) the complete reaction. 


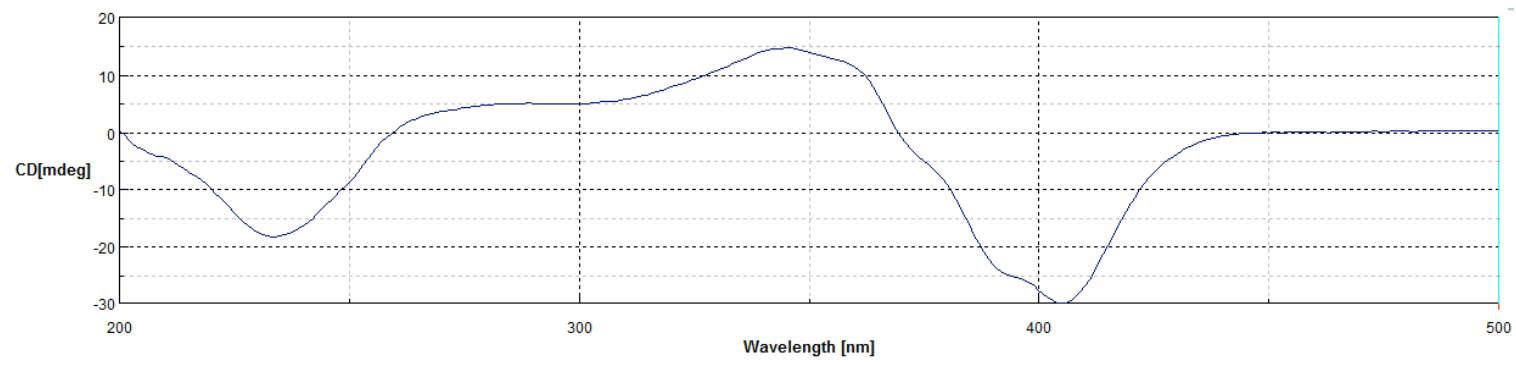

Figure S5. Experimental ECD spectrum of $\mathbf{3}(0.5 \mathrm{mg} / \mathrm{ml}$ in ethanol).

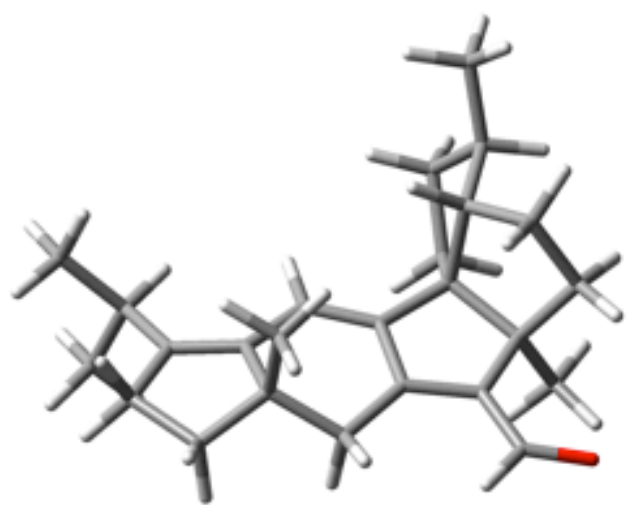

3a (Most stable)

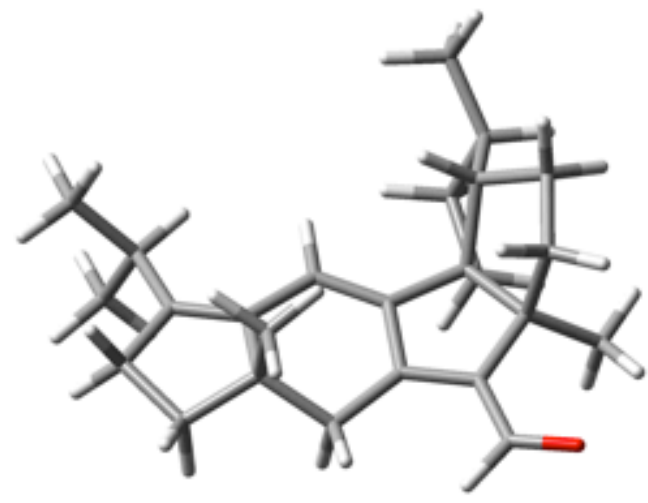

3c

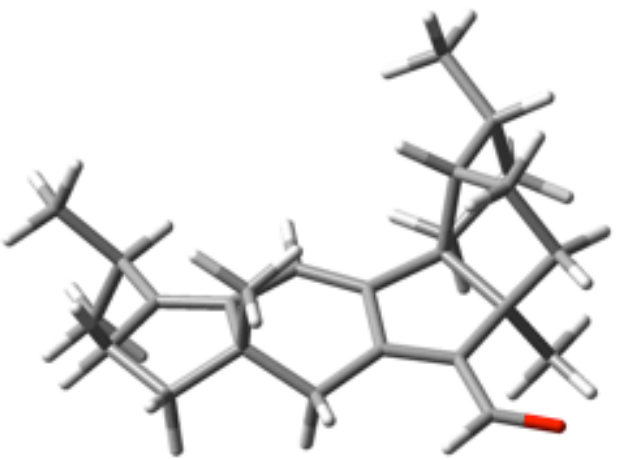

3b (Second most stable)

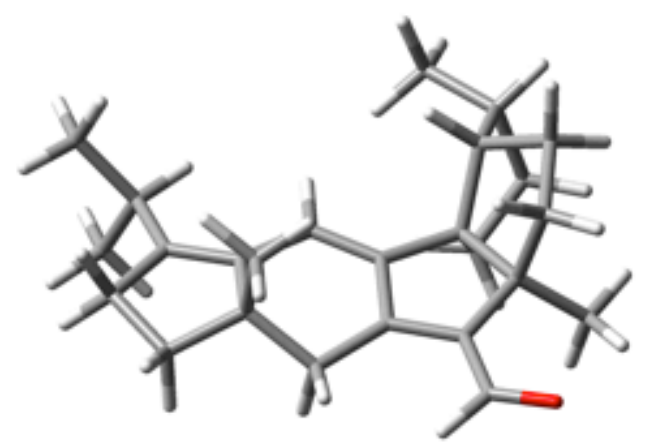

3d

Figure S6. Optimized geometries of 3a-3d at the B3LYP/6-31G(d) level with PCM model in ethanol. 

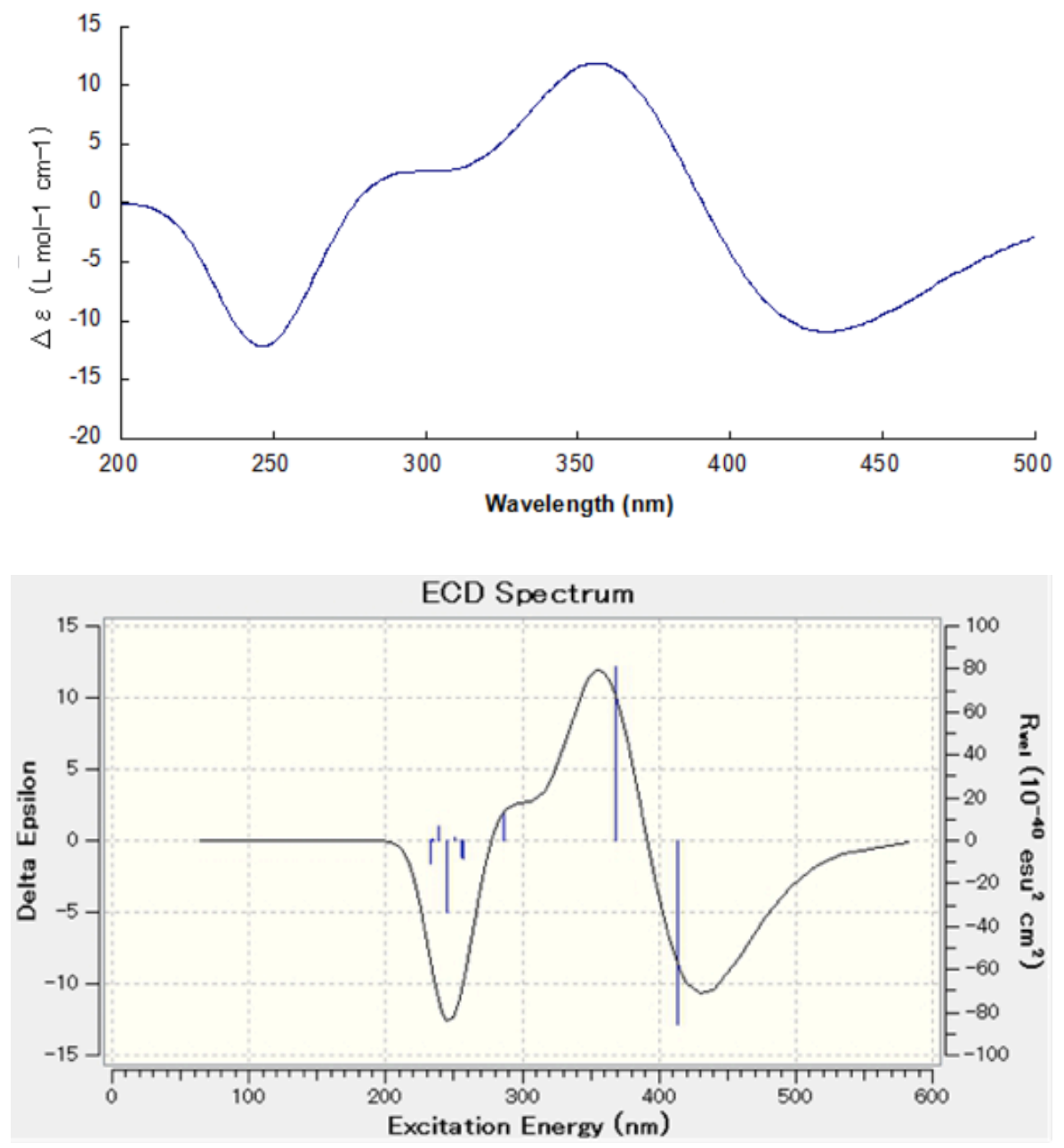

$3 a\left(P_{E}=89.0 \%\right)$

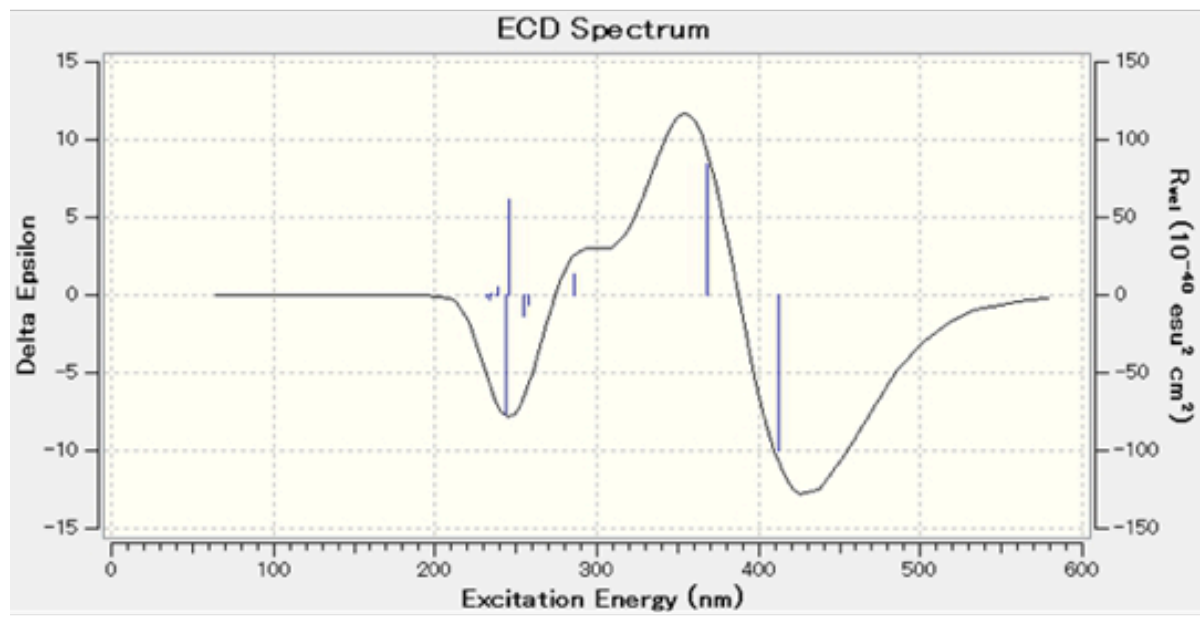

$$
\text { 3b }\left(P_{E}=9.6 \%\right)
$$

Figure S7. Calculated ECD spectrum of $\mathbf{3}$, weighting the calculated CD curves of $\mathbf{3 a}$ and $\mathbf{3 b}$ by the Boltzmann law. 


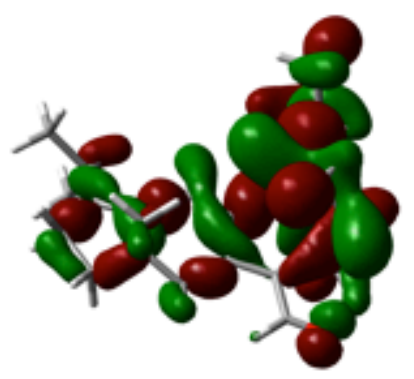

M092

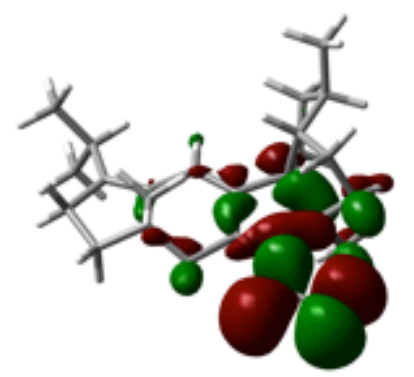

M095

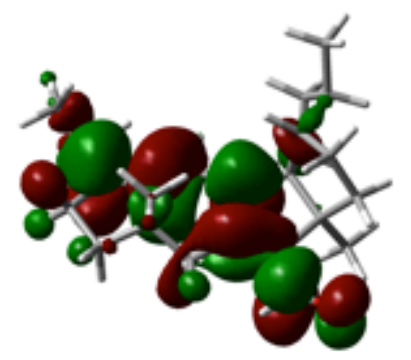

M098

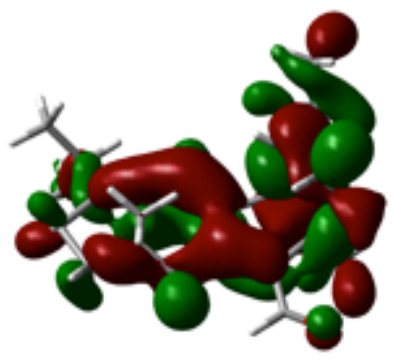

MO93

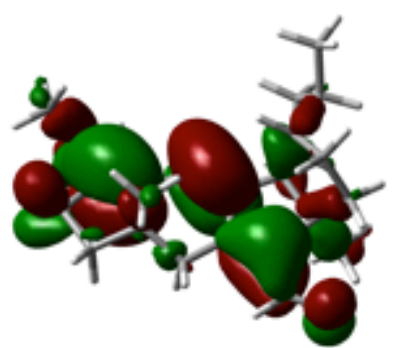

MO96 (НОМО)

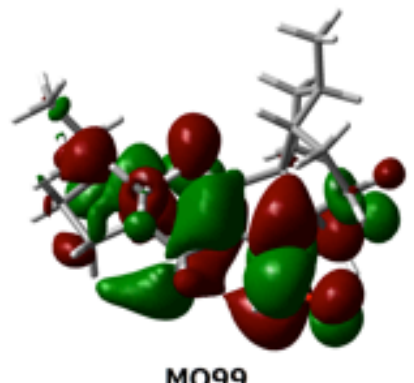

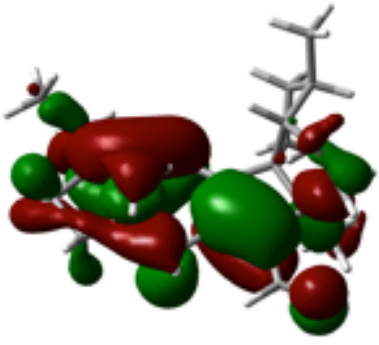

M094

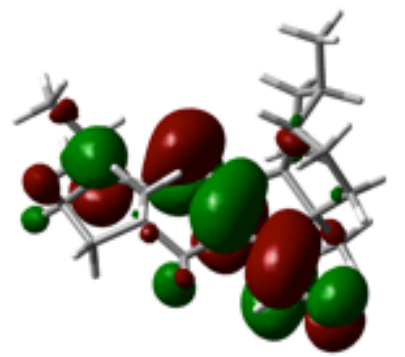

MO97 (LUMO)

Figure S8. Important molecular orbitals (MOs) of 3a for ECD calculation. 


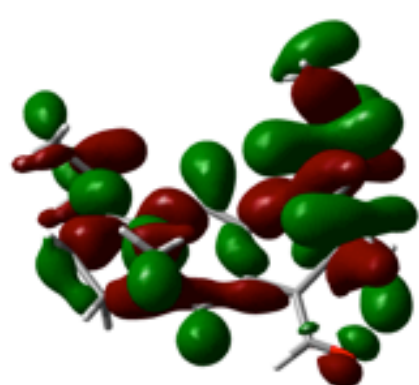

M091

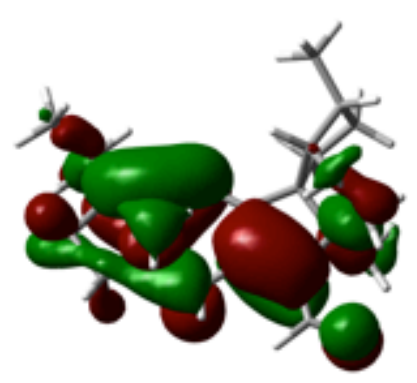

MO94

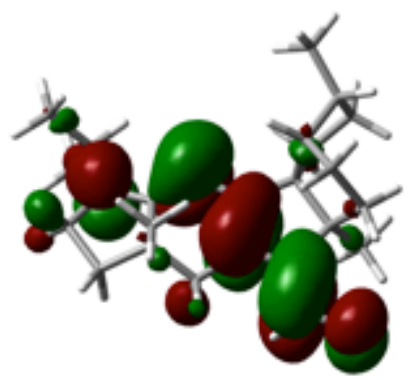

MO97 (LUMO)

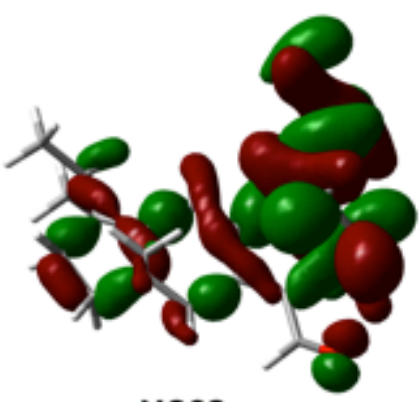

MO92

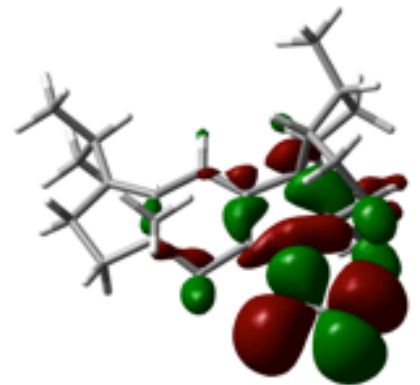

MO95

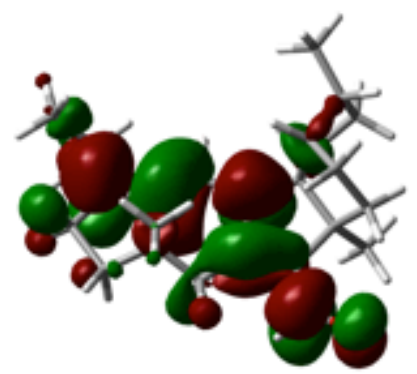

MO98

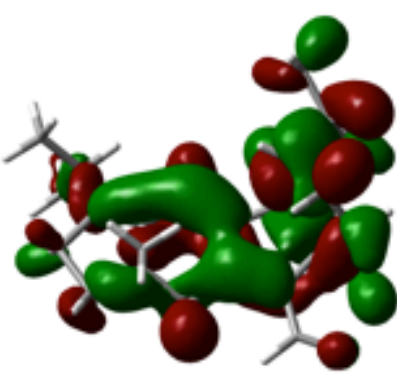

M093

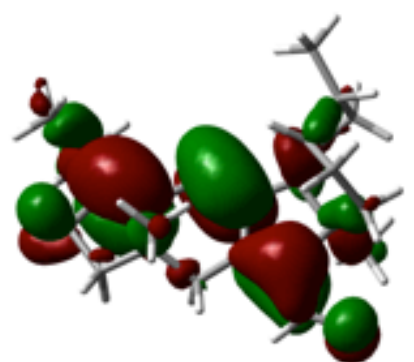

MO96 (НОМО)

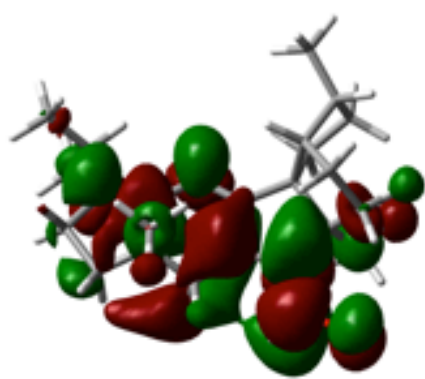

M099

Figure S9. Important molecular orbitals (MOs) of $\mathbf{3 b}$ for ECD calculation. 


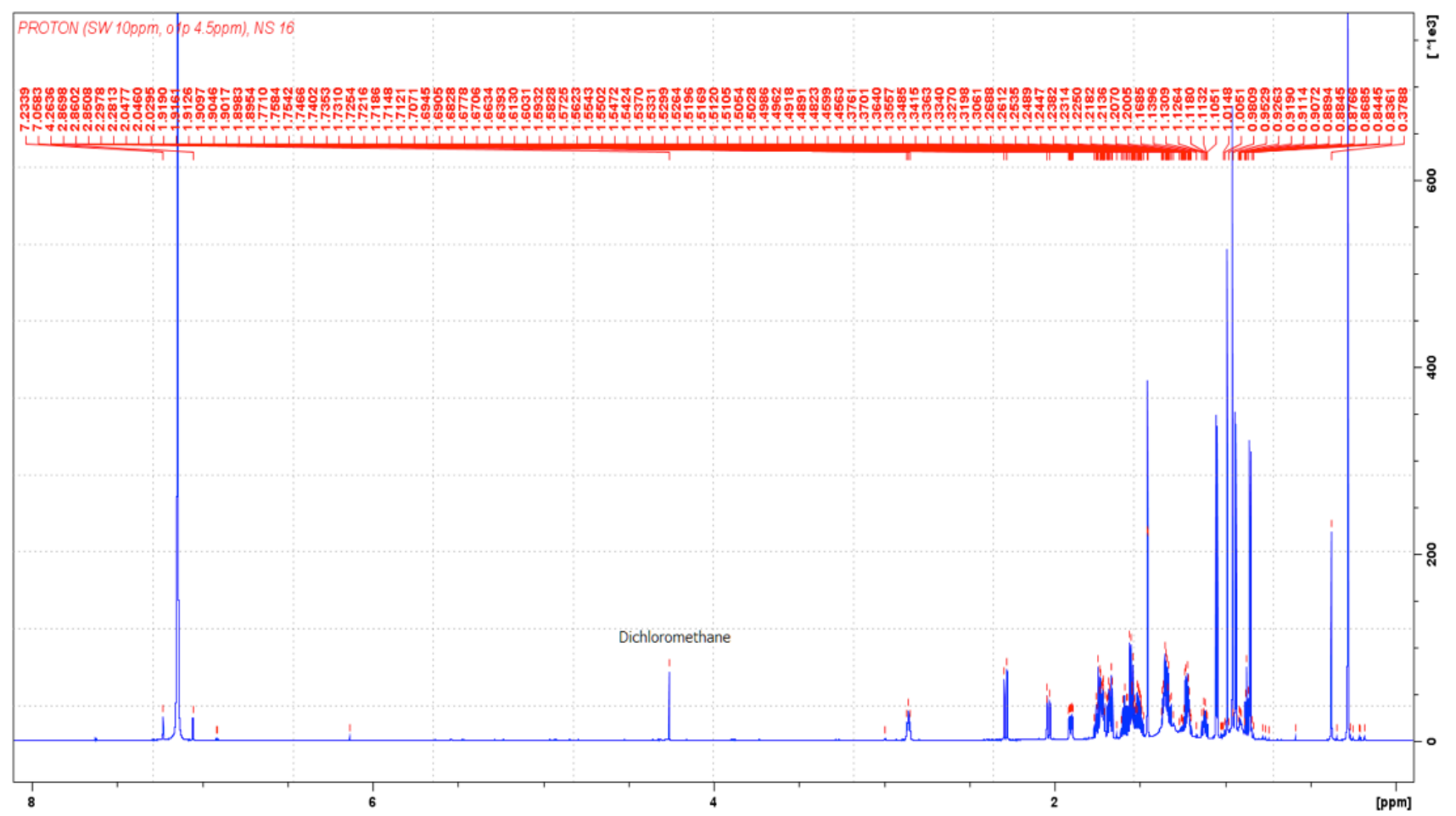

Figure S10. ${ }^{1} \mathrm{H}$ NMR spectrum of $\mathbf{1}\left(900 \mathrm{MHz}\right.$, in $\left.\mathrm{C}_{6} \mathrm{D}_{6}\right)$

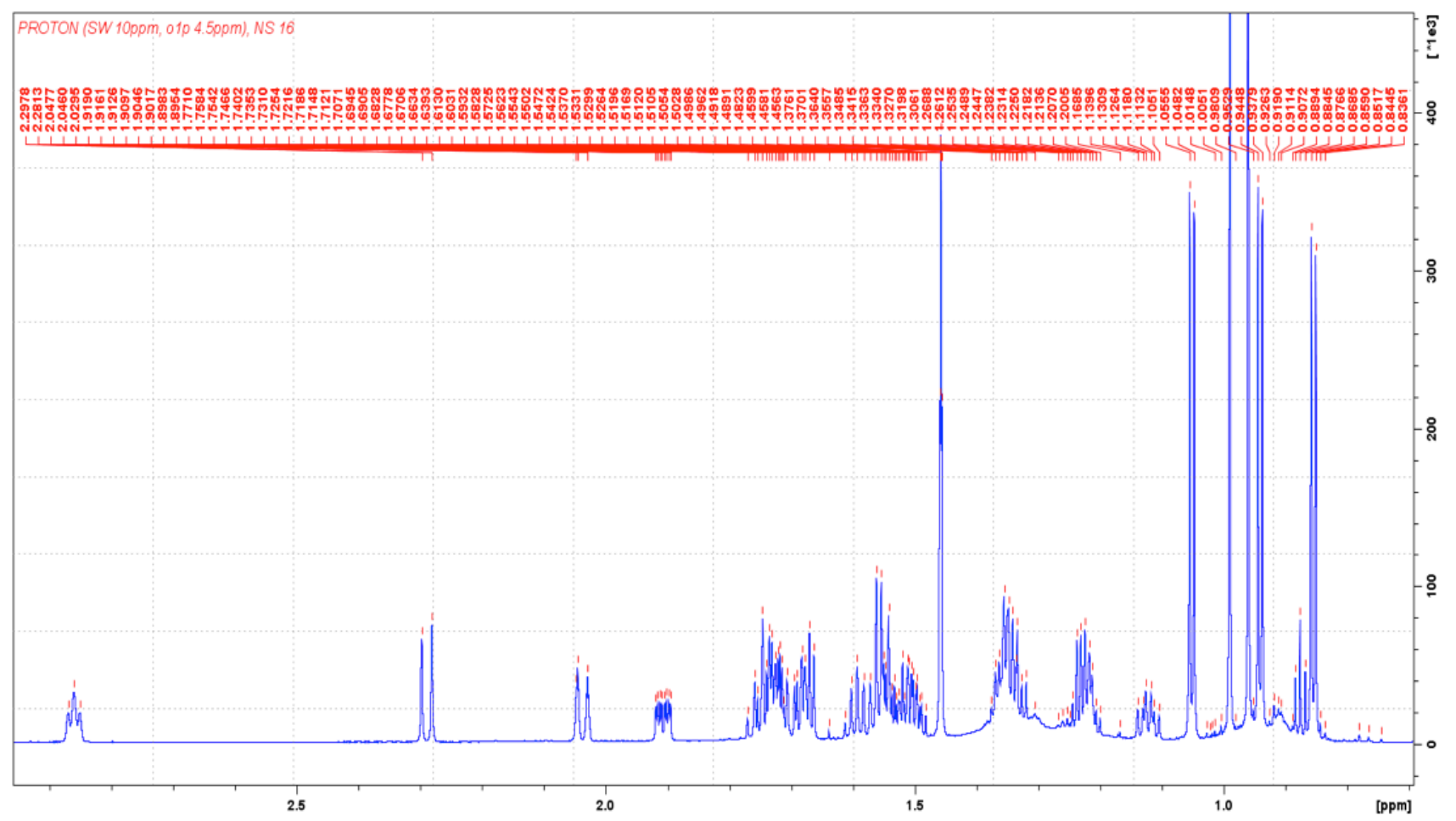

Figure S11. ${ }^{1} \mathrm{H}$ NMR spectrum of $\mathbf{1}$ in 0.7-2.9 ppm $\left(900 \mathrm{MHz}\right.$, in $\left.\mathrm{C}_{6} \mathrm{D}_{6}\right)$. 


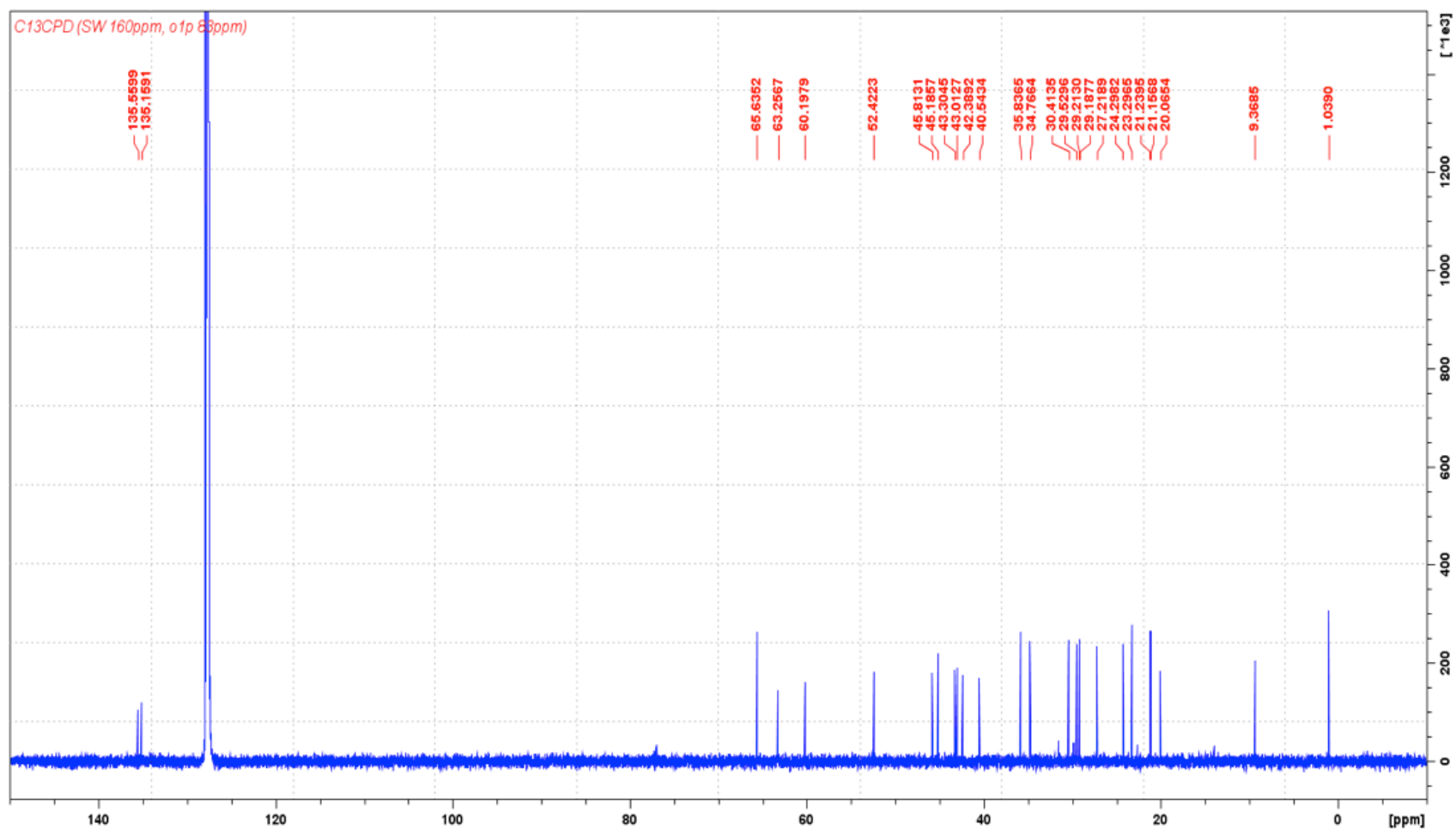

Figure $\mathrm{S} .12{ }^{13} \mathrm{C}$ NMR spectrum of $\mathbf{1}\left(225 \mathrm{MHz}\right.$, in $\left.\mathrm{C}_{6} \mathrm{D}_{6}\right)$.

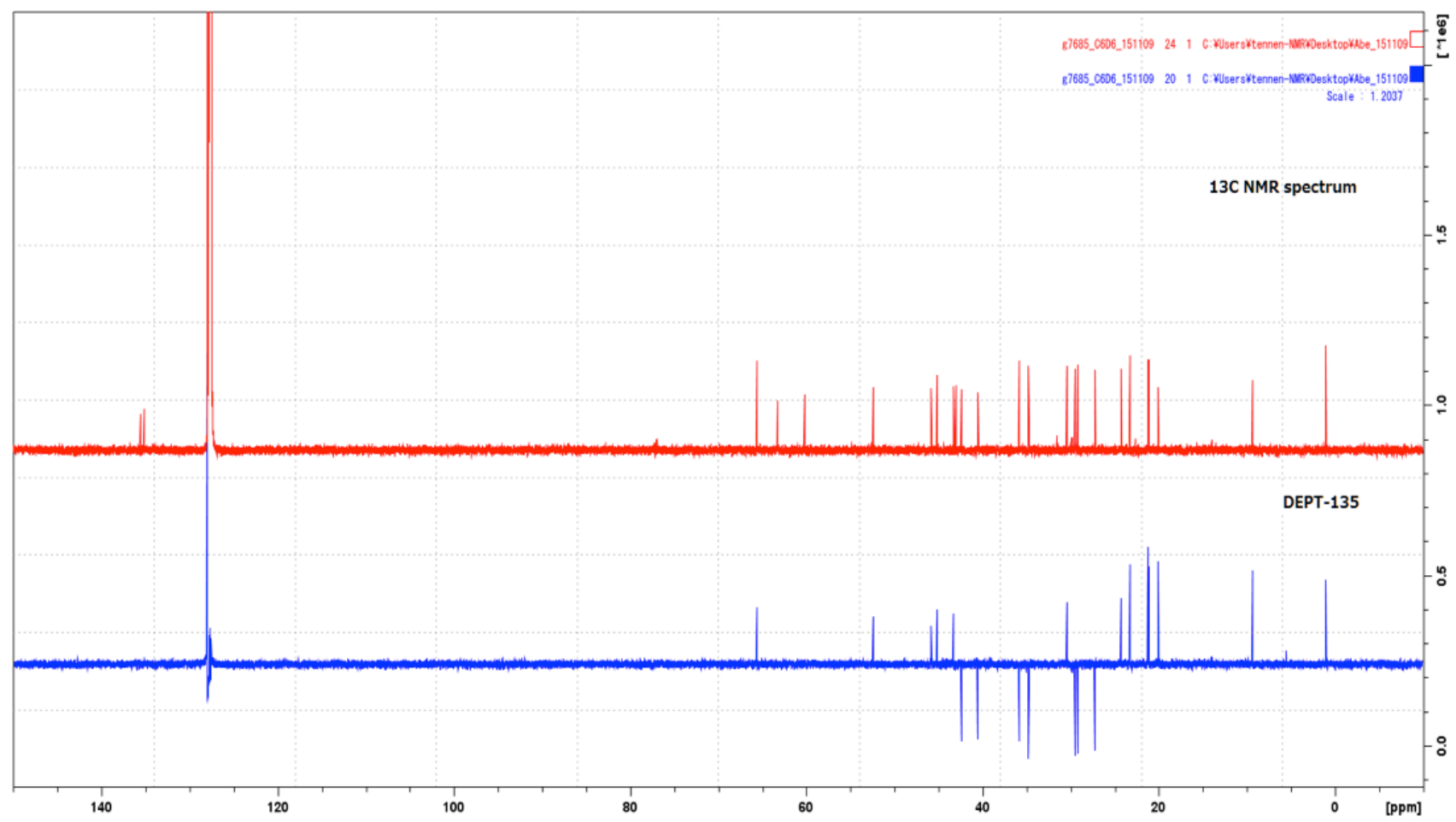

Figure S13. DEPT-135 spectrum of $1\left(225 \mathrm{MHz}\right.$, in $\left.\mathrm{C}_{6} \mathrm{D}_{6}\right)$. 


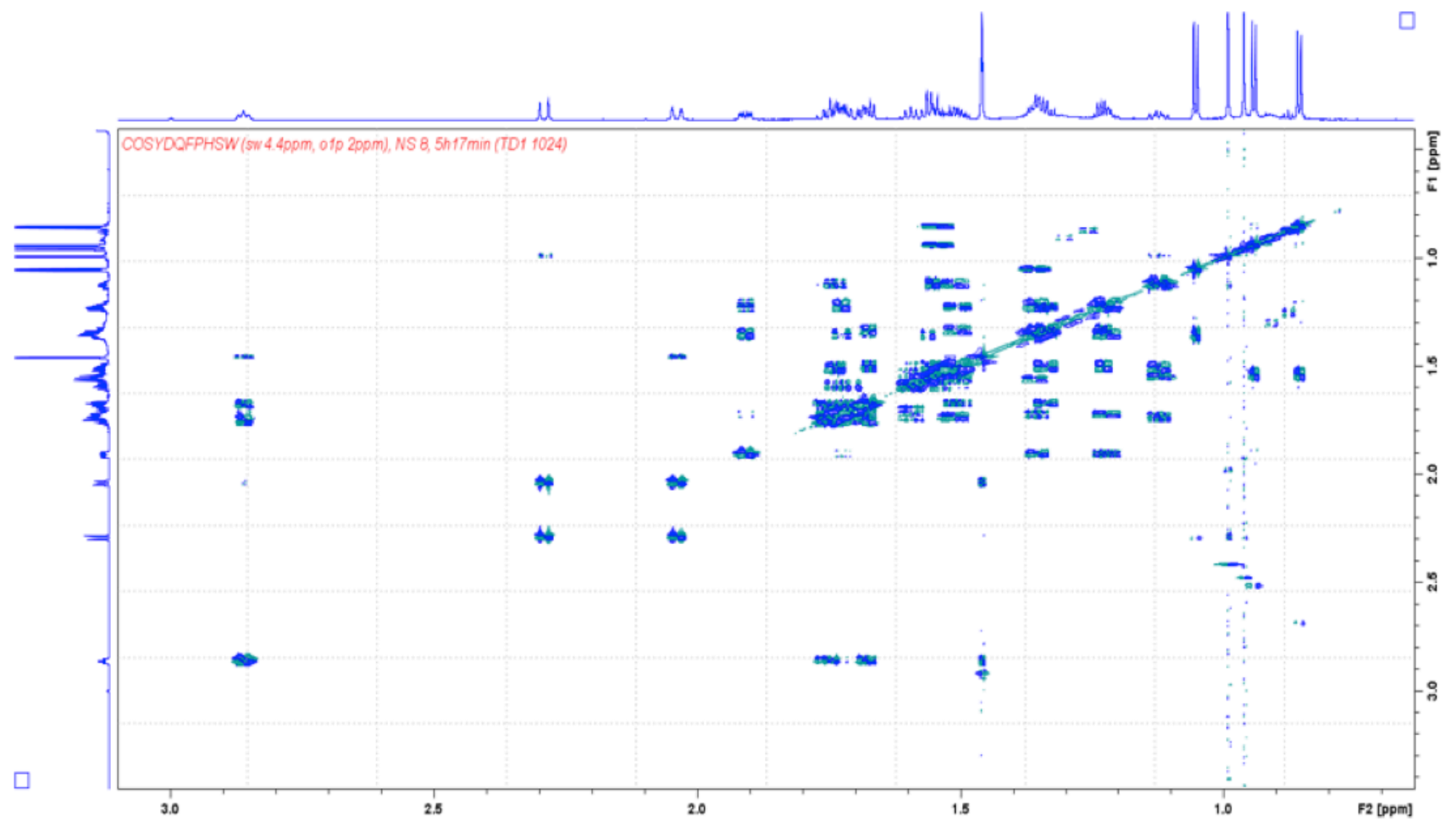

Figure S14. DQF-COSY spectrum of $\mathbf{1}\left(900 \mathrm{MHz}\right.$, in $\left.\mathrm{C}_{6} \mathrm{D}_{6}\right)$.

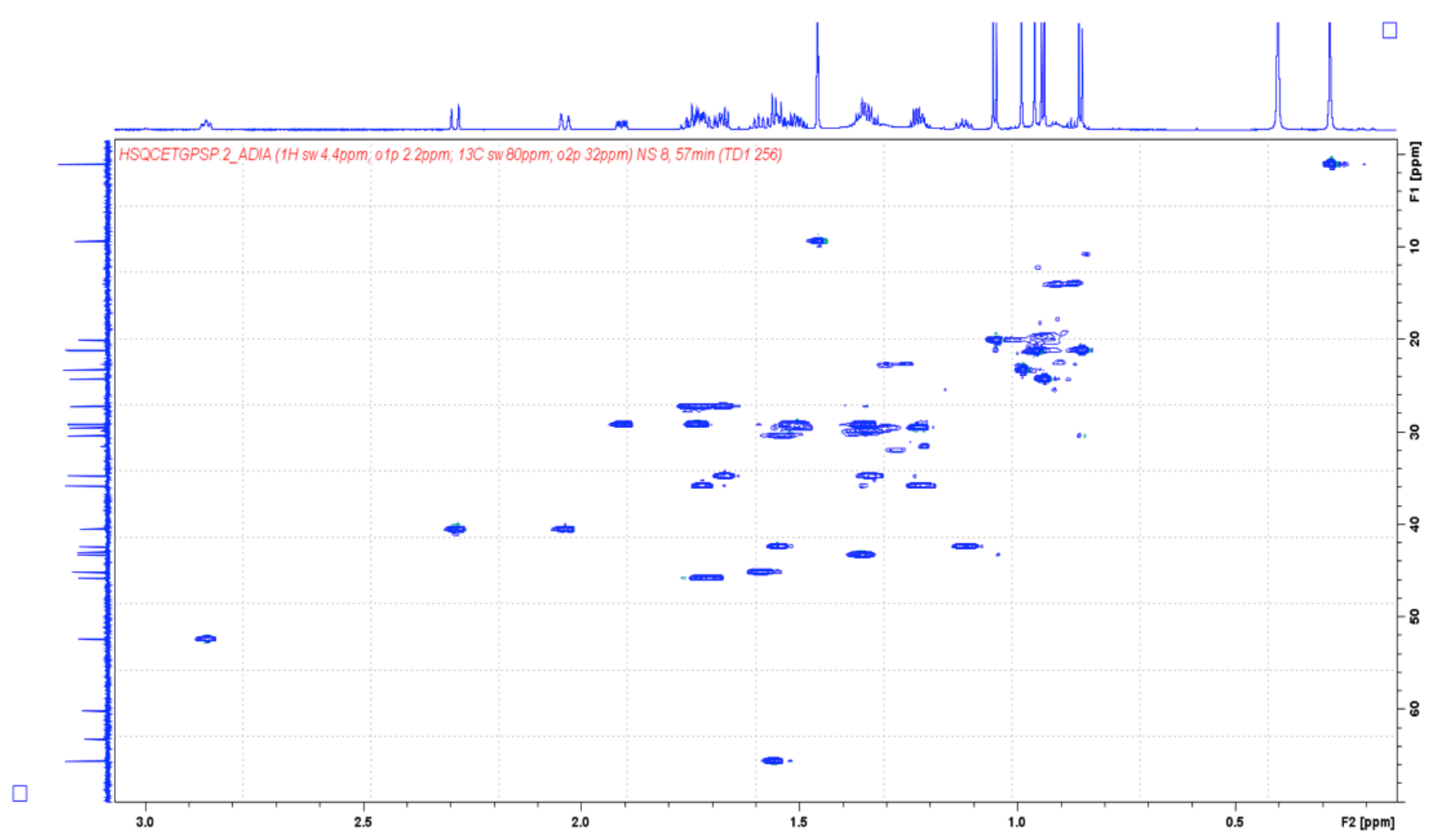

Figure S15. HSQC spectrum of $1\left(900 \mathrm{MHz}\right.$, in $\left.\mathrm{C}_{6} \mathrm{D}_{6}\right)$. 


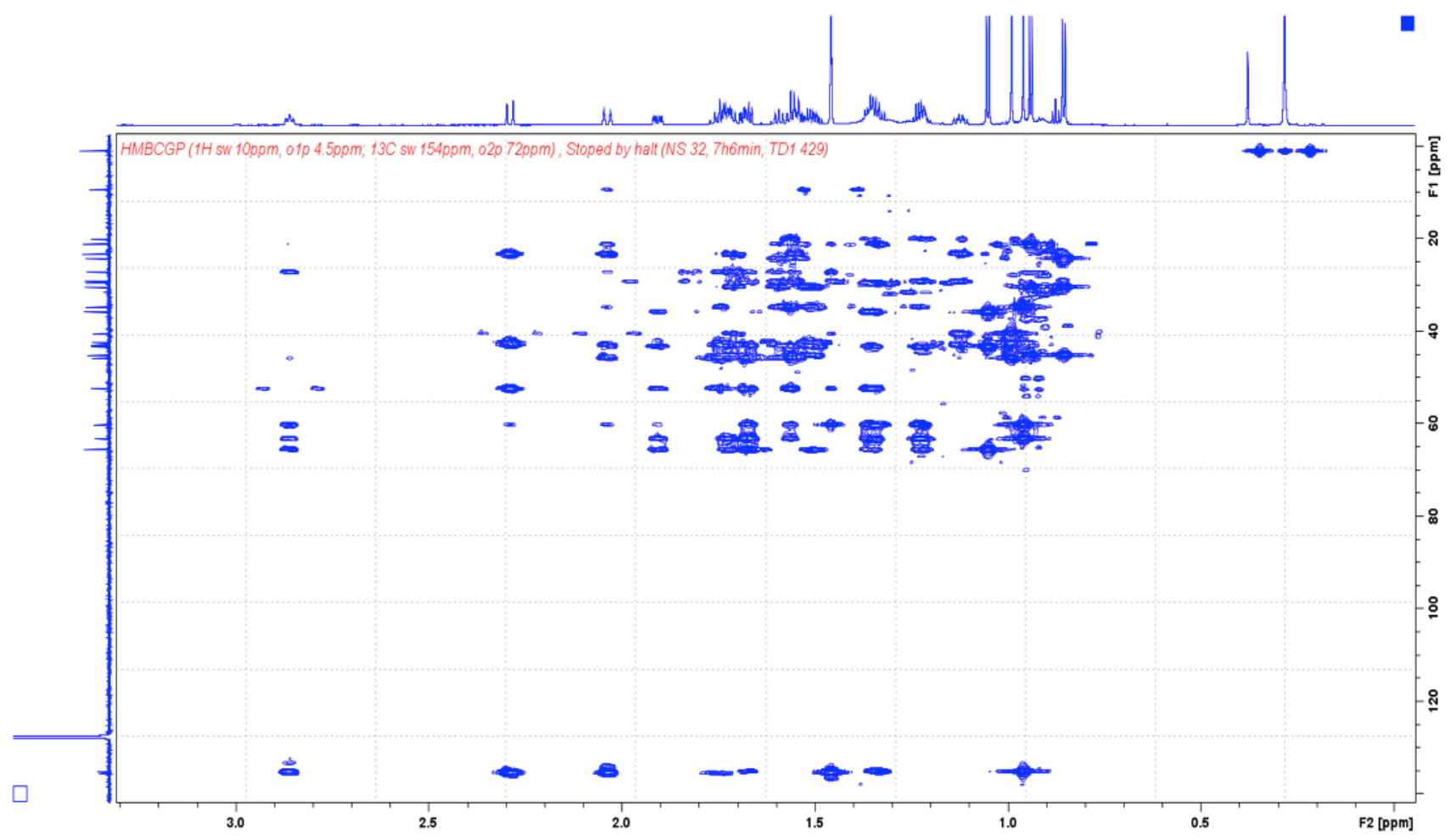

Figure S16. HMBC spectrum of $\mathbf{1}\left(900 \mathrm{MHz}\right.$, in $\left.\mathrm{C}_{6} \mathrm{D}_{6}\right)$.

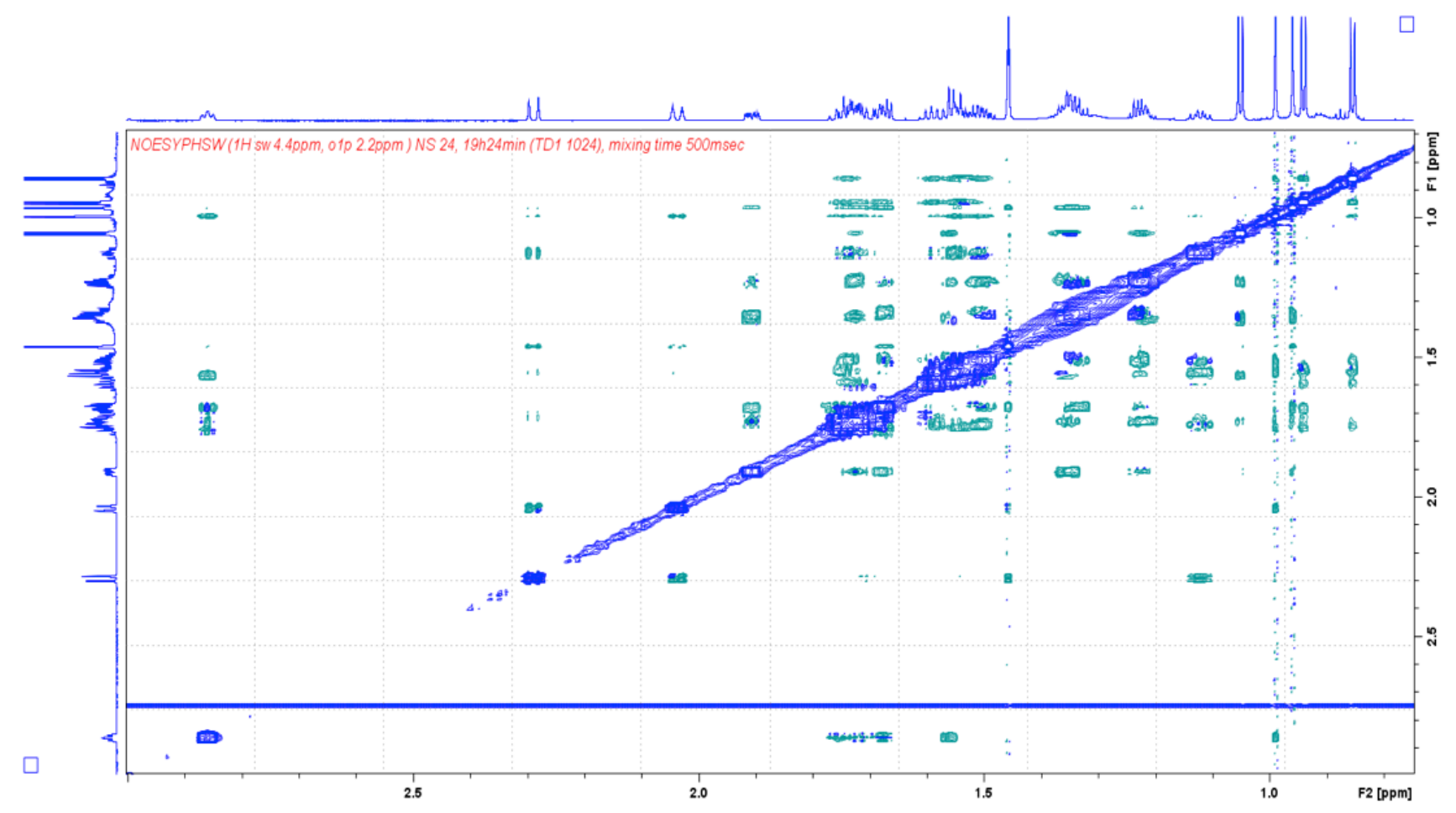

Figure S17. NOESY spectrum of $1\left(900 \mathrm{MHz}\right.$, in $\left.\mathrm{C}_{6} \mathrm{D}_{6}\right)$. 


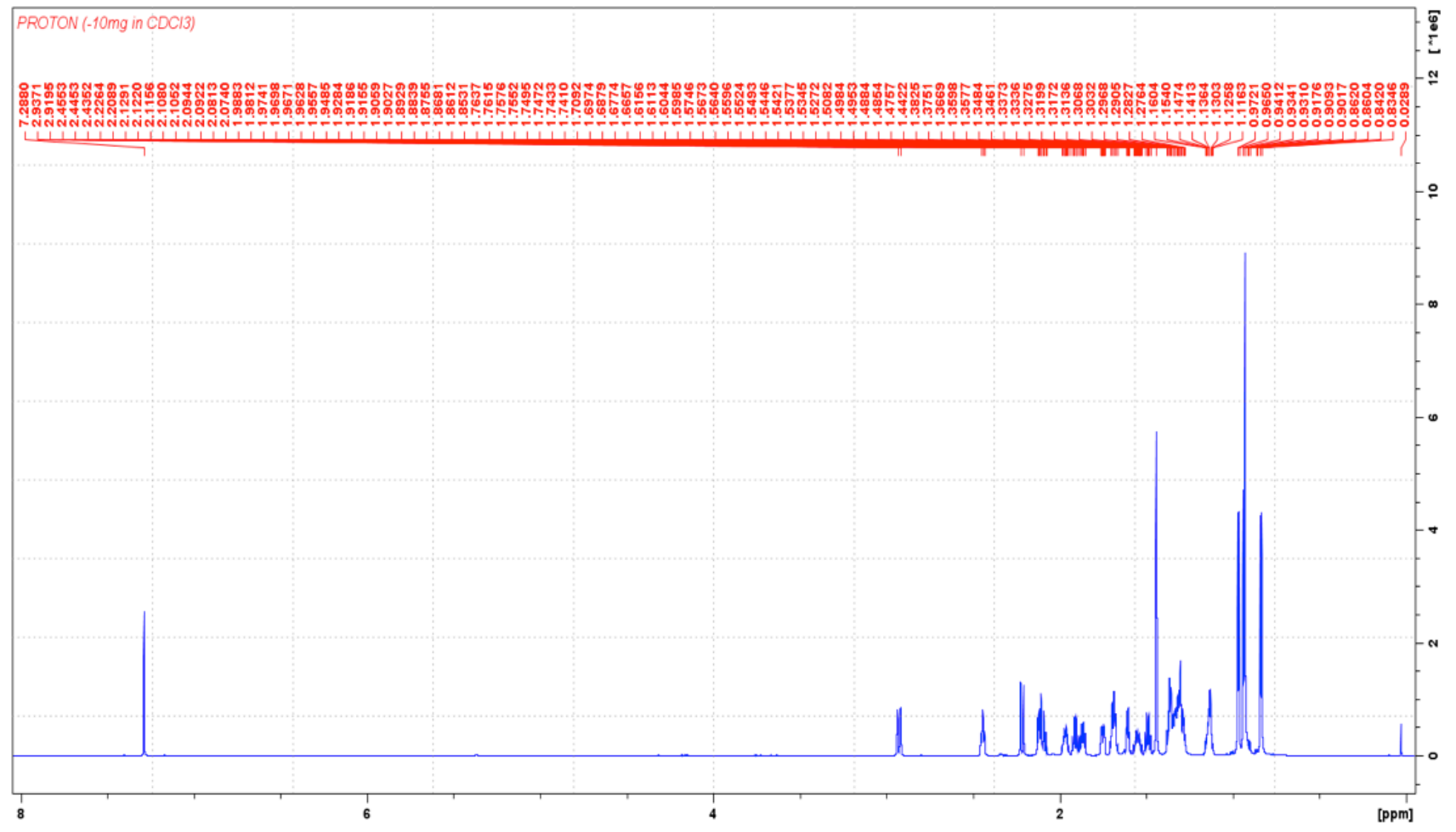

Figure S18. ${ }^{1} \mathrm{H}$ NMR spectrum of $2\left(900 \mathrm{MHz}\right.$, in $\left.\mathrm{CDCl}_{3}\right)$.

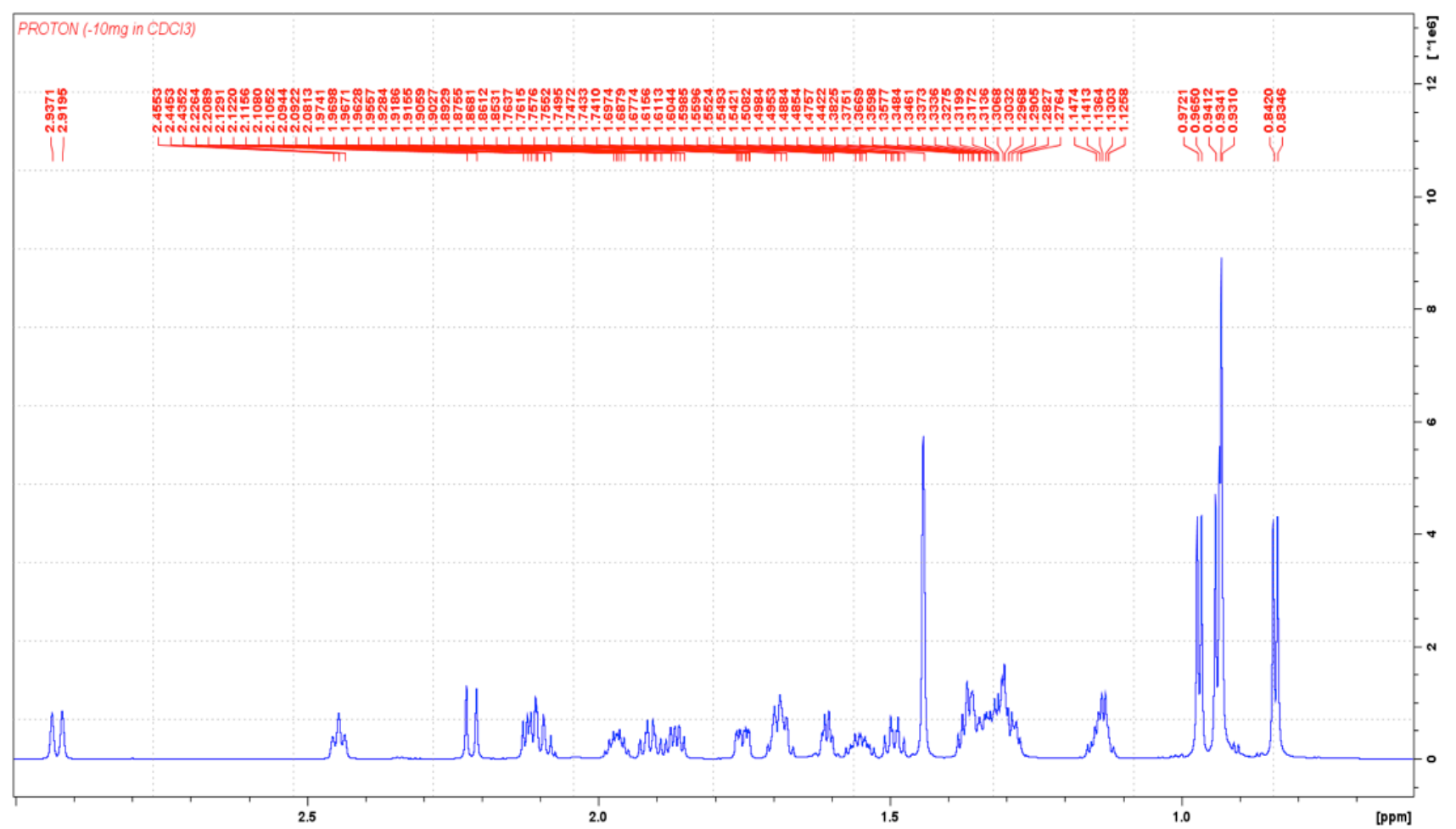

Figure S19. ${ }^{1} \mathrm{H}$ NMR spectrum of 2 in $0.8-3.0 \mathrm{ppm}\left(900 \mathrm{MHz}\right.$, in $\left.\mathrm{CDCl}_{3}\right)$. 


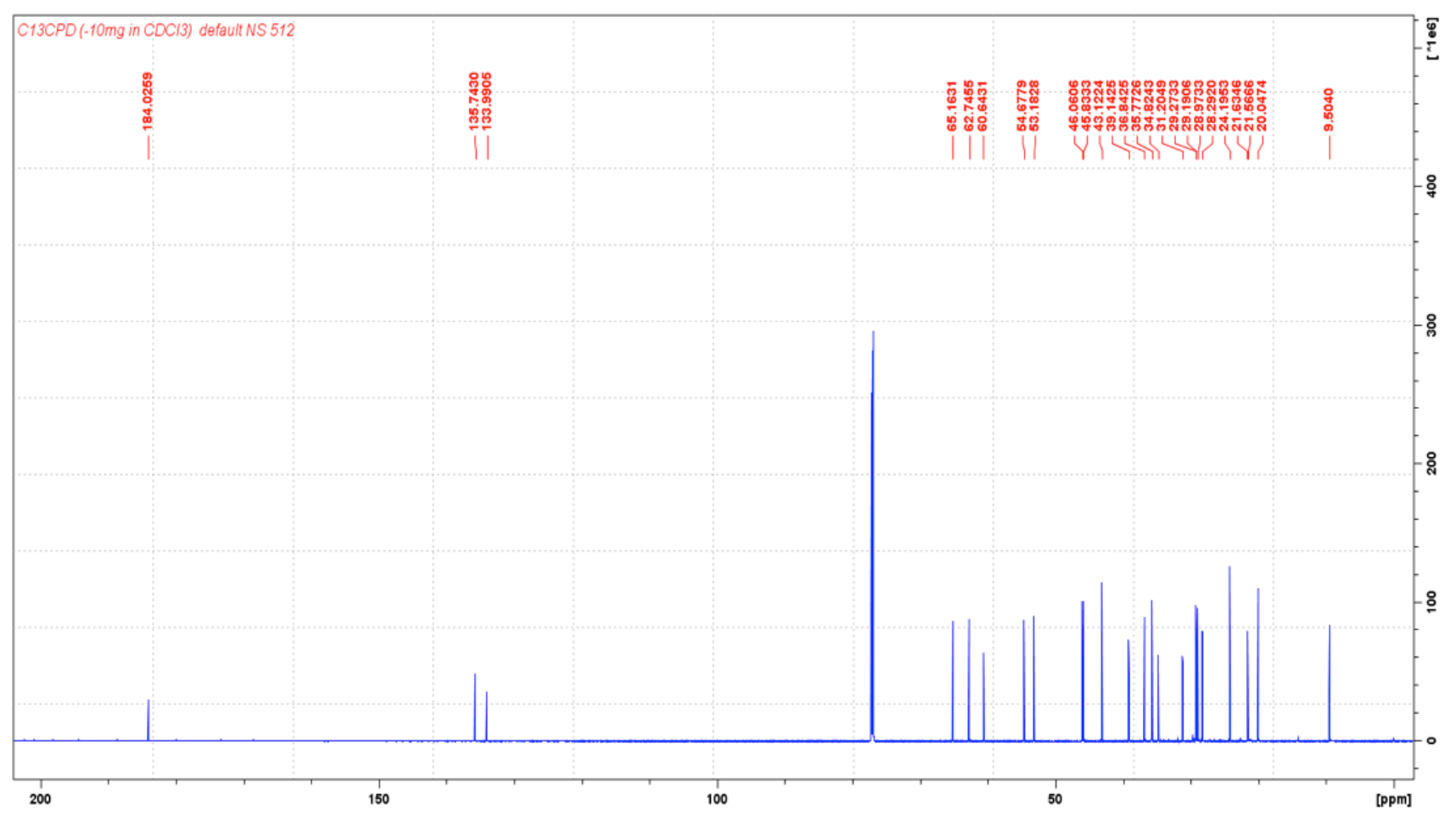

Figure S20. ${ }^{13} \mathrm{C}$ NMR spectrum of $2\left(225 \mathrm{MHz}\right.$, in $\left.\mathrm{CDCl}_{3}\right)$.

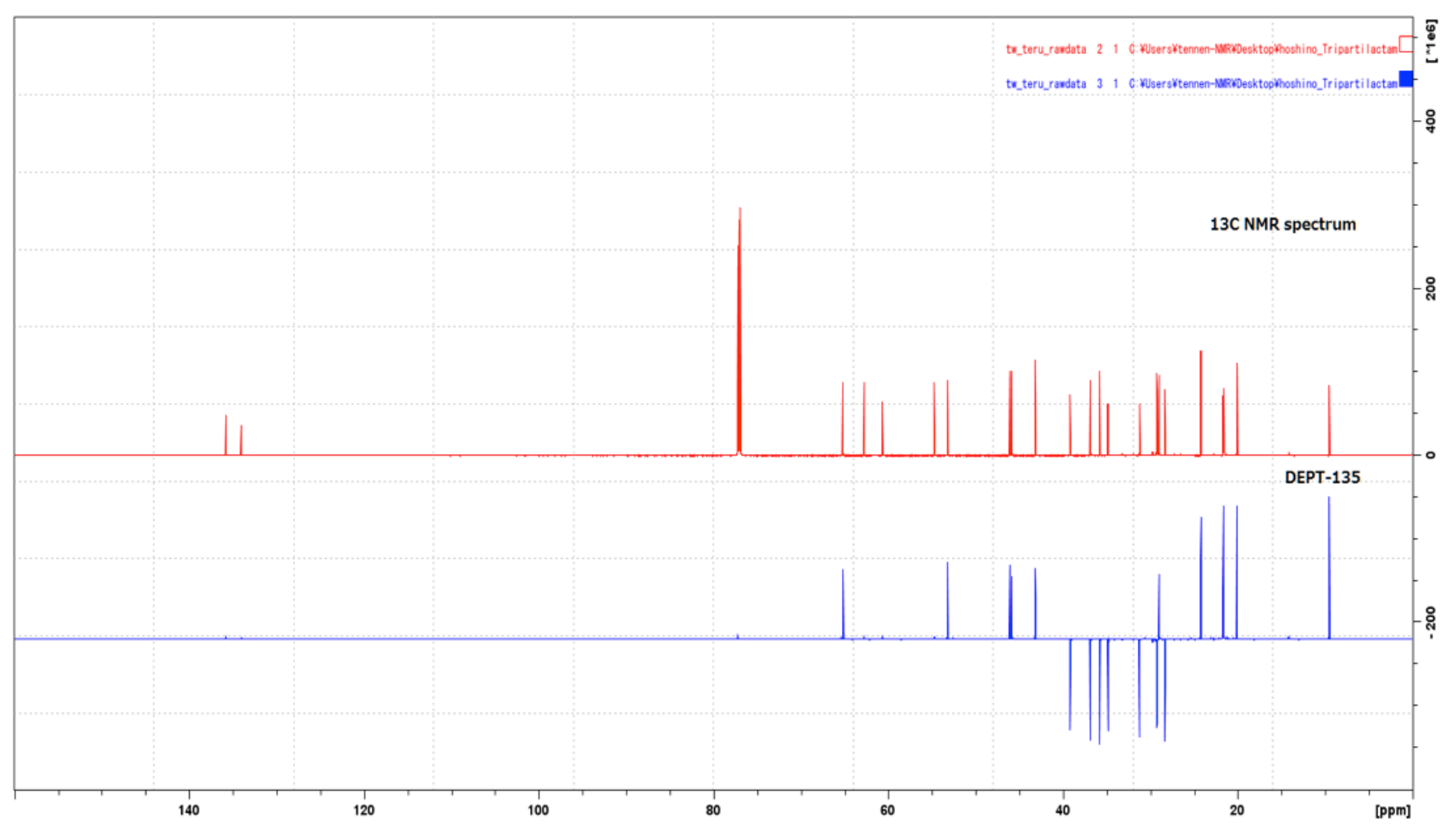

Figure S21. DEPT-135 spectrum of $2\left(225 \mathrm{MHz}\right.$, in $\left.\mathrm{CDCl}_{3}\right)$. 


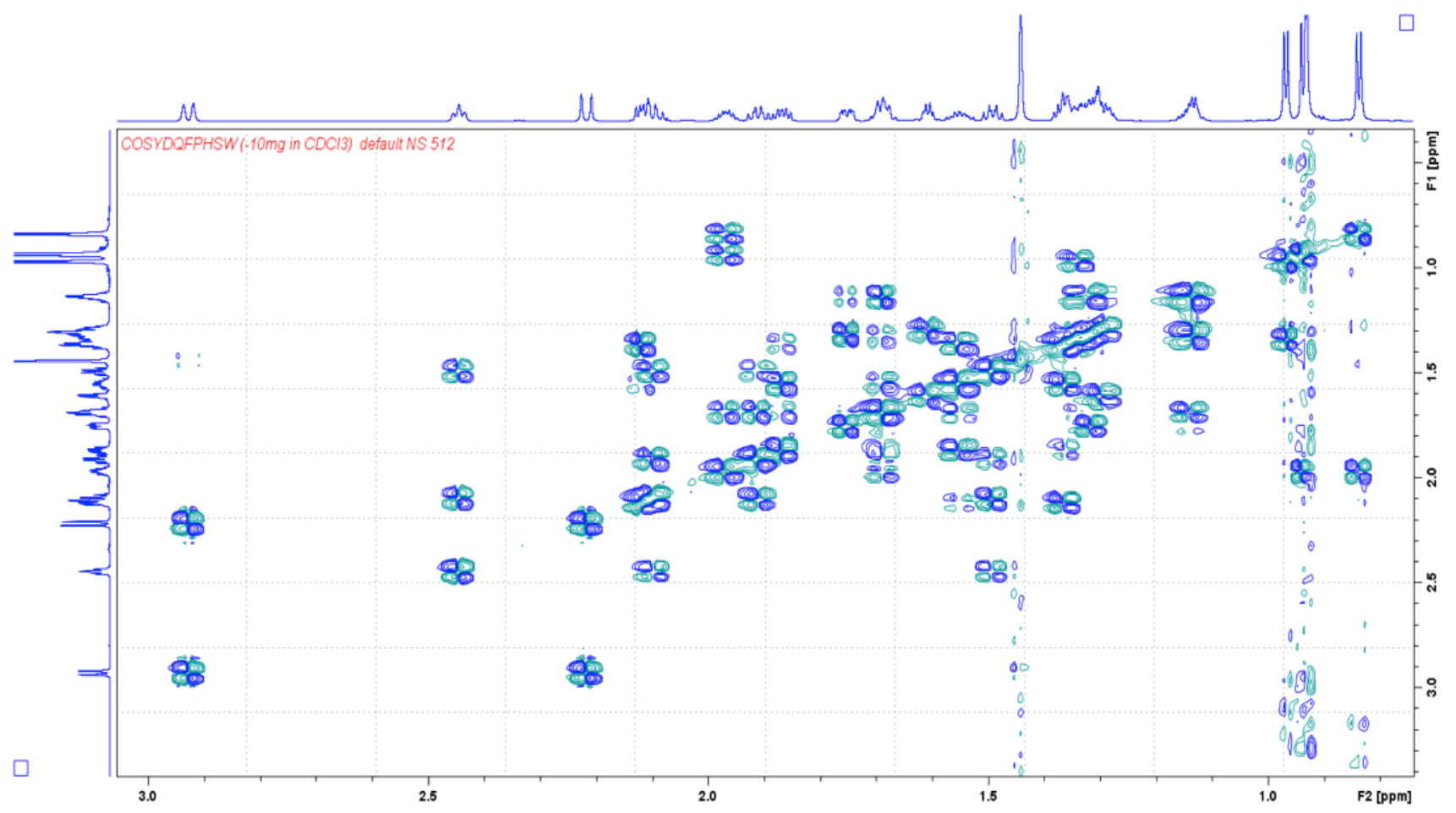

Figure S22. DQF-COSY spectrum of $2\left(900 \mathrm{MHz}\right.$, in $\left.\mathrm{CDCl}_{3}\right)$.

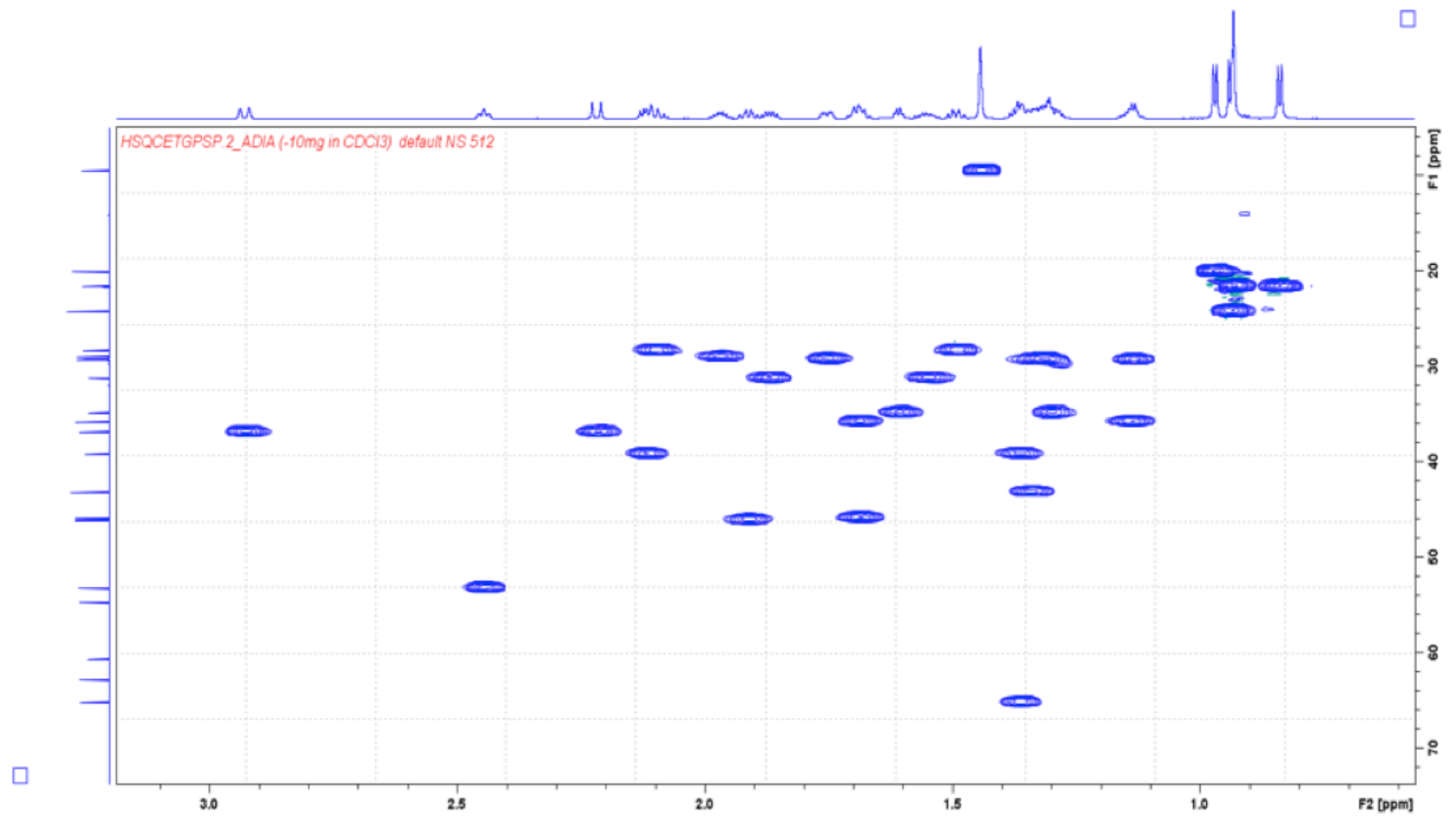

Figure S23. HSQC spectrum of $2\left(900 \mathrm{MHz}\right.$, in $\left.\mathrm{CDCl}_{3}\right)$. 


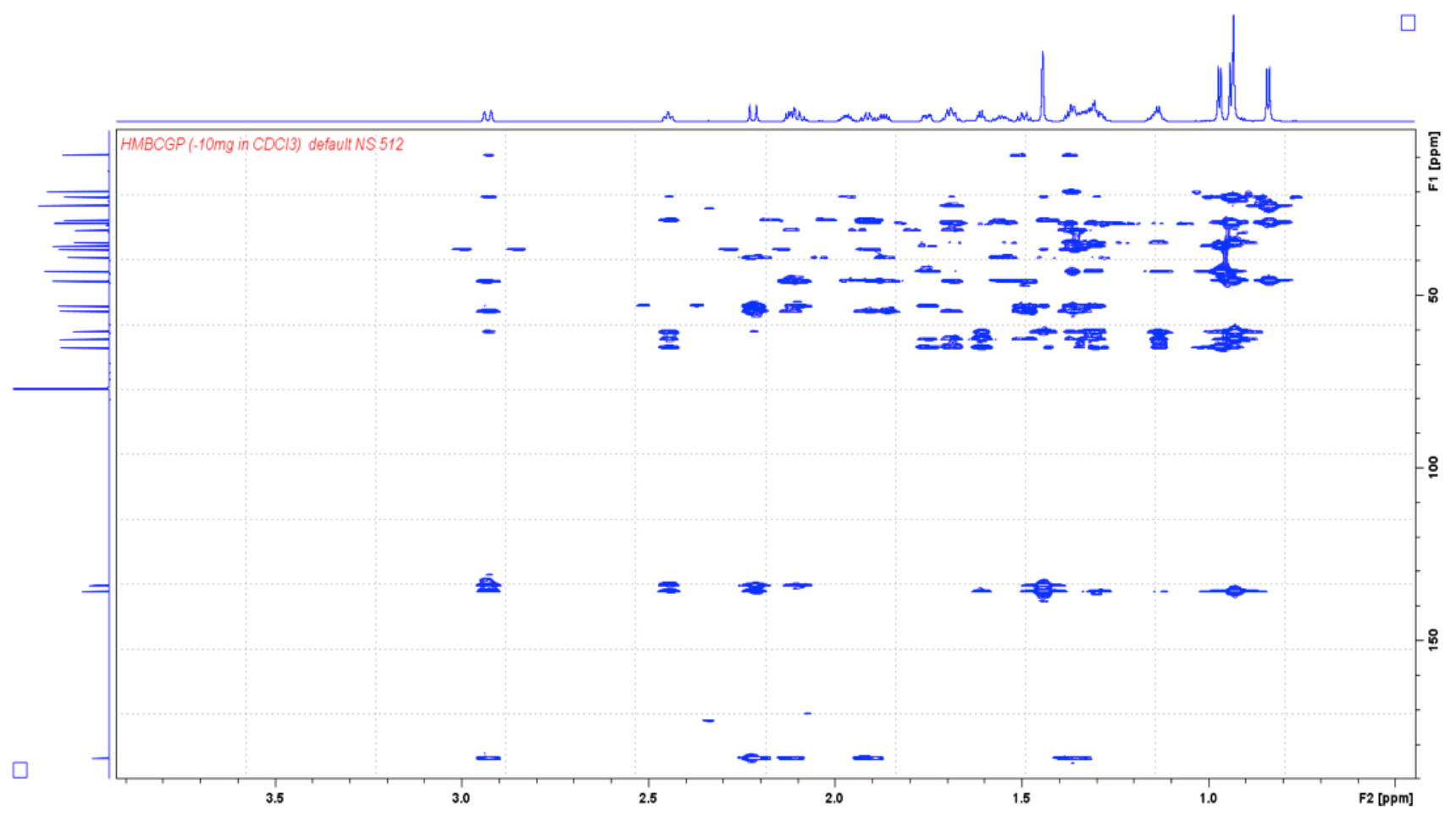

Figure S24. $\mathrm{HMBC}$ spectrum of $2\left(900 \mathrm{MHz}\right.$, in $\left.\mathrm{CDCl}_{3}\right)$.

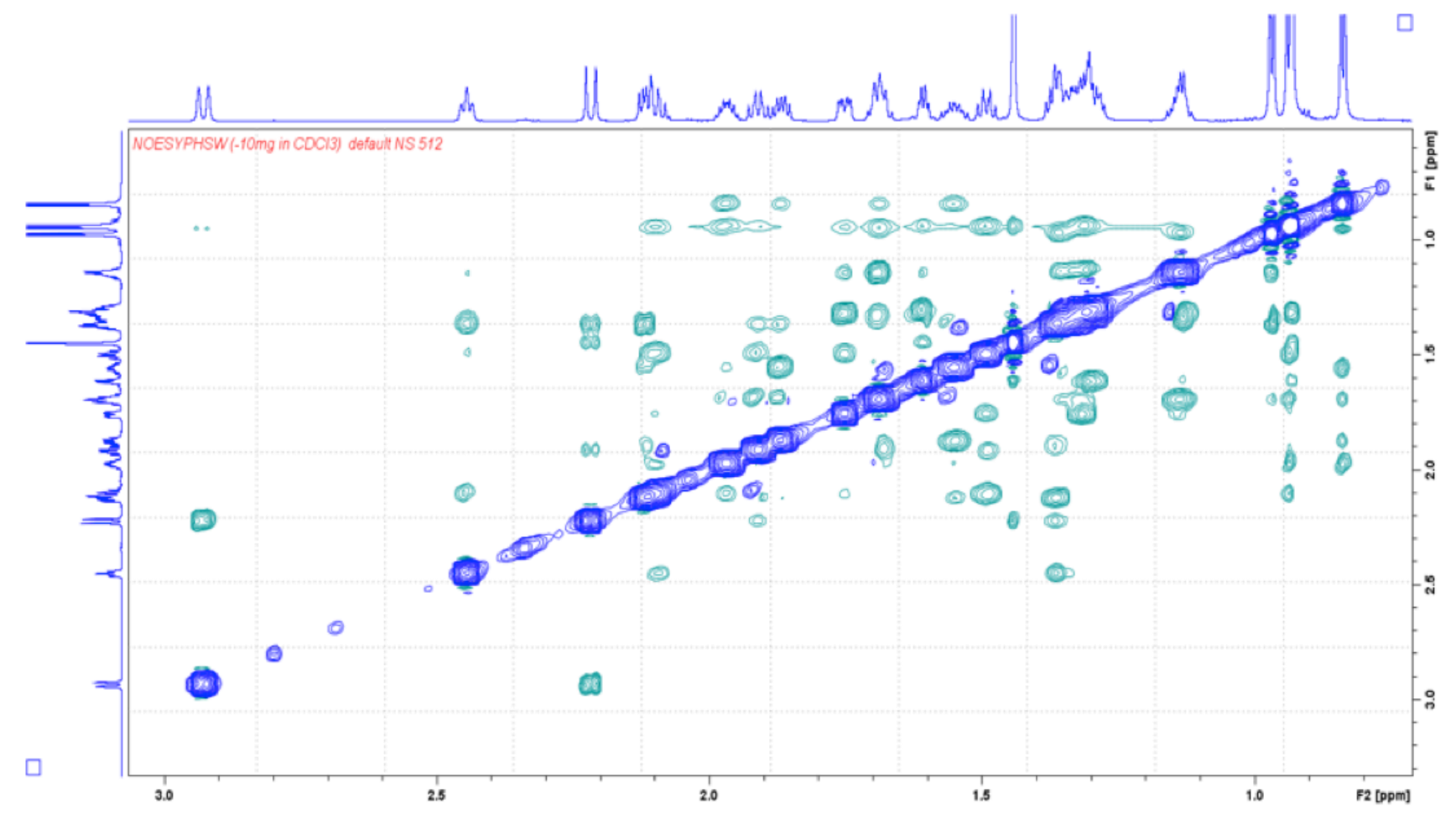

Figure S25. NOESY spectrum of $2\left(900 \mathrm{MHz}\right.$, in $\left.\mathrm{CDCl}_{3}\right)$. 


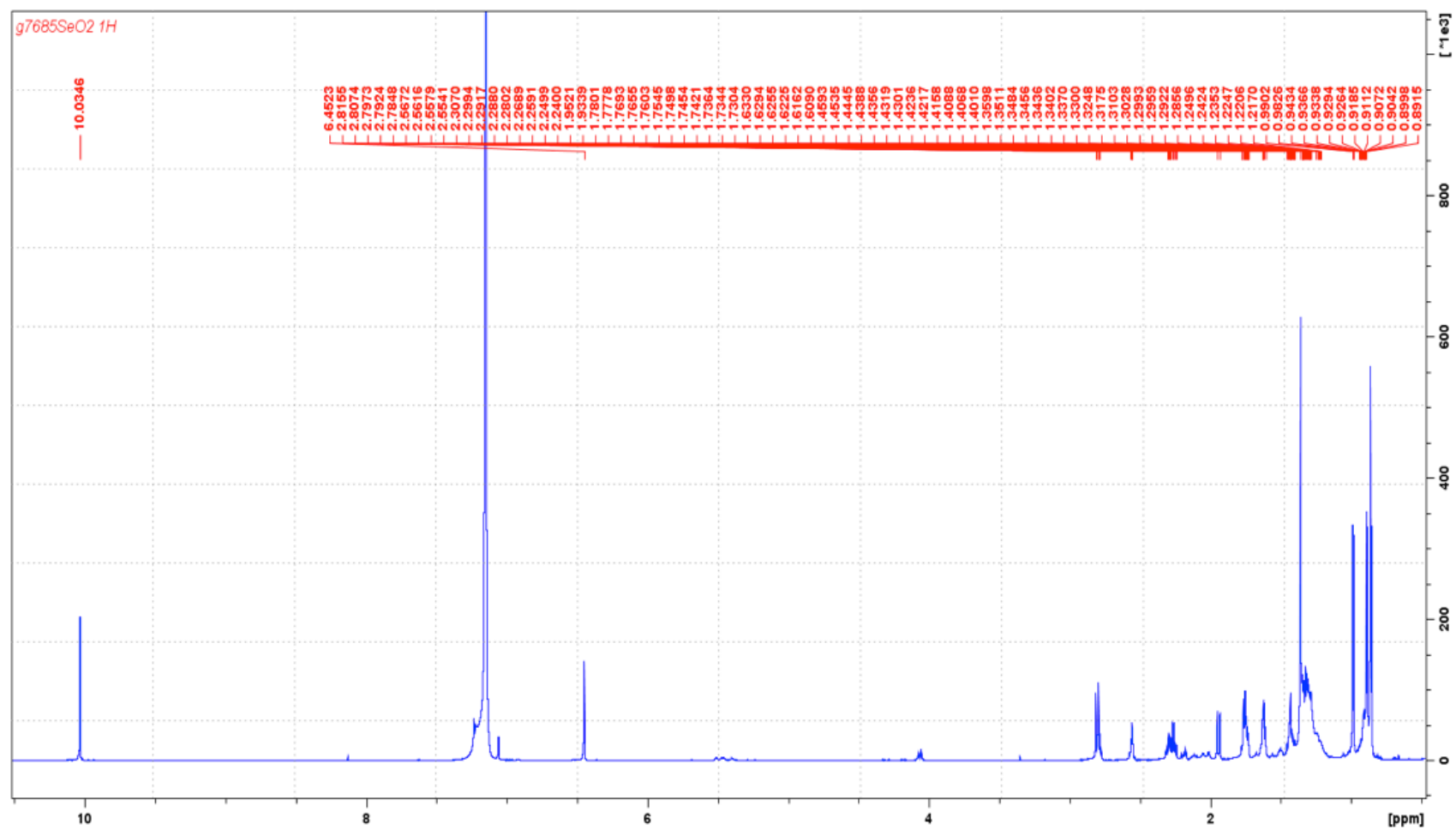

Figure S26. ${ }^{1} \mathrm{H}$ NMR spectrum of $\mathbf{3}\left(900 \mathrm{MHz}\right.$, in $\left.\mathrm{C}_{6} \mathrm{D}_{6}\right)$.

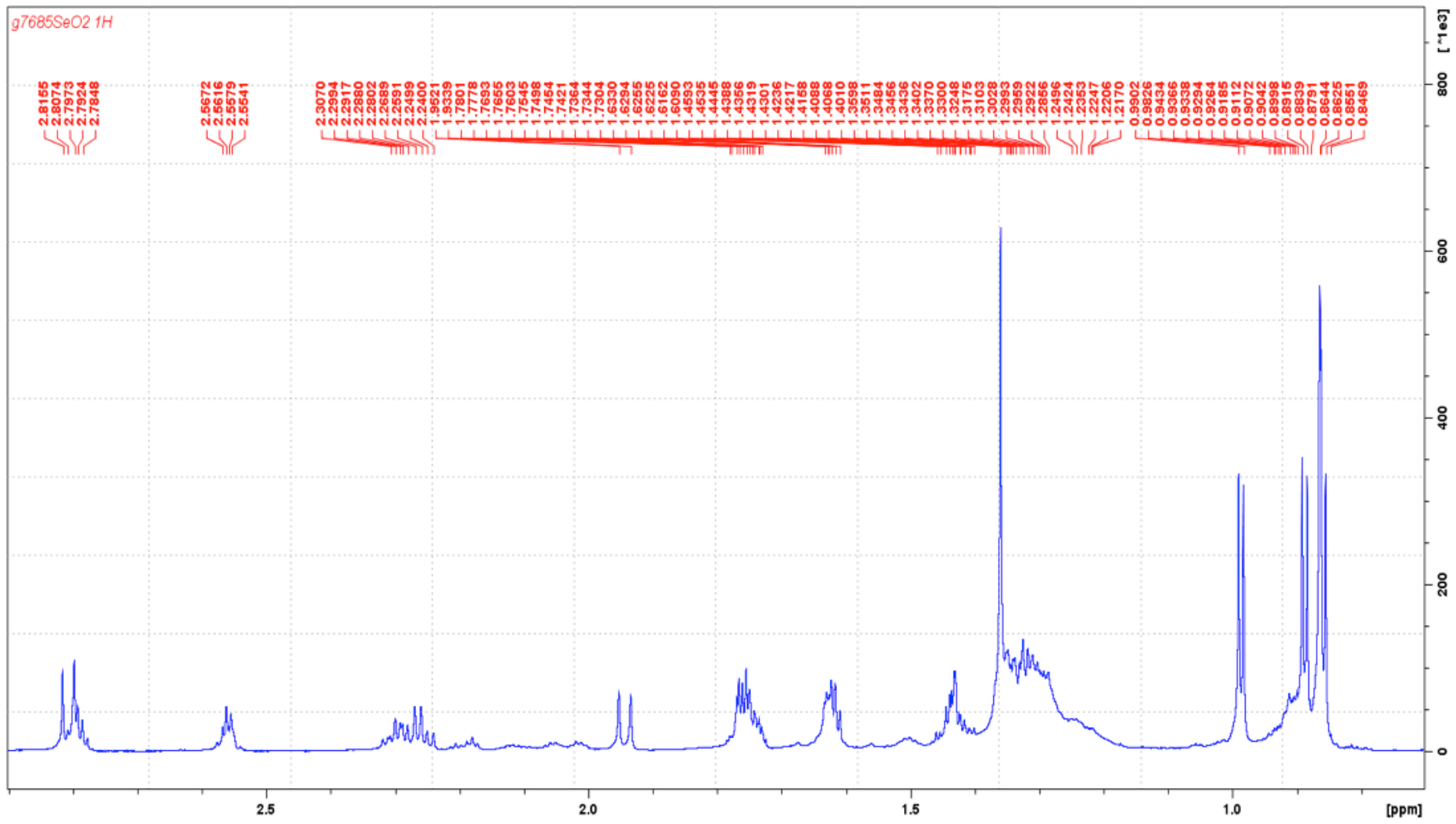

Figure S27. ${ }^{1} \mathrm{H}$ NMR spectrum of 3 in 0.7-2.9 ppm (900 MHz, in $\left.\mathrm{C}_{6} \mathrm{D}_{6}\right)$. 


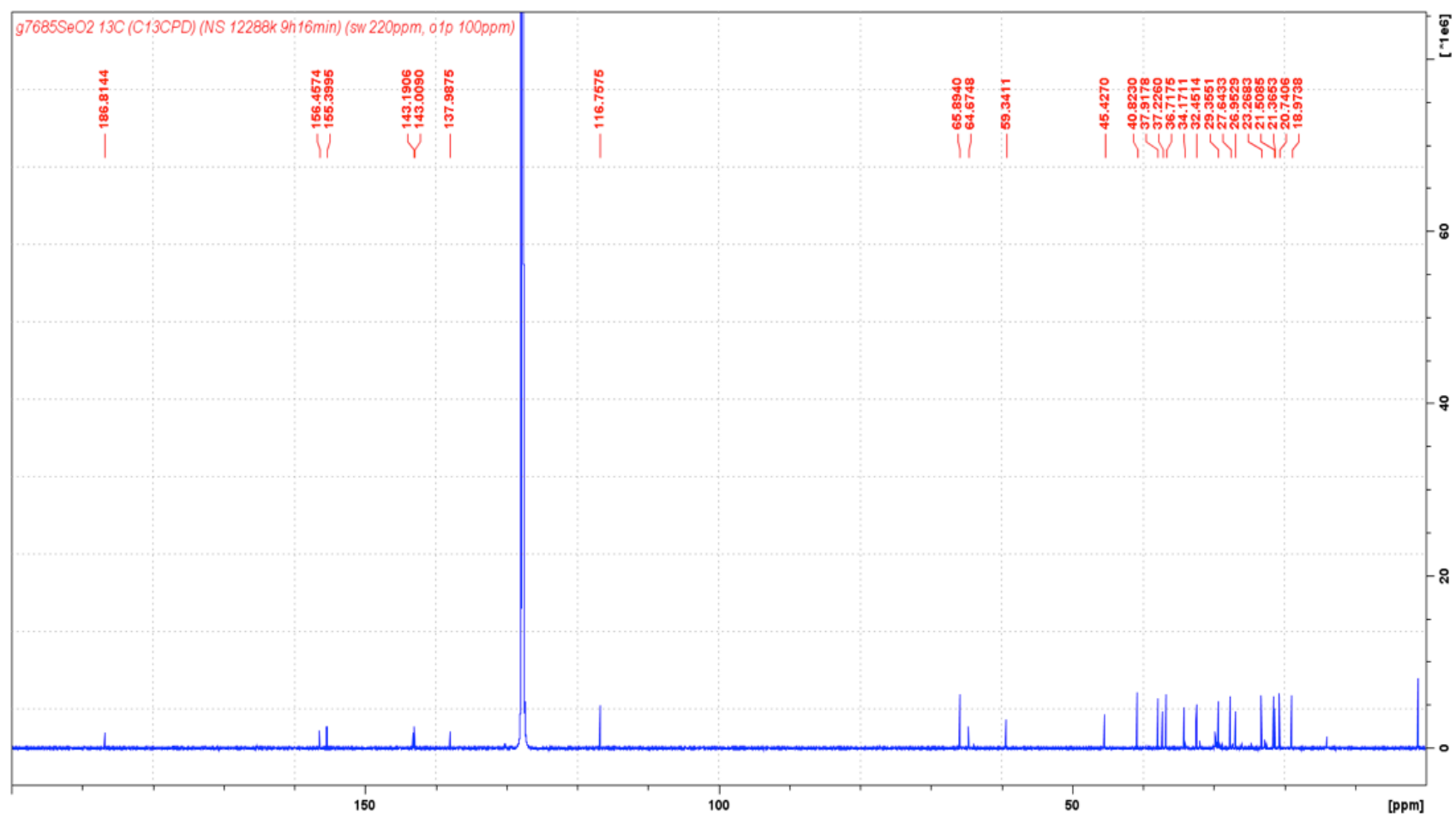

Figure S28. ${ }^{13} \mathrm{C}$ NMR spectrum of $\mathbf{3}\left(225 \mathrm{MHz}\right.$, in $\left.\mathrm{C}_{6} \mathrm{D}_{6}\right)$.

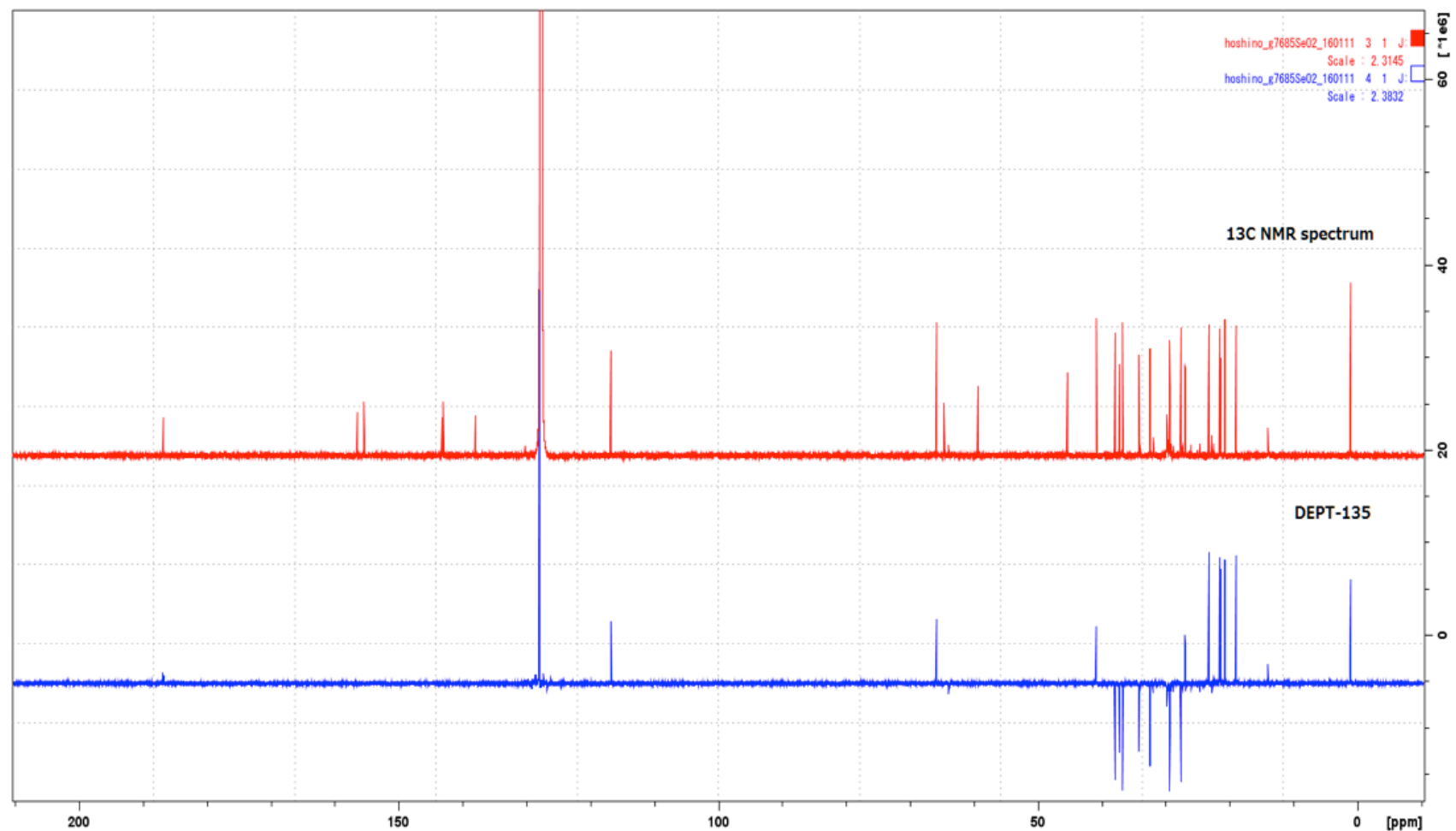

Figure S29. DEPT-135 spectrum of 3 (225 MHz, in $\left.\mathrm{C}_{6} \mathrm{D}_{6}\right)$. 


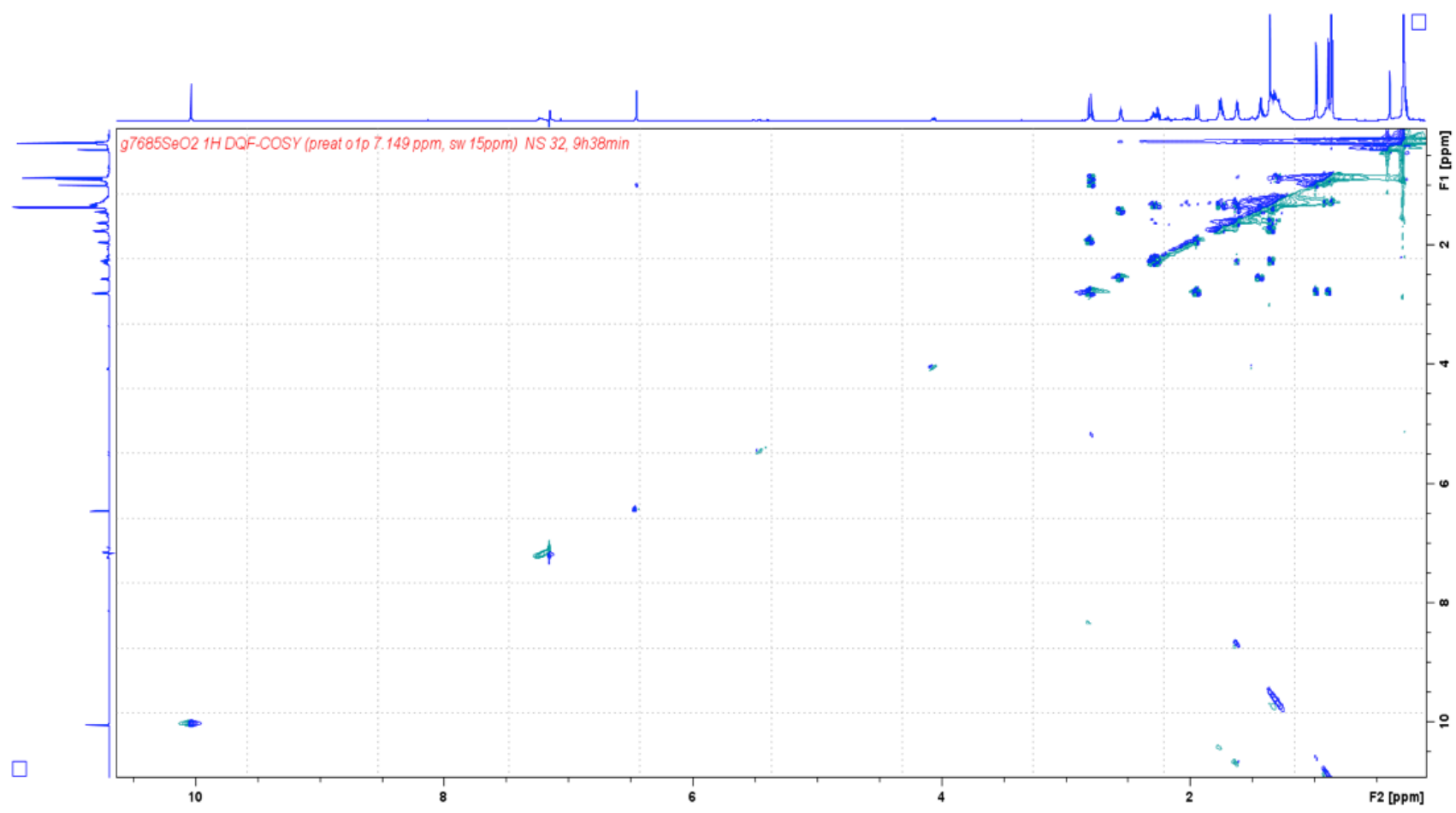

Figure S30. DQF-COSY spectrum of $3\left(900 \mathrm{MHz}\right.$, in $\left.\mathrm{C}_{6} \mathrm{D}_{6}\right)$.

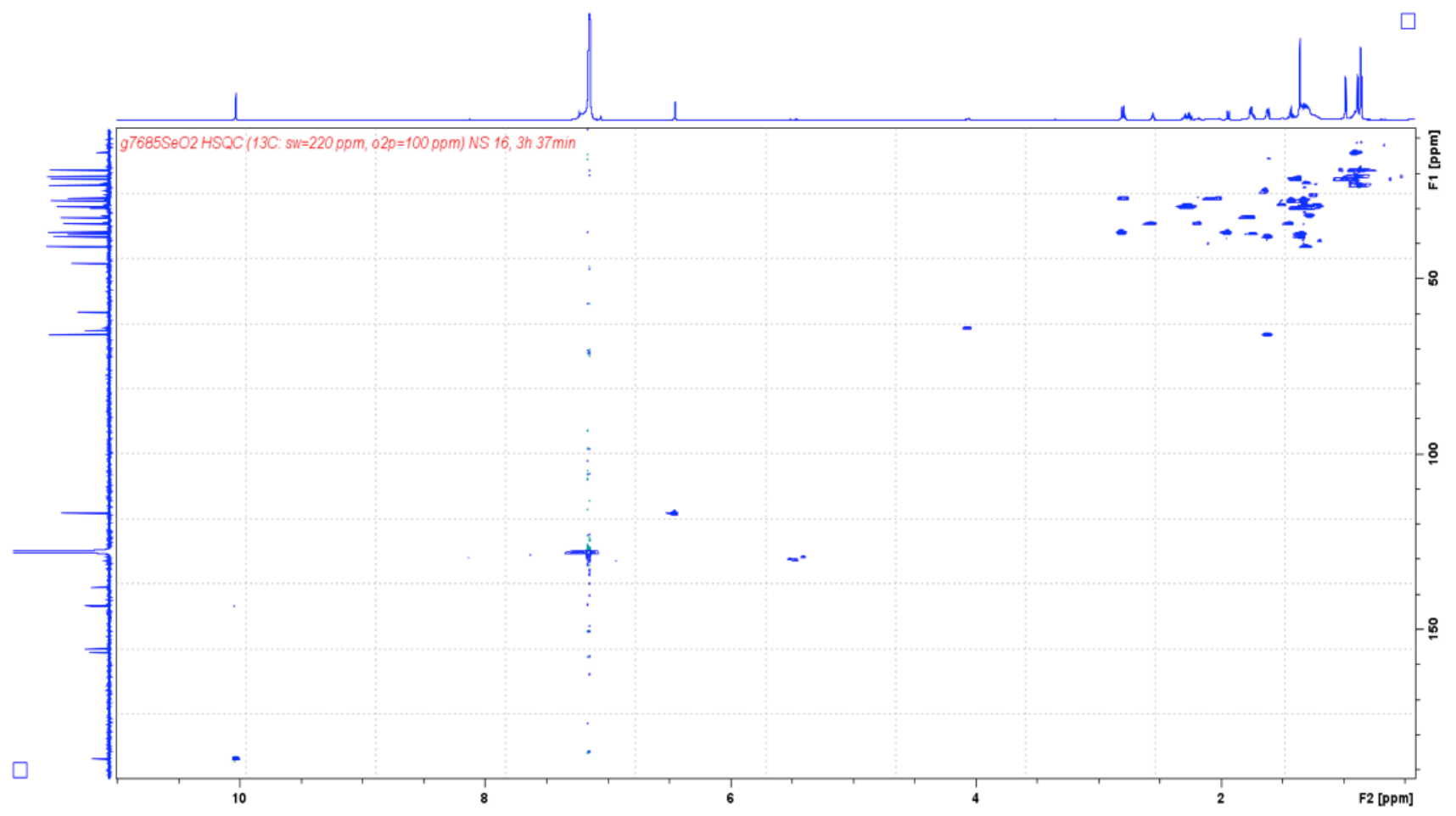

Figure S31. HSQC spectrum of $\mathbf{3}\left(900 \mathrm{MHz}\right.$, in $\left.\mathrm{C}_{6} \mathrm{D}_{6}\right)$. 


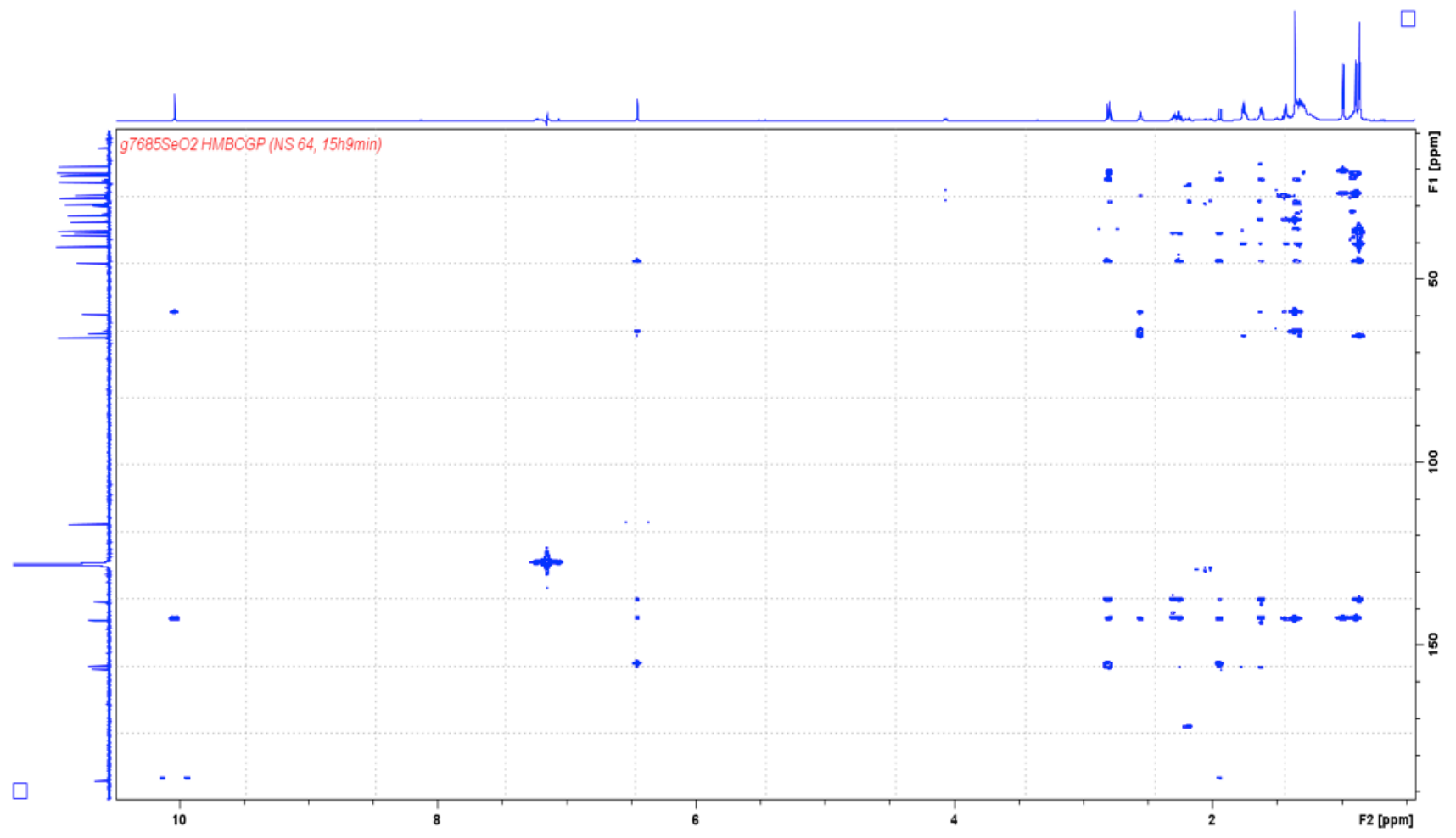

Figure S32. HMBC spectrum of $\mathbf{3}\left(900 \mathrm{MHz}\right.$, in $\left.\mathrm{C}_{6} \mathrm{D}_{6}\right)$.

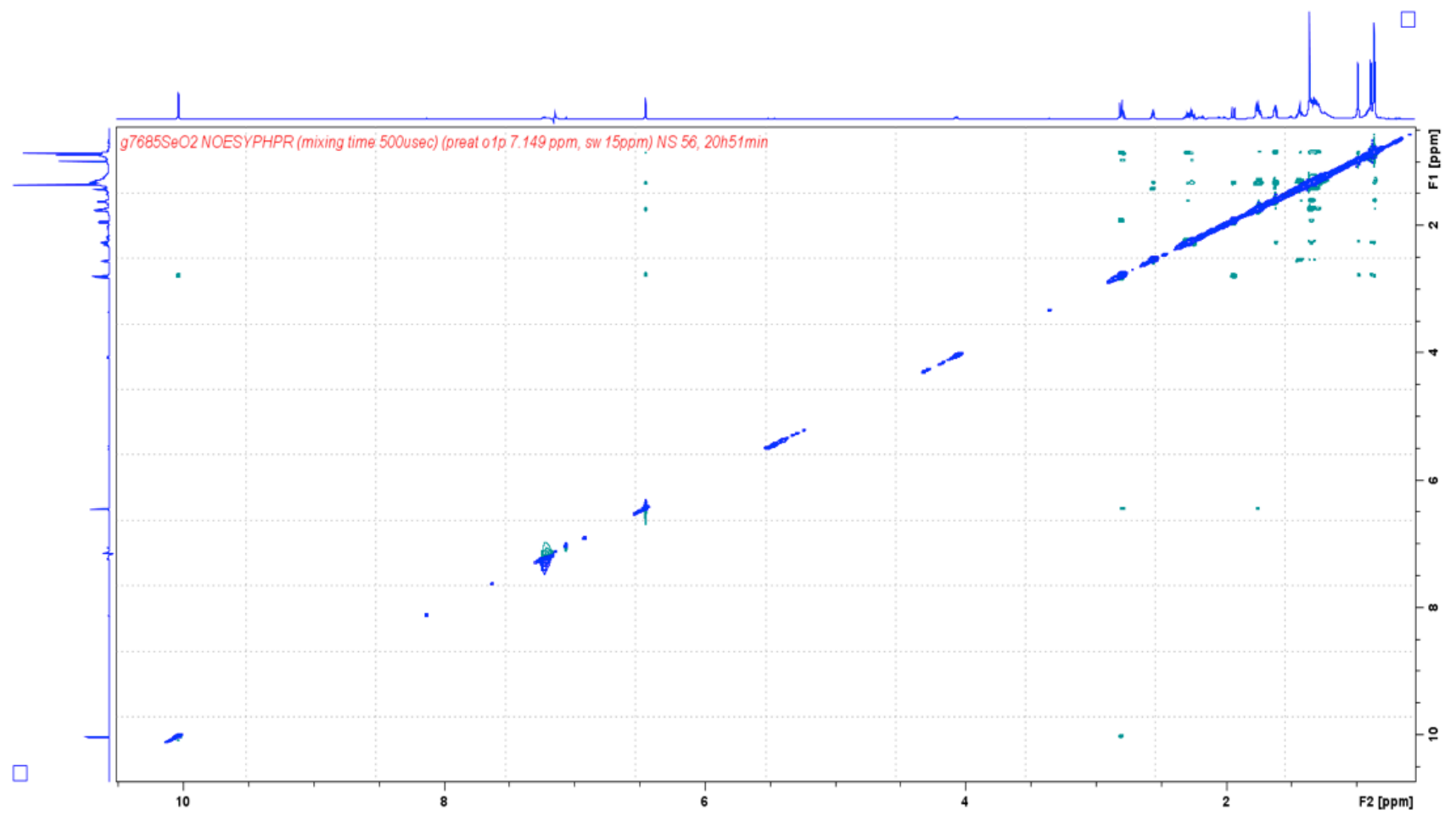

Figure S33. NOESY spectrum of $3\left(900 \mathrm{MHz}\right.$, in $\left.\mathrm{C}_{6} \mathrm{D}_{6}\right)$. 


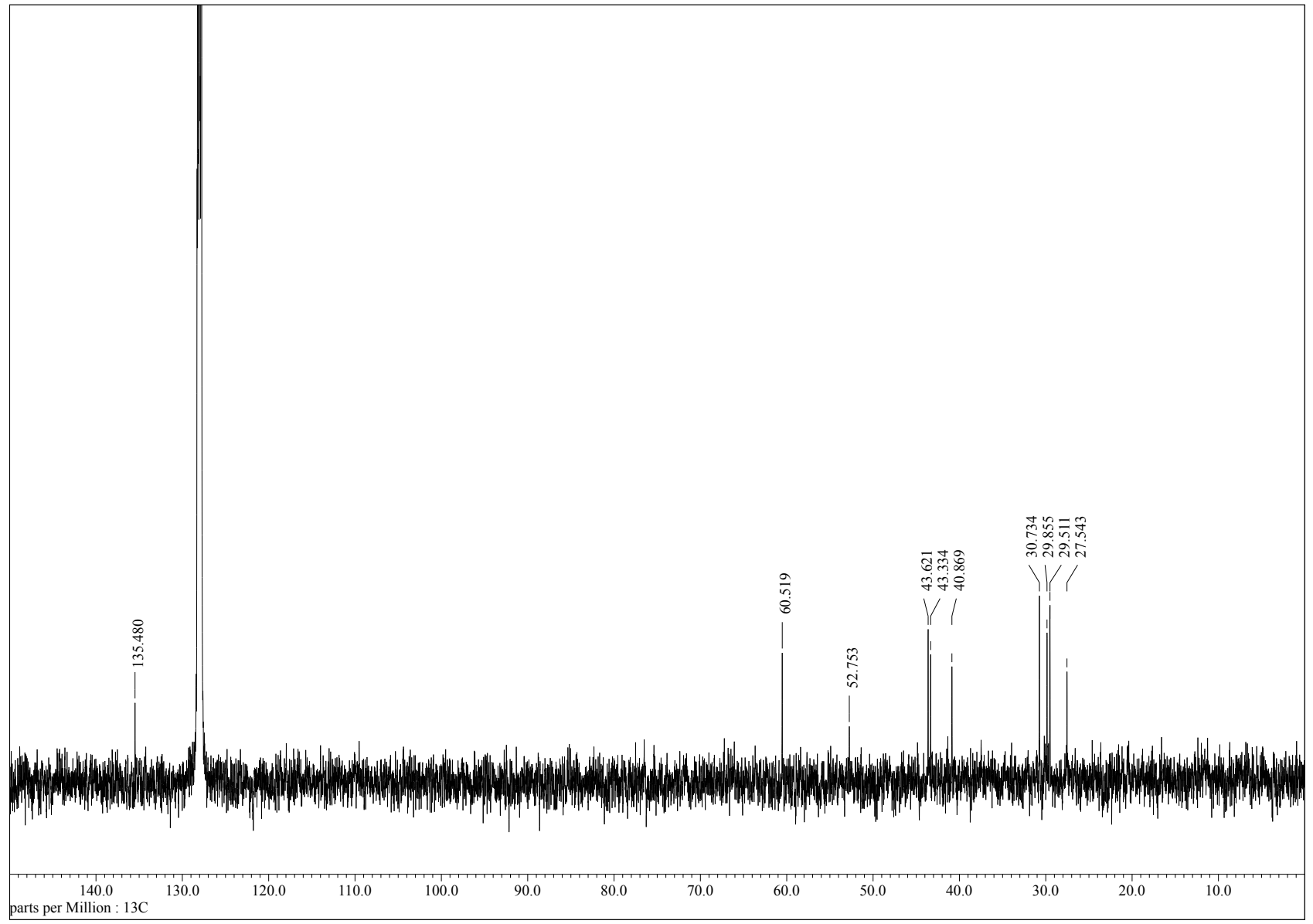

Figure S34. ${ }^{13} \mathrm{C}$ NMR spectrum of 1 obtained from the $\left[1-{ }^{13} \mathrm{C}\right]$-sodium acetate-feeding experiment $(125 \mathrm{MHz}$, in $\mathrm{C}_{6} \mathrm{D}_{6}$ ). 


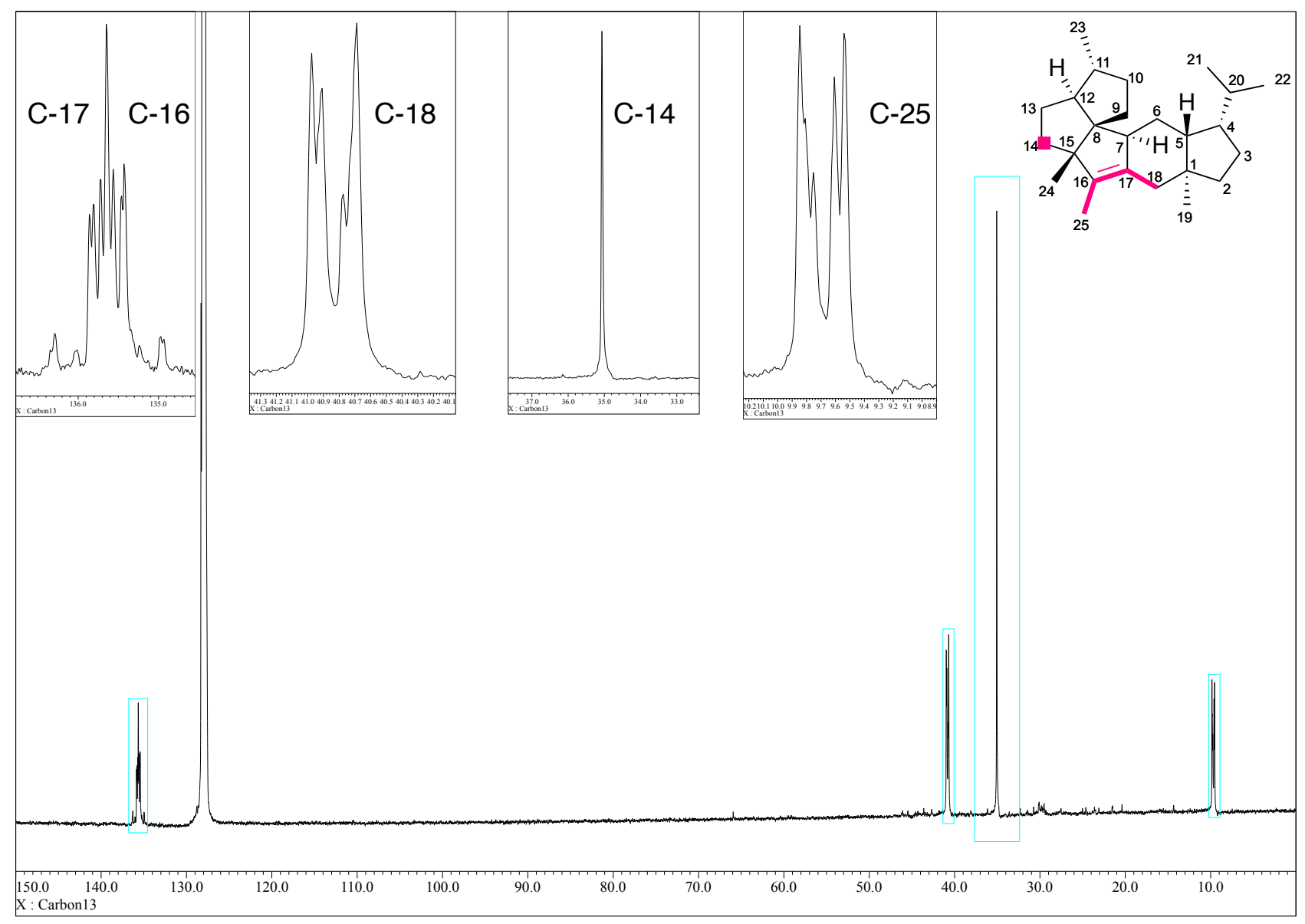

Figure S35. ${ }^{13} \mathrm{C}$ NMR spectrum of $\left[14,16,17,18,25-{ }^{13} \mathrm{C}_{5}\right]-\mathbf{1}\left(125 \mathrm{MHz}\right.$, in $\left.\mathrm{C}_{6} \mathrm{D}_{6}\right)$. 


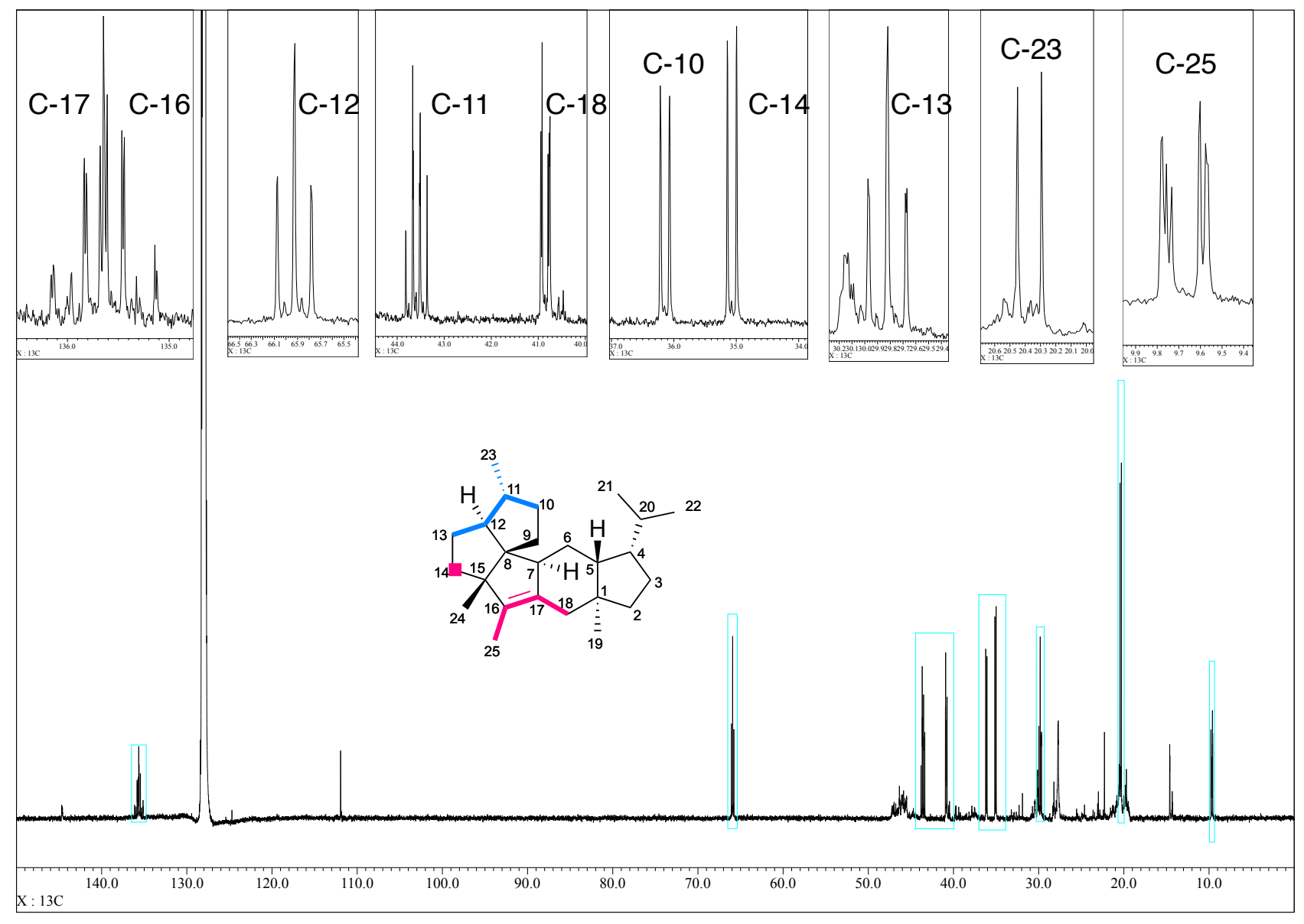

Figure S36. ${ }^{13} \mathrm{C}$ NMR spectrum of $\left[10,11,12,13,14,16,17,18,23,25-{ }^{13} \mathrm{C}_{10}\right]-\mathbf{1}\left(225 \mathrm{MHz}\right.$, in $\left.\mathrm{C}_{6} \mathrm{D}_{6}\right)$. 
(A)

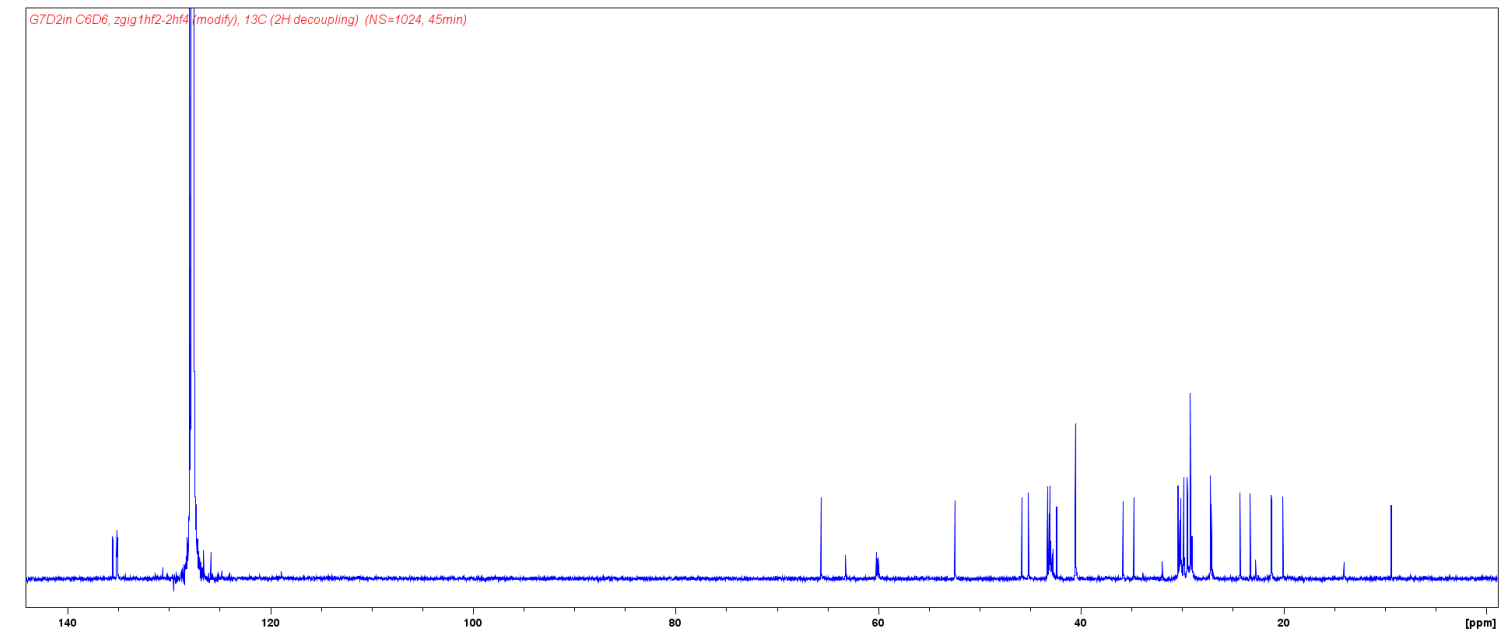

(B)

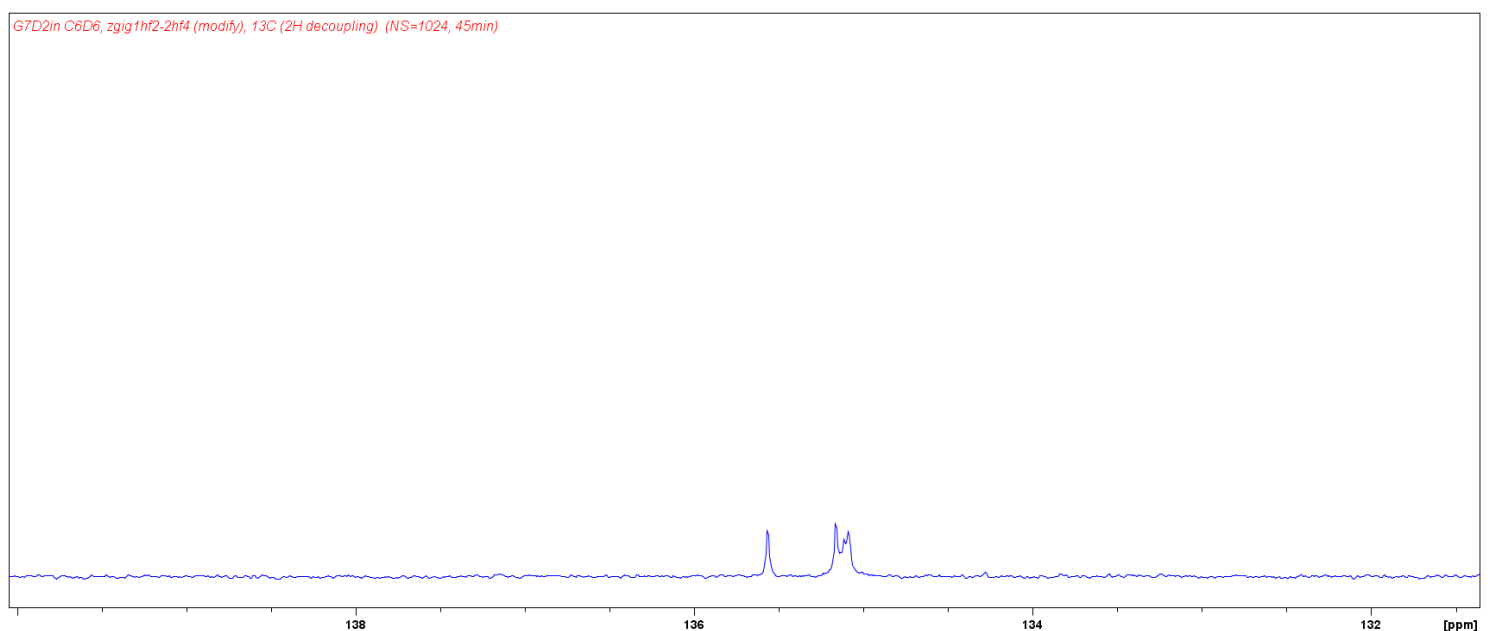

(C)

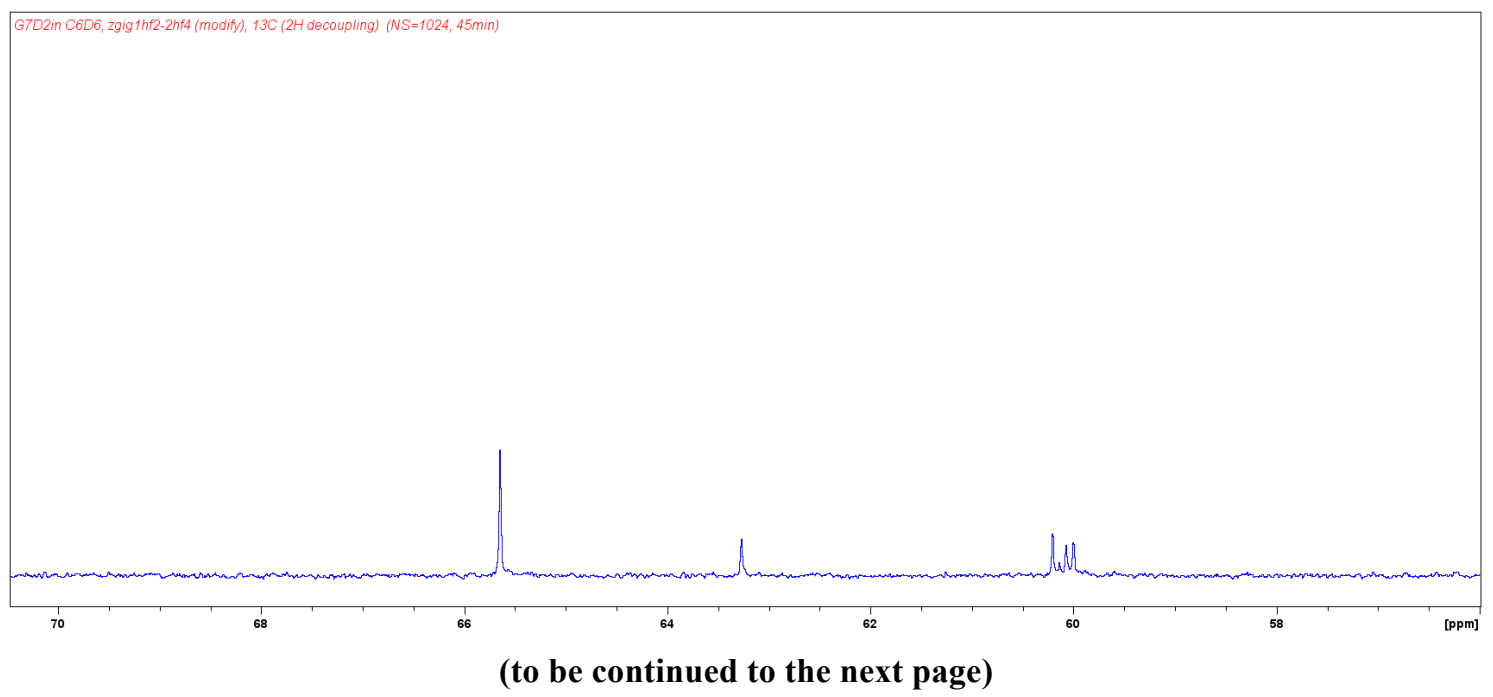


(D)

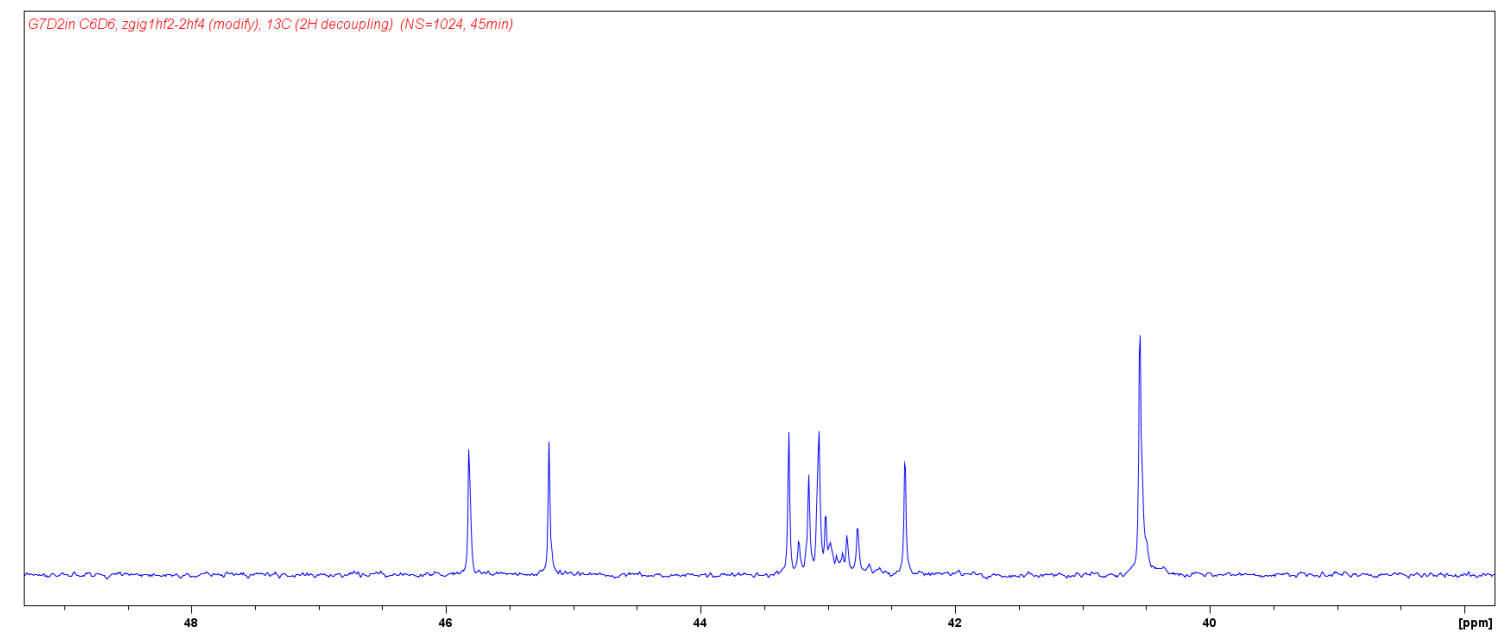

(E)

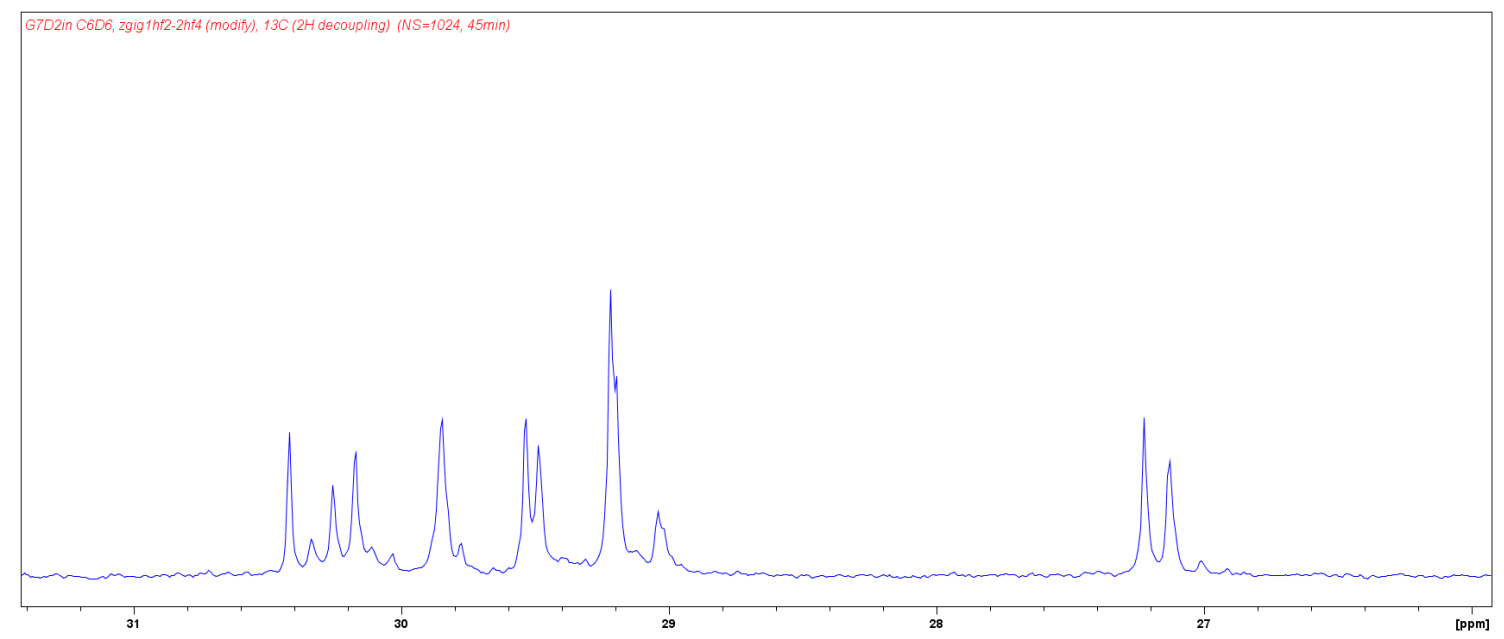

Figure S37. ${ }^{13} \mathrm{C}$ NMR spectrum of ${ }^{13} \mathrm{C},{ }^{2} \mathrm{H}$-labeled quinannulatene (1), obtained from the $\left[1-{ }^{13} \mathrm{C},{ }^{2} \mathrm{H}_{3}\right]$-sodium acetate-feeding experiment $\left(225 \mathrm{MHz}\right.$, in $\left.\mathrm{C}_{6} \mathrm{D}_{6}\right)$. (A) The entire spectrum and (B-E) expanded views of selected regions. 
(A)

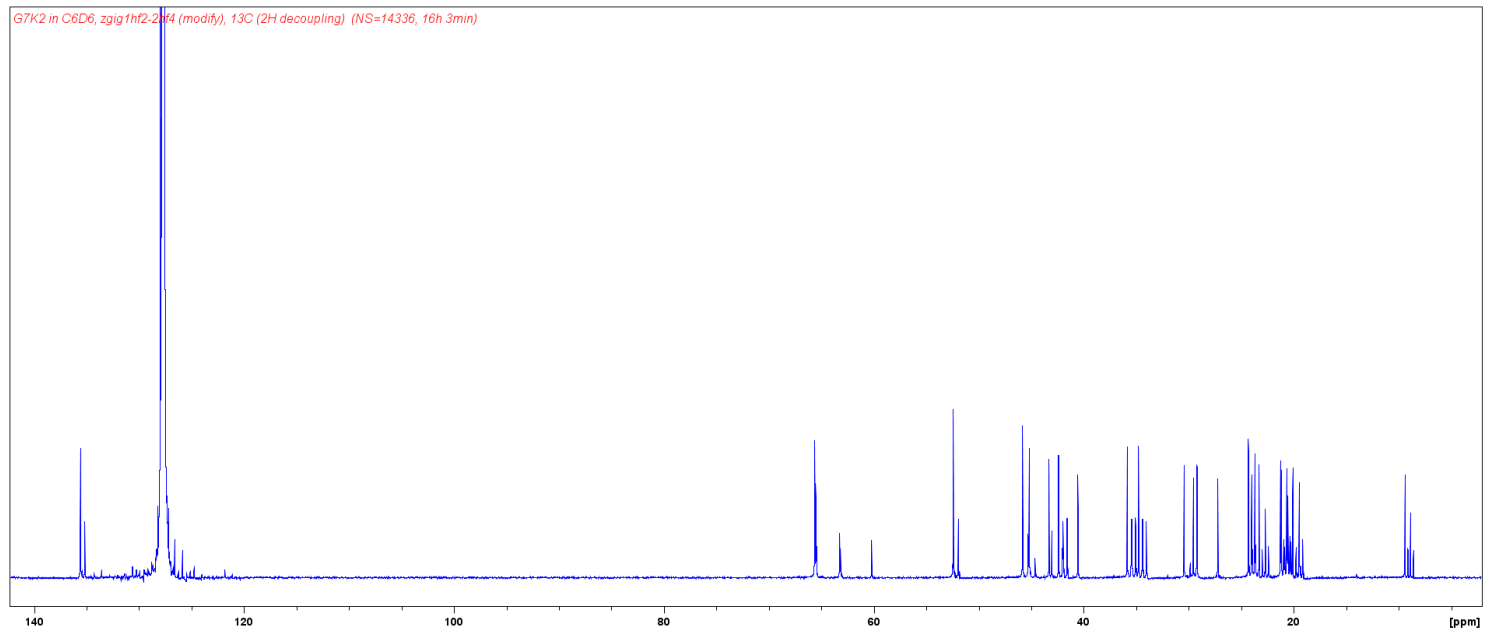

(B)

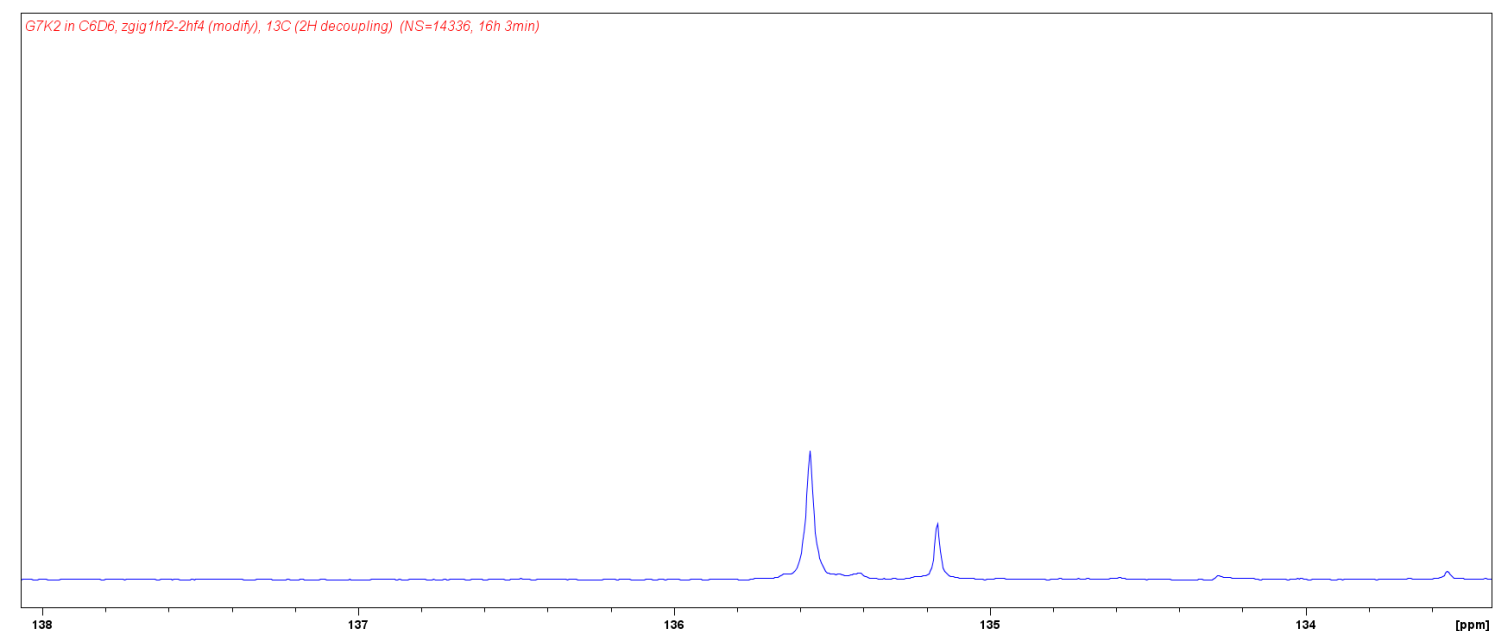

(C)

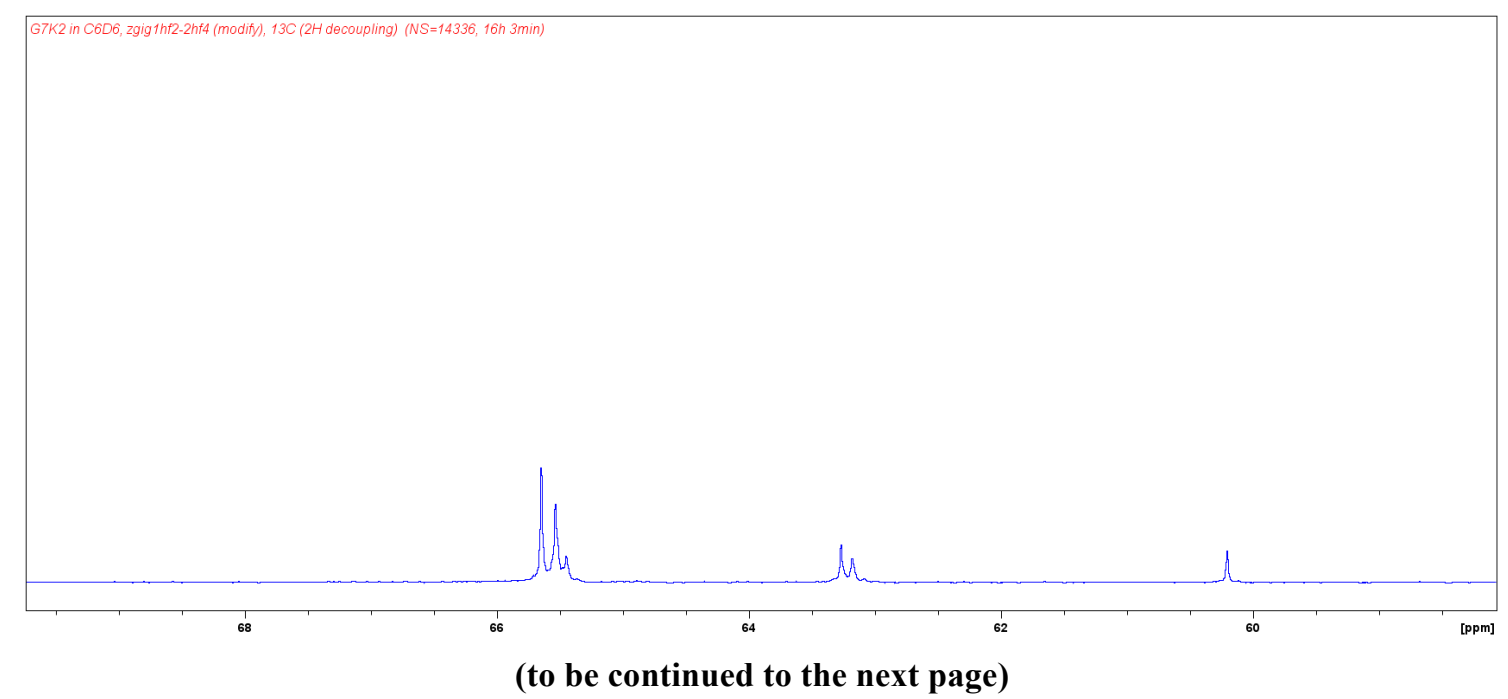


(D)

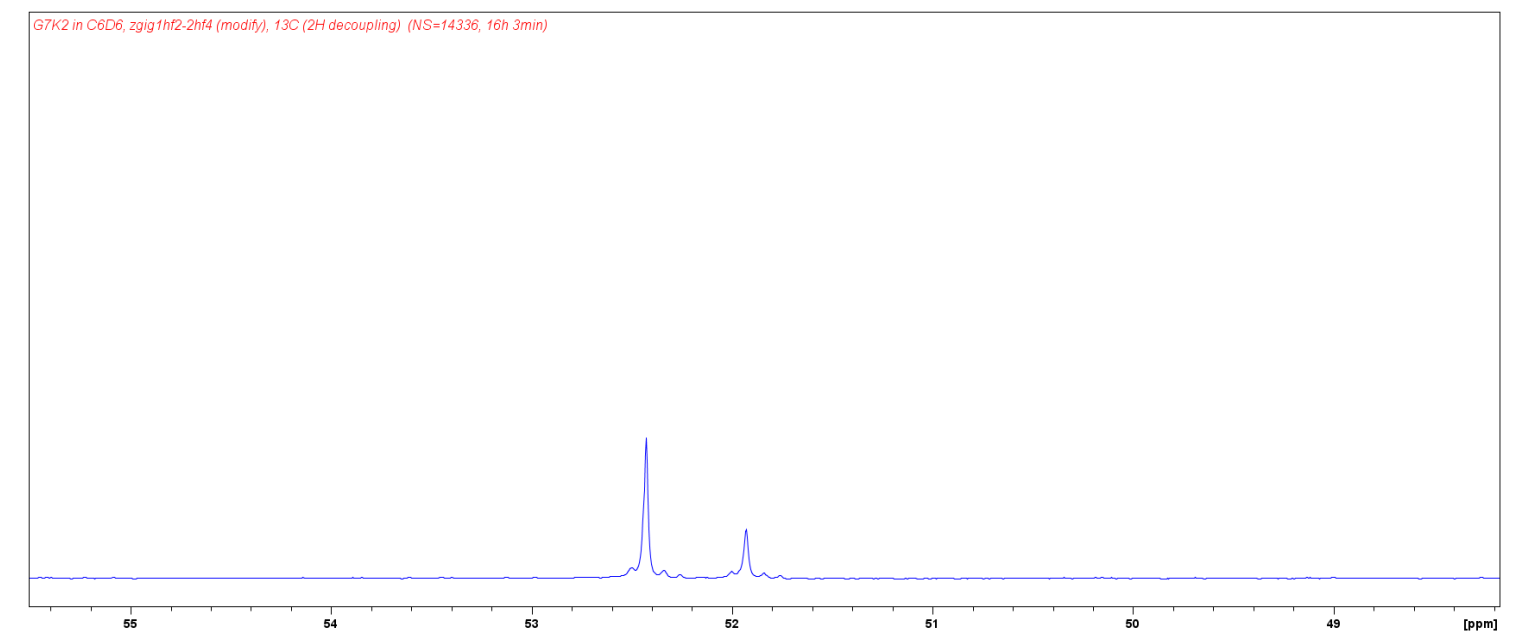

(E)

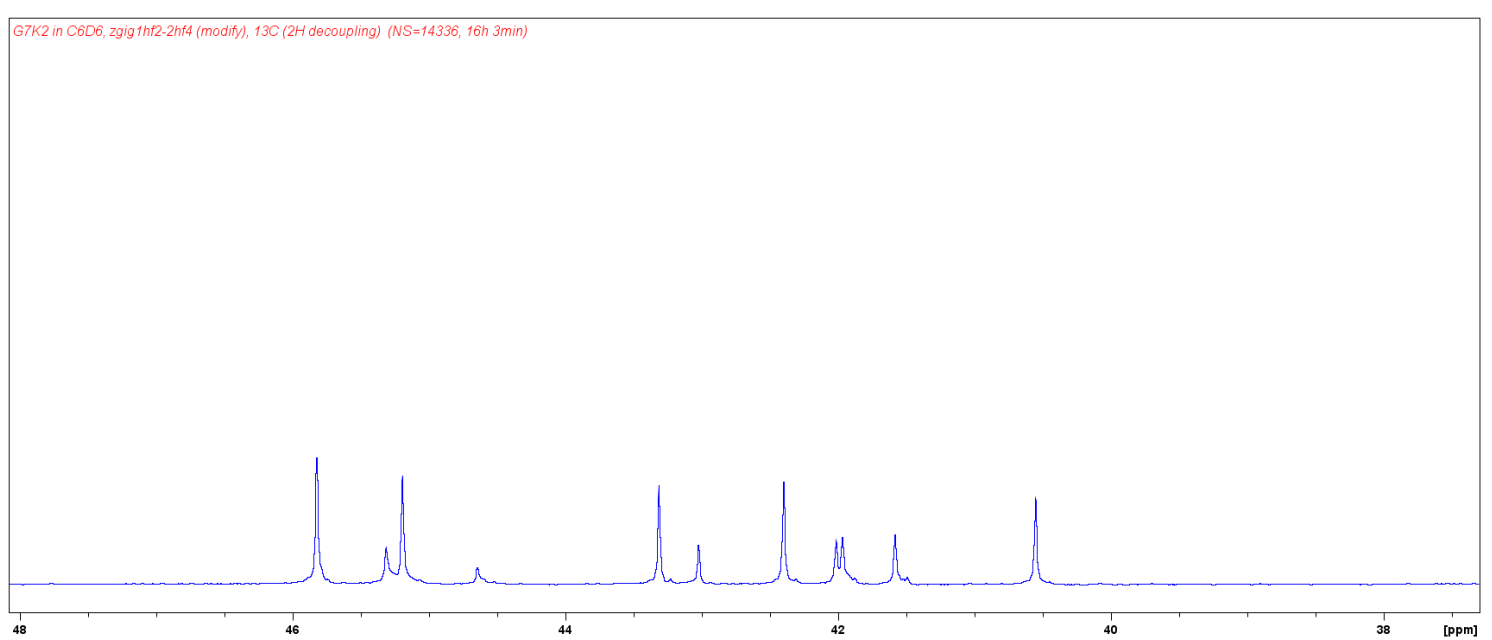

(F)

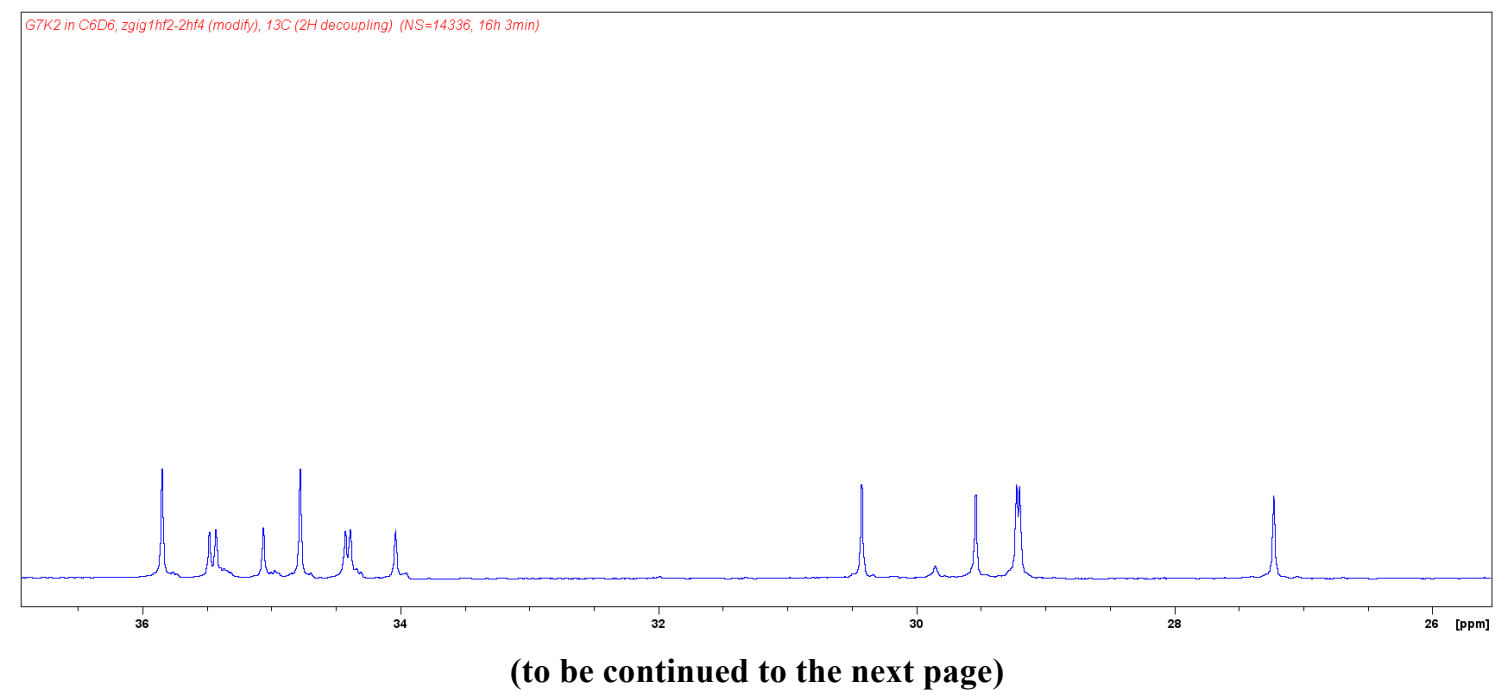


(G)

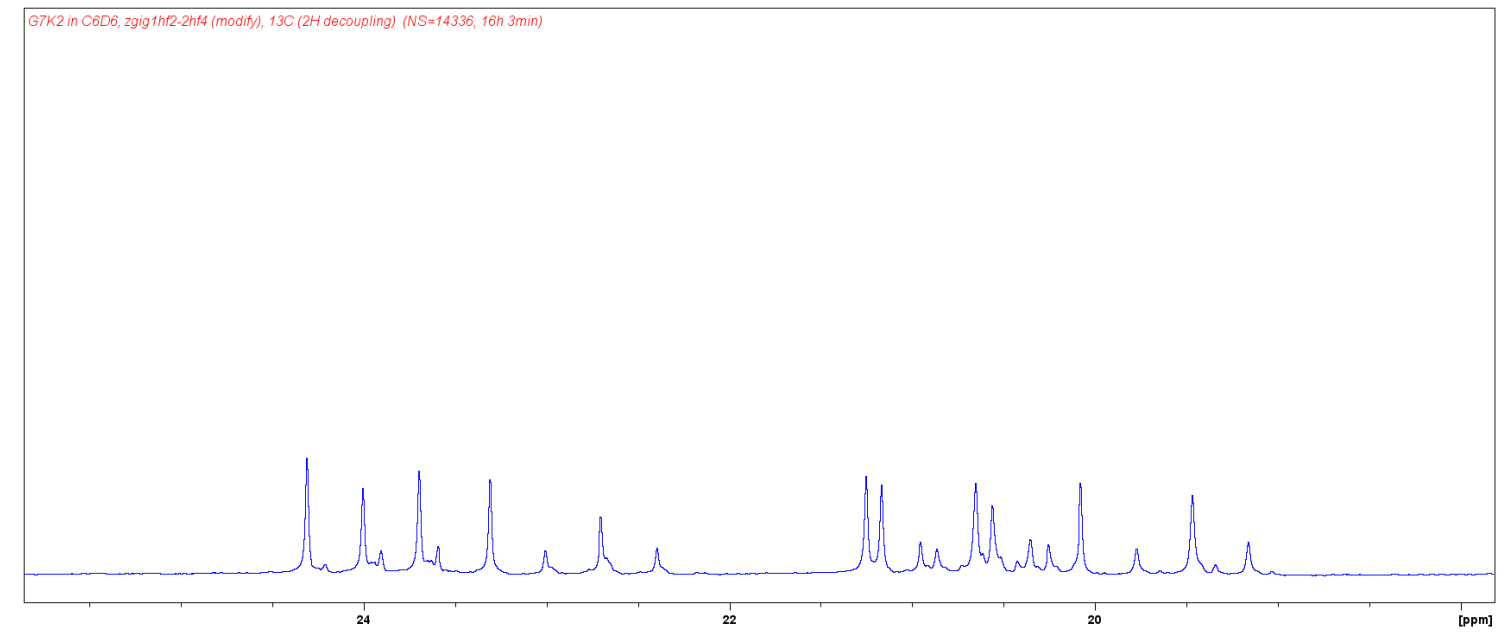

$(\mathrm{H})$

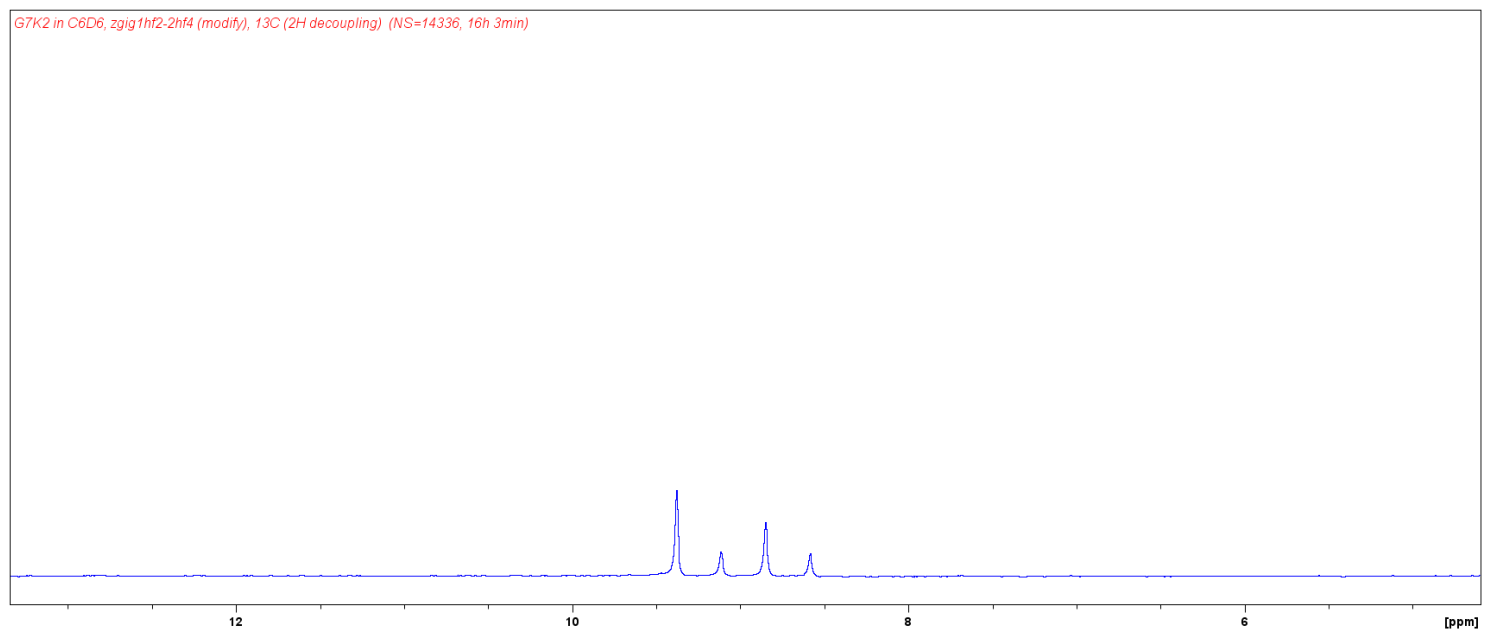

Figure S38. ${ }^{13} \mathrm{C}$ NMR spectrum of ${ }^{13} \mathrm{C},{ }^{2} \mathrm{H}$-labeled quinannulatene (1), obtained from the $\left[2-{ }^{13} \mathrm{C},{ }^{2} \mathrm{H}_{3}\right]$-sodium acetate-feeding experiment $\left(225 \mathrm{MHz}\right.$, in $\left.\mathrm{C}_{6} \mathrm{D}_{6}\right)$. (A) The entire spectrum and (B-H) expanded views of selected regions. The spectrum was obtained from the proton and deuterium simultaneously decoupled ${ }^{13} \mathrm{C}$ NMR analysis. 